\title{
Parental health and children's cognitive and non-cognitive development: New evidence from the Longitudinal Survey of Australian Children
}

\author{
Huong Thu Le \\ Queensland University of Technology
}

\section{Ha Trong Nguyen ${ }^{*}$}

Curtin University

This paper examines the effects of parental health on cognitive and non-cognitive development in Australian children. The underlying nationally representative panel data and a child fixed effects estimator are used to deal with unobserved heterogeneity. We find that only father's serious mental illness worsens selected cognitive and non-cognitive skills of children. Maternal poor health also deteriorates some cognitive and non-cognitive outcomes of children of lone mothers only. Our results demonstrate that either failing to account for parent-child fixed effects or using child non-cognitive skills reported by parents could overestimate the harmful impact of poor parental health on child development.

Key words: Intergenerational transmission, health, education, panel data, Australia.

JEL classifications: I14, J24

\footnotetext{
* Corresponding author: Bankwest Curtin Economics Centre | Curtin Business School | Curtin University | Tel:+61 892665711 | Fax:+61 892662373 | Postal: GPO Box U1987, Perth WA 6845, Australia | Email: ha.nguyen@curtin.edu.au.

Acknowledgements: We thank the editor, Michael Shields, and two anonymous referees for their suggestions. We would like to thank participants at the CBS Health and Well-being Economics Research Workshop for helpful comments and suggestions. The authors also thank Chelsi Wingrove and Vivienne Van Rooyen for their help with proofreading. Funding from Curtin Business School's Journal Publication Support Award is gratefully acknowledged. This paper uses unit record data from Growing Up in Australia, the Longitudinal Study of Australian Children. The study is conducted in partnership between the Department of Social Services (DSS), the Australian Institute of Family Studies (AIFS) and the Australian Bureau of Statistics (ABS). The findings and views reported in this paper are those of the authors and should not be attributed to the DSS, the AIFS or the ABS.
} 


\section{Introduction}

The last decades have seen increasing interests in cognitive and non-cognitive development in children. ${ }^{1}$ Much of this work has been motivated by the relationship between cognitive and non-cognitive development and a wide range of outcomes over the life course (Heckman et al., 2006). Recently, researchers have begun to explore the degree to which poor parental health interferes with child educational outcomes (Bratti and Mendola, 2014; Senne, 2014; Alam, 2015). This paper builds on these topics to estimate the effects of parental health on cognitive and non-cognitive development in children. Our focus on the impact of parental health on child development is also influenced by a growing literature documenting persistent intergenerational transmission of socio-economic status (Black and Devereux, 2011). As low socio-economic parents experience a higher probability of negative health shocks than more advantaged counterparts, a more robust link between parental health and child development could shed light on one channel through which disadvantage is transmitted across generations.

Although it is straight forward to obtain a magnitude of correlations between parental health and child development, identifying the causal impact of parental health is more challenging. It is well-documented that this is in part due to problems of unobservable individual heterogeneity correlated with both parental health and child development (such as genetic endowments common to the parent and the child or the parent's discount rate (Ahlburg, 1998; Black and Devereux, 2011) and reverse causality (whether parental health affects child development or vice versa). In the absence of a natural experiment, one common approach to address the unobservable individual heterogeneity is to use an individual fixed effects (FE) estimator. So far, a few papers have employed a child FE estimator to deal with unobserved heterogeneity when examining the impact of parental health on child education in the context of developing countries (Bratti and Mendola, 2014; Senne, 2014; Alam, 2015). However, socio-economic environments in developed countries are appreciably different from that in developing countries. As such, effects of poor parental health on child development may not be the same in countries with different development levels (Gertler et al., 2004; Wagstaff, 2007).

\footnotetext{
${ }^{1}$ In the child development literature, cognitive skills are often measured by IQ tests or achievement tests. "Noncognitive" skills are therefore used to describe the personal attributes not thought to be measured by IQ tests or achievement tests. "Non-cognitive" skills have been described under different names, including soft skills, personality traits, non-cognitive abilities, character skills, and socio-emotional skills (Heckman and Kautz, 2013).
} 
Using unusually rich information from five waves of the nationally representative Longitudinal Survey of Australian Children (LSAC) in combination with the National Assessment Program - Literacy and Numeracy (NAPLAN) datasets, we estimate the effects of parental health on child cognitive and non-cognitive development of Australian children. Our study makes two important contributions to the research into the impacts of parental health on child development for Australia and worldwide. First, this paper is the only study to date to apply a child FE estimator ${ }^{2}$ to study the impact of parental health on child development in the context of a developed country like Australia. Possibly due to the nature of datasets used in previous literature, all studies using datasets from developed countries have not been able to effectively address the unobserved heterogeneity issue (Propper et al., 2007; Frank and Meara, 2009; Morefield, 2010; Yamauchi, 2010; Mühlenweg et al., 2015; Nghiem et al., 2015). In our data, we observe parental health and child cognitive and noncognitive development indicators at multiple occasions, enabling us to employ a child FE method to deal with unobserved heterogeneity to present more robust estimates of parental health on child development.

Second, this paper also makes a methodological contribution by showing how the estimates of parental health on child non-cognitive skills are sensitive to who provides the assessment (Cunha and Heckman, 2008; Cunha et al., 2010; Johnston et al., 2014a; Johnston et al., 2014b). All existing studies into the impact of parental health on child non-cognitive skills use child non-cognitive skills evaluated by parents (Frank and Meara, 2009; Morefield, 2010; Yamauchi, 2010; Mühlenweg et al., 2015; Nghiem et al., 2015). One concern regarding such measures is that they may be dependent on parental health (Richters, 1992; De Reyes and Kazdin, 2005), which may result in a biased estimate of parental health from the child development equations. Our data also contain child non-cognitive skills reported by teachers, whose evaluations are arguably not subject to parental health status. We compare regression results using evaluations from parents and teachers and examine the implications for estimates of parental health impact on child non-cognitive skill development.

Using the LSAC data and a child FE method, we find only paternal serious mental illness hinders selected cognitive and non-cognitive development in children. Maternal poor (both mental and general) health also worsens some cognitive and non-cognitive development in children of single mothers only. Also, our results indicate that either failing to account for

\footnotetext{
${ }^{2}$ In our data, we observe only one child per household, so child FE, parent FE and child-parent FE approaches are equivalent.
} 
parent-child unobserved heterogeneity or using non-cognitive skills reported by parents could over-estimate the adverse effect of poor parental health on child development.

The paper unfolds as follows: Section 2 discusses the related literature, while Section 3 describes our data. Section 4 describes our empirical models, and Section 5 presents the results. Section 6 presents the robustness checks and Section 7 examines heterogeneous effects. Section 8 concludes the paper.

\section{Literature review}

This paper studies the effects of parental health on child development. Therefore, it relates to a very rich history of literature devoted to examining the intergenerational transmission of a number of factors, such as education, income and health (Black and Devereux, 2011; CobbClark and Nguyen, 2012). ${ }^{3}$ However, this paper is more closely connected to a small, yet growing area of literature focused on the relationship between parental health and child development. While research is limited, studies have provided evidence on a relationship between parental health and child development. This relationship has been identified within a number of countries with different development levels, from developing countries (Gertler et al., 2004; Case and Ardington, 2006; Sun and Yao, 2010; Bratti and Mendola, 2014; Cas et al., 2014; Senne, 2014; Alam, 2015) to developed countries (Propper et al., 2007; Frank and Meara, 2009; Morefield, 2010; Johnston et al., 2013; Mühlenweg et al., 2015).

Research has also utilised various parental health measures, including subjective general health (Bratti and Mendola, 2014; Mühlenweg et al., 2015), mental health (Farahati et al., 2003; Frank and Meara, 2009; Bratti and Mendola, 2014), negative health events (Morefield, 2010; Johnson and Reynolds, 2013; Alam, 2015), and death (Yamano and Jayne, 2005; Evans and Miguel, 2007; Chen et al., 2009; Adda et al., 2011; Cas et al., 2014; Senne, 2014). Furthermore, a number of child development outcomes have also been studied, including cognitive skills (Frank and Meara, 2009; Morefield, 2010), non-cognitive skills (Frank and Meara, 2009; Morefield, 2010; Mühlenweg et al., 2015), school participation (Farahati et al.,

\footnotetext{
${ }^{3}$ There is also a large collection of literature relating to the effects of parental neonatal health on a wide spectrum of child later-life outcomes, such as human capital development, wages and health (Haveman and Wolfe, 1995; Currie, 2009). The existing literature tends to reach a consensus that poor neonatal health of parents has negative effects on socio-economic and health outcomes of their children later in life. This current paper differentiates from this literature by examining the effects of parental concurrent health instead of past health. It is also related to a seemingly separate literature of intergenerational transmission of health (Johnston et al., 2013; Le and Nguyen, 2015). For a recent review of this literature and evidence on the impact of parental health on child physical health measures, see, for example, Le and Nguyen (2015).
} 
2003; Frank and Meara, 2009; Johnson and Reynolds, 2013; Alam, 2015), and health (Propper et al., 2007; Johnston et al., 2013).

Due to a complete lack of suitable instruments, studies in this area have used two main strategies to address the possible endogeneity of parental health in the child development equations. The first approach tries to limit the impact of unobservable individual heterogeneity by using a rich set of child and parent characteristics (Morefield, 2010; Mühlenweg et al., 2015). The second approach takes advantage of panel data and controls for time-invariant unobservable characteristics using a FE estimator. Following this path, some studies (Chen et al., 2009; Frank and Meara, 2009) have exploited differences in educational outcomes between siblings to remove unobserved differences (such as parental characteristics or family backgrounds) between siblings in a family FE estimator. However, this identification approach is challenged by an often observed pattern that children of same parents may differ in observed or unobserved characteristics and parents may adjust their investment in order to compensate or reinforce their effects on child development (Figlio et al., 2014). Instead, the child FE approach addresses the above concern by removing differences among individual children. Possibly due to data constraints, so far only a handful of studies (Yamano and Jayne, 2005; Evans and Miguel, 2007; Bratti and Mendola, 2014; Cas et al., 2014; Senne, 2014; Alam, 2015) have employed a child FE estimator, with all of these studies using datasets from developing countries. 
Regardless of the dataset and empirical methods used, existing evidence points to harmful effects of poor parental health on almost all child development outcomes considered. Empirical evidence has also suggested that the effects may not be homogenous. For example, while some studies document larger effects on school enrolments of girls than boys (Farahati et al., 2003; Yamano and Jayne, 2005; Sun and Yao, 2010; Senne, 2014), a US study by Morefield (2010) reports poor maternal health has more harmful effects on non-cognitive skills of sons than daughters. Some studies also report a larger effect for younger children (Sun and Yao, 2010; Senne, 2014) or children in poorer families (Yamano and Jayne, 2005; Senne, 2014). Studies into both paternal and maternal health have returned mixed results with some finding maternal health impacts more than paternal health (Case and Ardington, 2006; Evans and Miguel, 2007; Chen et al., 2009; Bratti and Mendola, 2014; Mühlenweg et al., 2015) while others found only paternal illness matters (Alam, 2015) or little difference based on the gender of the child or the parent (Gertler et al., 2004).

Australian studies have reported an association between maternal health and child development. For example, Yamauchi (2010) and Nghiem et al. (2015) both used LSAC-K cohort data. However, Yamauchi (2010) used data from the first wave of the LSAC-K cohort when the children were 4 or 5 years old, finding mothers with better mental health are more likely to have children with better cognitive and non-cognitive outcomes, particularly noncognitive outcomes. By contrast, Nghiem et al. (2015) used data from the first four waves, focusing on outcomes of 8-11 year old children. They returned contradictory results to Yamauchi (2010), finding that, in general, maternal health is not statistically significantly associated with child cognitive development. While this study (i.e. the current paper) uses the same LSAC data to examine the impact of parental health on child outcomes as the previous two Australian studies, it improves upon these studies in three important dimensions. First, this study employs the child FE approach to account for child time invariant unobservable characteristics while the previous Australian studies could not control for the child FE. ${ }^{4}$ Second, this study uses non-cognitive skills reported by parents and teachers while the two Australian studies only used non-cognitive skills reported by parents. Third, this study uses more recent waves of data than the previous Australian studies..

\footnotetext{
${ }^{4}$ Particularly, Yamauchi (2010) uses cross-sectional data which cannot control for the child FE. Similarly, the empirical approaches employed by Nghiem et al. (2015) cannot account for child time invariant unobservable characteristics. Unfortunately, Nghiem et al. (2015) do not report estimates of maternal health on child noncognitive development.
} 


\section{Data}

\subsection{Data sample}

We use data from the first five waves of the biannually nationally representative LSAC survey. The LSAC, initiated in 2004, contains comprehensive information about children's development indicators and other socio-economic and demographic background of children and their parents. The LSAC sampling frame consists of all children born between March 2003 and February 2004 (B-Cohort, infants aged 0-1 year in 2004), and between March 1999 and February 2000 (K-Cohort, children aged 4-5 years in 2004). In this study we focus on 4,983 children of K-cohort because measures on child development are more widely available for this cohort in the first five waves of the survey. Our current data thus allow us to study the subject during key developmental years of children, from pre-school (4/5 year old) to early secondary school (12/13 year old).

\subsection{Measures of parental health}

Three parental health measures are used in this study. The first measure is based on the K6 scale of psychological distress. The K6 was based on self-reported responses to 6 items which ask each parent about symptoms of depression or anxiety experienced in the past four weeks. It uses a five level response scale that ranges from "all of the time" (1) to "none of the time” (5). The 6 questions asked are: "In the past 4 weeks, how often did you feel...": 1. Nervous; 2. Hopeless; 3. Restless or fidgety; 4. Everything was an effort; 5. So sad couldn't cheer up; 6. Worthless. The sum of the scored responses to the six questions is used to generate a single score of psychological distress. The summed score ranges from 6 to 30, with higher scores indicating better mental health. K6 validation studies were carried out in a number of countries throughout the world (Kessler et al., 2010), including Australia (Furukawa et al., 2003). These studies uniformly found the K6 to have very good concordance with independent clinical ratings of mental health. For the sake of interpretation and consistency with other parental health measures used in this study, we use a reversed K6 score where a higher score indicates a worse mental health level.

While the K6 has been proven to be a high quality measure of mental health, concerns have been raised that as a subjective measure it may be prone to a self-reporting scale bias. ${ }^{5}$ To

\footnotetext{
${ }^{5}$ It is understood from the existing literature that individuals may have different scales of reference in answering the same question on the assessment of their health status (Bertrand and Mullainathan, 2001). Note that our empirical models which control for parent-child time invariant unobservable characteristics also help reduce any scale of reference bias.
} 
address such a concern, we use a binary indicator which takes the value of one if the mother (or father) was depressed for two weeks or more in the year prior to the survey time and zero otherwise. $^{6}$

In addition to the two above mental health measures, we also use a general health measure reported by each parent to indicate parental health states. Specifically, responses to the question "In general, would you say your own health is: 1 Excellent; 2 Very good; 3 Good; 4 Fair; 5 Poor" are used to construct a general health measure with higher values of this measure indicating worse subjective general health.

In this paper, we use all parental health measures available in our dataset. These measures while being subjective ${ }^{7}$ are commonly used in empirical research using survey data because they are found to be a strong predictor of true physical or mental health (Contoyannis et al., 2004; Kessler et al., 2010; Vaillant and Wolff, 2012; Doiron et al., 2015; Nielsen, 2016). As already mentioned in Section 2, possibly due to data limitations, some studies in this literature also use parental health measures similar to ours (Frank and Meara, 2009; Bratti and Mendola, 2014; Alam, 2015; Mühlenweg et al., 2015).

\subsection{Measures of child cognitive development}

Three indicators of the latent cognitive development of children are used in this study. ${ }^{8}$ The first indicator is drawn from results of the NAPLAN test. All Australian students are required to complete the NAPLAN test in grades 3, 5, 7 and 9 in the five domains of reading, writing, spelling, grammar and numeracy. The test scores range from 0 to 1000 and are comparable across the nation and over time (ACARA, 2014). The NAPLAN test results of children were collected via data linkage with LSAC data (Daraganova et al., 2013). At the time of this study, the linkage data for LSAC were mainly available for students in grades 3, 5, and 7. We

\footnotetext{
${ }^{6}$ This variable is derived from responses to the question "In the past year, have you had two weeks or more during which you felt sad, blue or depressed or lost pleasure in things that you usually cared about or enjoyed?” which was asked separately for each parent. This information is only available from wave 2.

${ }^{7}$ Unfortunately, our dataset does not contain a more objective or more traumatic measure of parental health shocks (e.g. clinical evaluations or hospitalizations). The only possibly more traumatic measure of parental health shock can be derived from responses to a question asking the parent 1 about events that have happened in the last year. One such event is whether the parent 1 or his/her partner suffered a serious illness, injury or assault. While this variable is highly correlated with all three parental health variables used in this study (see Appendix Table A2), given the correlation is not large and the fact that we are unable to identify to which parent the event was referred, we do not use such an event to measure parental health. Nevertheless, unreported results show that such an event does not worsen any child development outcome considered in this study.

${ }^{8}$ LSAC data also have other measures of students' academic performance assessed by a class teacher and a parent. These assessments are based on a relative comparison with the student's classmates, and therefore might differ across parents, teachers and schools (Daraganova et al., 2013). Therefore, we do not use them in our analysis.
} 
thus focus on test results at these grades and use results of all test subjects in order to measure the cognitive development of children. Since the NAPLAN test dates and LSAC survey dates are not the same, test results and survey data are merged in the way that test results are not pre-dated by survey data. This matching exercise ensures NAPLAN test scores in grades 3,5 , and 7 are merged with survey data in wave 2 , 3, and 4 , respectively.

Two additional indicators to measure the cognitive development in children are drawn from the Peabody Picture Vocabulary Test (PPVT) and Matrix Reasoning (MR) tests. The PPVT is an interviewer-administered test to assess a child's listening comprehension ability for spoken words in standard English (Dunn and Dunn, 1997). The MR test is also administered by an interviewer to assess a child's non-verbal intelligence. The raw MR score is presented as the number of correct answers, ranging from zero to 20. PPVT and MR test scores have been used widely to proxy child cognitive development in economics literature (Fiorini and Keane, 2014; Nghiem et al., 2015). Our current data include PPVT scores in waves 1 to 3 and MR in waves 2 to 4 .

\subsection{Measures of child non-cognitive development}

Measures of child non-cognitive skills are derived from the Strengths and Difficulties Questionnaire (SDQ). The SDQ is a standard psychometric measure of children's behaviour and socio-emotional skills (Goodman, 1997) and is widely used in psychopathological screening (Achenbach et al., 2008; Goodman and Goodman, 2009). The SDQ contains five sub-scales: pro-social behaviour (hereafter called Prosociality), hyperactivity and inattention (Hyperactivity), emotional symptoms (Emotional), conduct problems (Conduct), and peerrelationship problems (Peer). Each SDQ sub-scale is scored as the summation of the item scores on each of the five sub-items, and then rescaled to give values from zero to 10 . For ease of interpretation, we have rescaled the SDQ measures so that higher SDQ scores indicate "better” behaviours.

We follow some studies in this literature, including Australian studies which use the same dataset and similar child development outcomes as ours (Fiorini and Keane, 2014; Nghiem et al., 2015) or US studies which use an apparently similar set of outcomes to ours (Cunha and Heckman, 2008; Morefield, 2010), to name measures derived from the SDQ as "noncognitive” outcomes. However, some studies in this literature call such measures differently, namely "behavioural outcomes” (Frank and Meara, 2009; Yamauchi, 2010; Mühlenweg et al., 2015), “social/emotional development” (Frijters et al., 2009), or “mental health” 
(Johnston et al., 2014a). The fact that this literature uses different terms for a largely similar set of skills is consistent with that in the larger literature on "non-cognitive" development which also finds it difficult to identify and define such skills (Heckman and Kautz, 2013).

Our measures of child non-cognitive development are similar to those used in studies for Germany (Mühlenweg et al., 2015) and the US (Frank and Meara, 2009; Morefield, 2010). Possibly due to the nature of datasets used in international studies, all existing studies use non-cognitive skills reported by parents (mostly mothers). Australian studies (Yamauchi, 2010; Nghiem et al., 2015) using the LSAC data also use non-cognitive skills reported by parents. One concern regarding such measures is that they are subjective and might be influenced by the parents' own health. A possible consequence of using such measures would be a biased estimate of parental health from the child non-cognitive skill equations. Fortunately, our data contain responses to the same set of the SDQ identifying child behaviours administered separately to parents and teachers, roughly at the same time and repeatedly for children at school. ${ }^{9}$ This allows us to directly compare evaluations from parents and teachers and examine the implications for the estimate of parental health on child behavioural outcomes. Teachers' reports on the SDQ are our preferred measures of children's non-cognitive skills because their reports may not be subject to the health condition of parents. We therefore focus on SDQ scores reported by teachers. For comparison purposes with previous research, which only use parents' reports of children behaviours, we also report the results of the SDQ scores reported by parents. Like cognitive skill measures rather than NAPLAN test scores, we make up to five observations of non-cognitive skills for each child by ages of children in our data.

The presence of too many outcome variables increases the risk that we may find spurious effects. We address this multiple inference issue in two ways. First, we reduce the number of outcome measures by generating summary indices. Particularly, we form two summary indices of cognitive and non-cognitive skills. We still differentiate between cognitive and non-cognitive skills and components of each skill type in line with most of the previous literature (Cunha and Heckman, 2008; Cunha et al., 2010; Fiorini and Keane, 2014; Mühlenweg et al., 2015; Nguyen, 2015). The summary index is the simple average across all

\footnotetext{
${ }^{9}$ Precisely $98 \%$ of the child's teacher's questionnaires were completed by the child's main teacher. Furthermore, while parents' reports are available for almost all children in our main sample, teachers' reports are available for about $80 \%$ of children. It should be noted that cognitive outcomes such as NAPLAN scores are less likely to be subject to measurement errors because test papers are blind marked and test scores are linked using administrative data.
} 
available measures of each type of skills. ${ }^{10}$ Second, we calculate $p$-values that are adjusted for the multiple inference issue using the Simes-Benjamini-Hochberg method (Simes, 1986; Benjamini and Hochberg, 1995). ${ }^{11}$ Both approaches are increasingly used in economics (Kling et al., 2007; Anderson, 2008; Heckman et al., 2010; Hoynes et al., 2016).

\subsection{Sample}

In our analysis, we concentrate on $\mathrm{K}$ cohort children because child development measures are more widely available for them. Furthermore, because we are interested in the impact of both maternal and paternal health we restrict the sample to children who lived with both parents during the study period. This sample restriction also helps isolate the impact of parental health from that of parental separation and reduces the number of observations with missing information on important characteristics of both parents (mostly fathers). Nevertheless, some results for single mothers are provided in Section 7. We further restrict our sample to children without missing information on a list of important explanatory variables (as detailed in Section 4). Finally, since we will focus on results estimated using a child FE estimator; we necessarily restrict our sample to children who were observed at least twice in the data. Our above sample restrictions result in final samples which vary by measures of child development and parental health. As can be seen in Tables 1 to 3, our final sample sizes range from 3,786 wave-child observations (of 1,893 unique children) to 9,843 wave-child observations (of 2,774 unique children).

There are a variety of reasons that individuals may enter or exit the final sample, including original sample attrition, missing information on important variables, and the fact that we must observe an individual child at least twice to apply the FE regression technique. While reasons for original sample attrition are discussed elsewhere (Daraganova et al., 2013), we investigate whether our sample selection criteria lead to sample selection issues. One of the particular concerns relating to our research design is that parental health may affect the probability that an individual child is included in the final sample. Thus, we run a probit model where the dependent variable is equal to one if the child is in our sample and zero otherwise. The explanatory variables are basic demographic characteristics, including parental health variables. Appendix Table A3 presents the results. There is evidence of

\footnotetext{
${ }^{10}$ An exception is that PPVT test scores are not used to calculate the summary cognitive skill index for two reasons. First, they were not evaluated at wave 4 when all other cognitive outcomes were observed (see Section 3.3) and hence including PPVT test scores would reduce the number of times that the summary cognitive skill index is calculated for each child. Second, our FE empirical approach requires that child development measures are comparable over time.

${ }^{11}$ Adjusted $p$-values are calculated using the Stata command qqvalue (Newson, 2010).
} 
statistically significant selection on some observables. For instance, children in our sample tend to come from families with better educated or healthier parents. However, the pseudo- $\mathrm{R}^{2}$ values are small, indicating that selection on observable characteristics is quantitatively weak. More importantly, in four out of five regressions, $p$-values from a $t$ test for joint significance of all parental health variables included in the regression are greater than 0.1 , alleviating concern that our results may be driven by sample selection.

\section{Empirical framework}

\subsection{Theoretical backgrounds}

Theoretically, this study is motivated by various child development frameworks (Becker and Tomes, 1979; Cunha and Heckman, 2007; Heckman, 2007; Cunha et al., 2010) which link skill formation in children to parental capacities and parental investments in child development. According to these frameworks, one would expect that poor parental health affects child development through several channels. For example, poor parental health may reduce income, reduce household wealth, or reduce the quantity or the quality of time parents spend with their children. Poor parental health may also directly worsen the health of children or reduce the child's time diverted from study to take care of parents (Currie, 2009; Fiorini and Keane, 2014). The above theoretical grounds suggest that poor parental health reduces good development outcomes in children. However, there are some suggestions the impact may originate from the opposite direction. For instance, poor health may cause parents to reduce their labour market working time and hence, increase their time with their children (Cai, 2010). Furthermore, children of parents with poor health may also try to improve their test scores or behaviours to make their parents happy. The combining effects of those factors thus leave the impact of parental health on child development to be an empirical issue.

\subsection{Empirical models}

In practice, we lack suitable instruments and data to specifically identify which channel prevails. As such, most empirical studies focus on the estimation of the cumulative impact via all pathways using a reduced form model in which parental health is included as an explanatory variable in the child development equation. We therefore follow the previous literature to estimate the development outcome $Y$ of child $i$ at time $t$ as follows:

$$
Y_{i t}=\alpha+\beta_{m} M H_{i t}+\beta_{f} F H_{i t}+X_{i t} \gamma+\varepsilon_{i t}
$$


where $M H(F H)$ is a measure of maternal (paternal) health which we measure in different ways; $X_{i t}$ is a vector of individual characteristics; $\varepsilon_{i t}$ represents an error term; $\alpha, \beta$ and $\gamma$ are parameters to be estimated; and $\beta_{m}$ and $\beta_{f}$ are our parameters of interest. With our above coding of parental health and child development measures, a negative estimate of any parental health measure indicates that worse parental health is associated with lower levels of child development, and vice versa.

We include in $X_{i t}$ a rich list of factors contributing to the child development such as the child's characteristics (i.e., gender, age, migration status, ethnicity, birth weight, school sectors, and number of siblings), parental characteristics (i.e., age, education, and migration status), and indicators of neighbourhood characteristics. ${ }^{12}$ We also control for the differences in the survey time by including dummies for years and quarters of survey time in regressions. We additionally include state (location) dummy variables to control for differences in socioeconomic environments by states/territories. We further address the issues of children sitting the NAPLAN test in different years for the same grade by using information both on the age of children at the year they sat the test and dummy variables for the test year.

We apply equation (1) to a pooled sample of all children and use an Ordinary Least Squares (OLS) method to estimate all equations. Results from these regressions are called "OLS" results. As already mentioned in the Introduction, the error term $\varepsilon_{i t}$ in equation (1) contains child-parent time-invariant unobserved characteristics $\delta_{i}$. Some of them (such as parental discount factor or ability) may be correlated with both the parental health and child development, causing the OLS estimate to be biased. We employ a child FE estimator to eliminate the role of $\delta_{i}$ in the following regression:

$$
Y_{i t}=\alpha+\beta_{m} M H_{i t}+\beta_{f} F H_{i t}+X_{i t} \gamma+\delta_{i}+\mu_{i t}
$$

where $\mu_{i t}$ is an idiosyncratic error term. We also apply the OLS method to estimate the regression (2) and name the results as FE results. ${ }^{13}$ In all regressions, standard errors are clustered at the individual level to account for the fact that each child has up to five observations, one for each age/grade in which he or she was evaluated.

\footnotetext{
${ }^{12}$ Local variables include percentages of individuals completing year 12, working, speaking English, being born in Australia, or having an Aboriginal/Torres Strait Islands origin in linked areas, percentages of households with household income less than AU $\$ 1,000 /$ week in linked areas, and a metropolitan dummy.

${ }^{13}$ All time invariant variables such as gender, birth weight and migration status are dropped in the FE estimator. Variable descriptions and summary statistics are detailed in Appendix Table A1. Appendix Table A2 shows that parental health measures are highly statistically significantly correlated. Similarly, child development measures are statistically significantly correlated. However, the correlation is not very high in magnitude, suggesting that each measure may capture a different aspect of parental health or child development.
} 


\section{Empirical results}

\subsection{Parental health and child cognitive development}

Estimates of parental health from child cognitive development equations are presented in Table 1. Table 1 reports the estimates from two alternative specifications (OLS versus FE), using three alternative measures of parental health, seven child cognitive skill indicators, and a summary index of child cognitive skills. The OLS results (odd columns in Table 1) show that estimates for all parental mental health measures are not statistically significantly different from zero, suggesting that parental mental health does not affect child cognitive development. Similarly, estimates of the general health measure of both parents (last panel of Table 1) are not distinguishable from zero, indicating that cognitive development in children is not affected by their parents' general health either. Two exceptions, estimates of maternal general health on the child's writing and spelling scores, are negative and statistically significant (at least at the 5\% level, using unadjusted standard errors reported immediately below coefficient estimates), suggesting that children of mothers with poor general health may have lower test scores in these two test domains. Accounting for the multiple inference problem turns the estimate of maternal general health on the child's writing to statistically insignificant (see adjusted $p$-values reported in curly brackets below each skill component).

The FE estimator also turns the estimates of maternal general health on the child's writing and spelling scores to statistically insignificant (see even columns in Table 1). The only negative and statistically significant (at the 5\% level) FE estimate is that of the maternal depression dummy on reading test scores. This estimate suggests that children of mothers who reported having been depressed have reading scores of about 6 points lower than children of mentally healthy mothers. In addition, the $p$-value of a $t$ test for the equality of the estimates of paternal and maternal mental health dummies in the reading score equation suggests that these estimates are statistically different at the $10 \%$ level. By contrast, FE estimates (without controlling for the multiple inference problem) suggest some positive and statistically significant (at the $5 \%$ level or lower) association between poor parental health and child cognitive skills: paternal mental (general) health on PPVT (grammar) and all maternal health indicators on MR. However, accounting for the multiple inference problem, none of the above FE estimates is statistically significant. The above results suggest that failing to account for parent-child FE estimates would result in an over-estimation of the harmful effects of poor parental health on child cognitive development. Overall, our preferred FE estimates suggest that poor parental health does not impair cognitive skills in children. 


\subsection{Parental health and child non-cognitive development}

\subsubsection{Child non-cognitive skills reported by parents}

We next turn to estimates of parental health on child non-cognitive skills. We first follow the previous literature (Frank and Meara, 2009; Morefield, 2010; Mühlenweg et al., 2015) in using child non-cognitive skill measures reported by parents and present OLS estimates of our three parental health measures from various child non-cognitive skill regressions, shown in the odd columns of Table 2.

The OLS estimates reveal two noticeable patterns. First, poor parental health is negatively and highly statistically significantly (at the 1\% level) associated with good behaviours of children. The above pattern holds for all health measures of either mothers or fathers and for all non-cognitive skills in children, regardless of whether the multiple inference issue is accounted for. This pattern suggests that children of parents with poorer health consistently appear to have less desirable behavioural outcomes, a finding which is in line with that reported in the previous studies for Australia (Yamauchi, 2010), Germany (Mühlenweg et al., 2015), and the US (Frank and Meara, 2009; Morefield, 2010). Second, as compared to the estimates of maternal health, those of paternal health are much less pronounced in terms of the magnitude. For example, the first column of Table 2 shows that, depending on parental health measures, the estimates of maternal health on the overall non-cognitive scale are about two or three times greater than that of paternal health. Indeed, the $p$-value of a $t$ test for the equality of the estimates of paternal and maternal health variables (reported at the bottom of each panel in Table 2) confirms that these estimates are statistically different at the $1 \%$ level for the vast majority of child non-cognitive skill measures (exceptions are estimates of the parental depression dummy and general health measure on the Prosociality). Our finding from the OLS estimates of a more detrimental impact of maternal poor health on child behaviours is thus consistent with that reported in the study by Mühlenweg et al. (2015) for German children aged 3-6 years. ${ }^{14}$

In Table 2 (even columns), we also report estimated results from our preferred FE specifications. The FE estimates show that controlling for child FE changes the results noticeably. In particular, the FE estimates are much smaller than OLS estimates in terms of the magnitude and statistical significance level. Specifically, controlling for child heterogeneity at least halves the size of the estimates of parental health measures. Accounting

\footnotetext{
${ }^{14}$ Unfortunately, other studies (Frank and Meara, 2009; Morefield, 2010; Yamauchi, 2010) focus on maternal health so we cannot compare our results with theirs.
} 
for child FE also turns the estimates of parental health from highly statistically significant to less statistically significant (such as estimates of maternal depression dummy on Hyperactivity) or statistically insignificant (e.g. estimates of paternal K6 on all child noncognitive skill measures) for more than a half of the combinations between parental health and child non-cognitive skill measures. The calculations of the adjusted $p$-values from Table 2 suggest that the above results hold up after accounting for the multiple inference problem. Overall, the above comparisons between OLS and FE estimates suggest that failing to account for the child FE would over-estimate the detrimental impact of poor parental health on child non-cognitive development. This finding gives support to our empirical approach which effectively controls for child-parent time-invariant unobserved characteristics. One of the unobserved characteristics of parents would be their discount rates. Parents with lower discount rate have a more risky life style and hence worse health and also invest less in child development (Lawless et al., 2013). As a result, the simple OLS estimate which fails to account for this unobserved parental characteristic over-estimates the adverse impacts of poor parental health on child development.

Results in Table 2 also indicate that controlling for child FE while reducing the detrimental effects of maternal and paternal poor health tends to have more pronounced effects on estimates of maternal health. This is evidenced by changes in the results of a $t$ test which now show that differences in estimates of maternal and paternal health measures are no longer statistically significant for nine combinations of estimates of parental health and child noncognitive skill measures. These include estimates of the K6 on the Peer sub-scale and estimates of the depression dummy and general health on the overall non-cognitive scale and its three sub-scales of Hyperactivity, Conduct and Peer. The above differences between the OLS and FE estimates by parent gender suggests that failing to control for child FE may also result in misleading conclusions about the relative effects of paternal and maternal health on child non-cognitive development. One possible reason for the changes in relative effects of paternal and maternal health is that in our case, as in all prior studies in this literature, almost all (99\%) SDQ responses are by mothers and that maternal health itself may affect the way the mother reports the child's behaviour. Below, we investigate this prediction using the teacher's evaluation of the child's behaviour. Teacher's evaluations, arguably, do not depend on the health status of parents. 


\subsubsection{Child non-cognitive skills reported by teachers}

Table 3 reports OLS (odd columns) and FE (even columns) estimates of parental health from various separate regressions of child non-cognitive outcomes as reported by teachers. The OLS results indicate that poor parental health is associated with worse behaviours in children. However, estimates are statistically significant for some combinations of parental health measures and child non-cognitive outcomes only. In particular, for maternal health, statistical significant estimates are observed for estimates of $\mathrm{K} 6$ on all non-cognitive measures, estimates of the depression dummy on all non-cognitive measures (except Prosociality), and estimates of general health on the overall non-cognitive scale, Emotional and Peer. For paternal health, statistical significant estimates include those of K6 on all non-cognitive skill measures, those of the depression dummy on all non-cognitive skill measures (except Prosociality), and those of general health on all non-cognitive skill measures (except Emotional).

Comparing the magnitude of OLS estimates of paternal and maternal health variables on child non-cognitive skills using evaluations from parents (Table 2) and teachers (Table 3) reveals an interesting pattern: while estimates of paternal health measures are quite similar in the two tables those of maternal health drop considerably from Table 2 to Table 3 . Contrasting the results of a $t$ test for the equality of the OLS estimates of paternal and maternal health variables in the child non-cognitive skill equations from the two tables also uncovers an apparent pattern: while Table 2 shows maternal poor health has more harmful effects than paternal poor health, Table 3 suggests that effects are not statistically different from each other. ${ }^{15}$ These two patterns when viewed with the fact that the vast majority of SDQ responses are by mothers convey an important implication: mothers with worse health tend to over-report that their children have behavioural problems. This implication is consistent with the depression-distortion hypothesis and with its supporting empirical evidence in the psychology and medical literature, which suggests that depression promotes a negative bias in the way in which mothers perceive their children's emotional or behavioural problems (Richters, 1992; De Reyes and Kazdin, 2005). ${ }^{16}$ As such, using mothers' evaluations of child non-cognitive skills would over-estimate the harmful impact of poor

\footnotetext{
${ }^{15}$ An exception is that maternal poor health (as measured by a higher general health score) has a more harmful effect on the Emotional index of children than paternal poor health ( $p$-value of $t$ test is 0.02).

${ }^{16}$ This does not necessarily mean that teachers' reports are less biased than those of parent/s (Johnston et al., 2014a).
} 
maternal health on child non-cognitive development and result in misleading conclusions about the relative effects of maternal and paternal health on such development outcomes.

Table 3 shows FE estimates are much smaller than OLS estimates in terms of the statistical significance level and magnitude. Specifically, when controlling for child FE, only a handful of estimates of parental health on child non-cognitive skills are statistically significant at the 5\% level or higher. These include estimates of maternal K6 on Hyperactivity, paternal K6 on Hyperactivity and Conduct, and paternal depression dummy on Hyperactivity and the noncognitive skill index. In addition, for estimates that remain statistically significant, FE estimates are at least about 25\% smaller than OLS estimates. These findings again suggest that being unable to control for the child FE could over-estimate the harmful effects of poor parental health on child non-cognitive development. The calculations of the adjusted $p$-values from Table 3 indicate that only the estimate of paternal depression dummy on Hyperactivity remains statistically significant (at the $5 \%$ level) after accounting for the multiple inference problem. Thus, accounting for both individual heterogeneity and the multiple inference problem, only the paternal depression dummy appears to worsen the child's non-cognitive skills (as measured by the non-cognitive skill index and Hyperactivity).

Table 3 also suggests that controlling for child FE appears to have similar impact on the estimates of paternal and maternal health measures. Indeed, consistent with results of a $t$ test from the OLS regressions, test results from FE regressions also suggest that effects of maternal and paternal health are not statistically significantly different. ${ }^{17}$ The similarity of the test results from the two specifications suggests that teachers' evaluations of their students' behaviours in our data may be truly independent of parental health status.

\subsubsection{Discussion}

In the above results, using our preferred FE specifications and measures of child noncognitive skills, we found little evidence supporting the proposition that poor parental health worsens cognitive and non-cognitive development in children. If poor cognitive and noncognitive development eventually results in early school dropout as found in the literature (De Witte et al., 2013), our findings are in stark contrast to the finding of a negative effect of poor parental health on the child's school participation probability reported in six prior studies which use a similar child FE approach (Yamano and Jayne, 2005; Evans and Miguel, 2007; Bratti and Mendola, 2014; Cas et al., 2014; Senne, 2014; Alam, 2015).

\footnotetext{
${ }^{17}$ An exception is that paternal depression has a more harmful effect on Hyperactivity than maternal depression, as shown in column 6 - panel 2 of Table 3 (p-value of $t$ test is 0.02 ).
} 
Differences in parental health measures used among studies could be a possible reason for differences in our findings. Our measures of poor parental health are obviously much less traumatic than parental death as used in four out of six of the above studies. ${ }^{18}$ As such, the impact would be less severe in this study than in the previous ones. However, the following three observations make this prediction less likely to hold. First, using a largely similar set of parental health measures ${ }^{19}$ as ours, Bratti and Mendola (2014) find that poor maternal health statistically significantly reduces the probability of attending school for children from Bosnia and Herzegovina. Second, using data from Tanzania and probably a more severe measure of poor parental health than ours ${ }^{20}$, Alam (2015) also finds that fathers' illness reduces the probability of attending school for children aged 7-to-15 years old. Third, because child development measures are more continuous in this study than in all the above six studies, it is easier to detect an effect in the former. These three observations also suggest that other factors are behind the differences in findings. One such factor would be differences in the children's socio-economic environment. As compared to the developing countries examined in all six above-mentioned studies, Australia, as a high-income country, has a better system of social protection. It has been evidenced that in countries with poor systems of social protection, ill health may have significant economic consequences for both current and future generations (Gertler et al., 2004; Wagstaff, 2007). Therefore, we may expect a less detrimental impact of poor parental health on child education in Australia than in developing countries. This prediction is supported by evidence from two US studies (Frank and Meara, 2009; Morefield, 2010) reporting no significant impact of poor maternal health on child cognitive development.

Our finding of little significant effect of poor parental health on child non-cognitive development is also different from a universal finding in prior research of a harmful effect (Frank and Meara, 2009; Morefield, 2010; Yamauchi, 2010; Mühlenweg et al., 2015). Because these studies (including the current study) use largely similar measures of parental

\footnotetext{
${ }^{18}$ Parental deaths are very rare events in our data so we do not examine their effects.

19 Specifically, Bratti and Mendola (2014) also use parental self-reported health status and mental health indicators. Children in our Australian study are aged from 4 to 13 years so they are younger than the 15 to 24 year old children in Bratti and Mendola's (2014) study from Bosnia and Herzegovina. Because existing evidence suggests a more harmful effect of poor parental health on outcomes of younger children (Morefield, 2010; Sun and Yao, 2010; Senne, 2014), the differences in ages of children between the two studies may not explain the difference in our findings. However, it should be noted that the reduction in the probability of 15-24 year old children attending school found in the study by Bratti and Mendola (2014) may not come from the impact on child development, but for instance, from an income impact.

${ }^{20}$ In particular, Alam (2015) considers an individual to be ill if the person reports any illness and is unable to conduct their usual activities for at least a day.
} 
health and child non-cognitive skills, and datasets from developed countries, factors other than differences in variable measurements or socio-economic environments may explain the difference in our findings. Our analyses in Sub-section 5.2 suggest that the difference in the findings can be mainly attributed to the differences in capacities to control for child FE and the use of more objective measures of child non-cognitive skills. In what follows, we will use child non-cognitive skills evaluated by teachers as well as the FE specification.

\section{Robustness checks}

\subsection{Threats to identification assumptions}

There are a number of issues that challenge our FE identification assumptions. The first threat is a lack of variation in parental health variables. Three following observations suggest that such a threat may not be present in our data. First, Appendix Table A1 (last column) shows large variations in parental health variables for the same child. Second, the estimates for standard errors (reported in square brackets in Tables 1 to 3) are about the same between pooled and FE regressions, indicating that insufficient variation in parental health variables is indeed not a problem for our data (Allison, 2009). Third, unreported F test statistics confirm that FE models are preferred to OLS models in all cases.

The second threat is the omission of time-variant factors which are correlated with both parental health and child development. It is hard to pinpoint what these unobservable factors might be. Bratti and Mendola (2014) suggest that the child's health status could be one such unobservable factor. Current child development literature also suggests that parental working status, household income, and other negative events happening to other family members may be important factors because they are correlated with parental health and child development (Currie, 2009). ${ }^{21}$ In this section, we test the robustness of our results to the inclusion of these variables by adding each of them separately to the existing list of explanatory variables used in our baseline regressions. Unreported results from these robustness checks show that estimates for parental health measures are unchanged, suggesting that our findings are not sensitive to including further time-variant observable variables.

The third threat to our FE identification is that of reverse causality. One could anticipate that given some negative shocks in child development parental health would worsen. As such,

\footnotetext{
${ }^{21}$ In our baseline specifications, we purposely did not include these variables because they are reasonably considered to be influenced by parental health. We use the death or illness of other household members other than the parents of the study child or the study child to represent a negative event happening to other family members.
} 
what we estimate as effects of parental health on child development is simply capturing this reverse causality between parental health and child development. One popular method to alleviate some of the concern over reverse causality is to use lags of parental health measures in the regressions of child development (Johnston et al., 2013). In our study, as mentioned in Section 3, parental health is recorded before some child development outcomes (such as all NAPLAN test scores) are observed. Such time arrangement helps mitigate some of the concern over reverse causality. Additionally, we alleviate some of the concern by testing whether each current child development outcome affects the future health status of each parent. The results (reported in Appendix Table A4) do not indicate any significant correlation, suggesting that our results may not be driven by reverse causality. ${ }^{22}$

Finally, we address the second and third threats by employing a FE instrumental variables (FE-IV) model, which is identified by time-variant sources of arguably exogenous variations in maternal mental health to estimate a causal impact of maternal mental health shocks on child development. In particular, we follow some previous studies to use the death of a close friend of the mother (Frijters et al., 2014; Johnston et al., 2014a; Le and Nguyen, 2015) and a recent serious injury of a close relative (not a parent, partner or child) of the mother (Heitmueller, 2007; Van Houtven et al., 2013; Nguyen and Connelly, 2014) as two instruments in maternal mental health equations. ${ }^{23}$ These instruments affect about $34 \%$ of mothers in our sample, vary for the same mother over time and are shown to strongly determine maternal mental health (Kendler et al., 1999). These instruments are also theoretically sound: the (arguably unexpected) recent death of a close friend or serious injury/illness of a close relative should directly affect the mother's mental health, but only indirectly affect her child's development through the maternal mental health channel.

FE-IV estimates are reported in Appendix Table A5. Two results from FE-IV regressions suggest that our instruments are empirically strong. First, the first-stage F statistic is close or above the rule of thumb value of 10 for a strong instrument (Stock and Yogo, 2005). Second, the Sargan-Hansen statistic for over identification restrictions suggests that our instruments

\footnotetext{
22 Two exceptions are negative and statistically significant (at the 5\% level) estimates of lags of Emotional (Conduct) on the current K6 (depression dummy) of mothers.

${ }^{23}$ In LSAC data, parent 1 is asked "in the last year, have any of the following happened to you". We use statements about "A close family friend or another relative (aunt, cousin, grandparent) died" and "A serious illness, injury or assault happened to a close relative" to construct the two instruments. We restrict this robustness check to maternal mental health variables only because these instruments are mainly available for them. We also implemented several robustness checks as suggested by Le and Nguyen (2015) and found our results are largely robust.
} 
are exogenous. Also consistent with our FE estimates, all FE-IV estimates suggest that maternal depression has no detrimental impact on child cognitive or non-cognitive skills.

\subsection{Functional forms of parental health and child development models}

Above we introduced parental health variables other than the depression status dummy as continuous because any arbitrary transformation of these variables could be controversial. Threshold effects of parental health on child development might exist. To test such a possibility, we use a dichotomous method. Specifically, we use a dummy indicating the parent has probable serious mental illness if his/her reported K6 is lower than 19 (Furukawa et al., 2003; Kessler et al., 2010). Similarly, following Bratti and Mendola (2014), we define a dummy variable describing parental poor health if the parent reported his/her general health condition as "fair" or "poor", compared to other choices of "good”, "very good", and “excellent”. In this specification, we also include an interaction term between maternal and paternal health to check for any joint impact of parental health.

Estimation results (reported in Appendix Table A6) show weak evidence of some thresholds on the impact of paternal K6 on selected child development outcomes such as Numeracy, cognitive index, and Conduct. In particular, we find negative and marginally statistically significant (at the 10\% level) estimates of paternal K6 depression dummy on these outcomes. Previously, using the continuous paternal K6 variable we did not find any statistically significant impact of this variable on any child development outcome. The evidence of a threshold on the impact in paternal K6 found here when viewed with one of our previous FE findings that only the paternal depression dummy is statistically significantly associated with less desirable non-cognitive skills in children (Section 5.2.2.) suggest that a harmful effect on development outcomes is observed for children of fathers with probably more serious mental health issues only. However, the estimates of all interaction terms are statistically insignificant, suggesting there is no joint effect of parental health on child development outcomes.

Our FE results above indicate little contemporaneous impact of parental health on child outcomes. It would be possible that it may take time for parental health to have a visible impact on some child development outcomes. We investigate this possibility by including a one-wave lag of parental health in the FE regressions of current outcomes of children. Regression results (reported in Appendix Table A7) suggest that poor maternal health does not impair subsequent outcomes of children. By contrast, poor paternal mental health (as 
measured by the depression dummy) worsens some child subsequent non-cognitive skills (as measured by the overall non-cognitive skill index and its two components: Prosociality and Conduct).

We also estimate a model of child development similar to regression (2) with a lag of child development outcome as an additional explanatory variable in the spirit of a dynamic child development model (Todd and Wolpin, 2007; Cunha and Heckman, 2008; Cunha et al., 2010). Because OLS is inconsistent in this case, we estimate the dynamic child development model by employing a system General Method of Moment (GMM) estimator developed by Arellano and Bover (1995) and Blundell and Bond (1998). ${ }^{24}$ In addition to the existing list of controls described in Section 4.2, we draw from the human capital theory (Becker, 1981; Becker and Tomes, 1986) by including other indicators representing parental investment in child development in this extended specification. These indicators include (1) parental labour supply and an out-of-home activities inde ${ }^{25}$ to capture the parental time investment in children (Currie, 2009; Fiorini and Keane, 2014), (2) the log of family income to proxy for parental material investment in children (Currie, 2009), (3) parenting styles ${ }^{26}$ (Fiorini and Keane, 2014), and (4) child general health status (Bratti and Mendola, 2014).

Estimation results (reported in the first row of Appendix Table A8) show that, with the exceptions of spelling and grammar outcomes, outcomes in the previous wave are a statistically significant determinant of all current cognitive and non-cognitive skills. This result is in line with the dynamic theory of skill formation and with previous empirical evidence (Todd and Wolpin, 2007; Cunha et al., 2010). Also consistent with our previous FE results, estimates of parental health variables from the dynamic model of child development also suggest that poor parental health does not worsen child development outcomes.

\footnotetext{
${ }^{24}$ In a nutshell, the system GMM estimator uses a transform of differences in other control variables as instruments for the lag of the outcome variable. One potential issue with this approach is that there are too many instruments available and this can lead to over-identification problems. Unreported $p$-values from a Sargan test are usually smaller than 0.1, suggesting that the over-identification issue may not be present in our case. Another potential issue with this estimator is that standard errors of estimates can be downward biased and therefore we employ the finite sample correction method proposed by Windmeijer (2005) in this study.

${ }^{25}$ This is measured by the number of "yes" answers to questions about activities that the family do together, such as going to a movie, sporting event, library, or religious service. Our data also include information about the frequency of activities the family do together at home such as reading, games, or drawing pictures. Unfortunately, such information is inconsistent across waves so that we cannot include it in regressions. We do not include a more direct measure of parental time spent with children, such as that of Fiorini and Keane (2014) who use responses from children's time use surveys because doing so reduces the sample size significantly.

${ }^{26}$ These include three parenting style scales: warm, hostile, and consistent (Lucas et al., 2010).
} 


\section{Heterogeneity}

It is possible that the impact of parental poor health may be different for children of single parents because, unlike coupled parents, single parents lack the capacity to compensate for health issues of the other (non-co-residing) parents. To explore this possibility, we estimate the model (2) for a sample of children of single mothers. ${ }^{27}$ Results (reported in Appendix Table A9) suggest that children of single mothers with worse health appear to have less desirable cognitive and non-cognitive outcomes (as demonstrated by the negative and statistically significant estimates of both maternal mental health indicators on the noncognitive skill index and the estimate of maternal general health on the cognitive skill index).

We also investigate heterogeneity in the impact of parental health by gender and age groups of children as well as the household income levels. Estimation results (reported in Appendix Tables A10 to A16) suggest no clear differential impact by such characteristics. ${ }^{28}$ Similarly, there is no clear indication that the parental mental health impact is different between entering versus exiting from depression (see Appendix Table A17).

\section{Conclusion}

Drawing on the recent and nationally representative panel of Australian children, we have examined the effects of maternal and paternal health on cognitive and non-cognitive development of children over 10 years in their early lives. This study improves on most previous research by using a child FE approach to deal with the endogeneity of parental health and better measures of child non-cognitive skills. Results from this paper have highlighted two important methodological implications. First, failing to control for the childparent unobservable characteristics may result in an over-estimation of the detrimental impact of poor parental health on child development. Second, using non-cognitive skills reported by parents could also over-estimate the harmful effect of poor parental health on child noncognitive development.

\footnotetext{
${ }^{27}$ The sample of children with single fathers is too small (i.e. less than 64 observations) for us to run a separate regression. We thank a referee for his or her comments which have led us to employ this regression. We also experimented with running a FE-IV model to maternal mental health variables for a sample of children of single mothers. Because the instruments do not explain the maternal mental health variables very well, possibly due to the small sample size, results from this experiment are not reported.

${ }^{28}$ Appendix Tables A15 and A16 report the heterogeneity of the results for two sub-groups of children, defined relative to the median of household income. It is possible that the impact of parental health is stronger at the very bottom of the household income distribution. We checked this possibility by separately estimating the model (2) for two samples of children from households at the first and fourth quartile of the income distribution and found no evidence to support such possibility.
} 
Our preferred results indeed indicate detrimental effects of poor parental health on selected cognitive and non-cognitive skills of children. However, our results suggest that such harmful effects are only observed for children of fathers with more serious mental illness or children of single mothers. This evidence suggests that policies aimed at improving health of these possibly more disadvantaged parents would be beneficial for their children's cognitive and non-cognitive development. Such policies would also help reduce persistence in intergenerational transmission of disadvantages (Black and Devereux, 2011).

The positive conclusion from our analysis is that we find little detrimental effects of poor parental health on child cognitive and non-cognitive skills. However, it is important to emphasize that the results we present only apply to parental health measures observed in our data; they cannot necessarily be generalized to the effects of other health conditions. Also they cannot be generalized to the case of parental health in other countries. Caution must also be exercised in interpreting the findings to ultimately mean that poor parental health does not worsen child cognitive and non-cognitive development.

There are three potentially limiting features of our analysis. First, our measures of parental health are all subjective so they may be subject to measurement errors. Second, parental health measures available in our dataset may not capture traumatic health shocks experienced by the parents and this should be taken into account when interpreting our results. Third, although our results have been proven to be robust to various sensitivity tests, including controlling for some important time-varying characteristics and employing a FE instrumental variable approach, we cannot totally rule out that our results are driven by other time-varying unobserved characteristics or reverse causality. These limitations thus prevent us from interpreting our estimated impact of parental health on child outcomes as causal. This work has highlighted the importance of controlling for individual heterogeneity and using more objective measures of child non-cognitive skills when modelling the effects of parental health on child development. Future work should take these important methodological implications into account when extending the topic to other countries' data. Further studies using better parental health measures or employing more robust econometric methods to study the subject are also worthwhile. 


\section{References}

ACARA, 2014. National Assessment Program - Literacy and Numeracy 2013: Technical Report. Sydney: Australian Curriculum, Assessment and Reporting Authority (ACARA).

Achenbach, T.M., Becker, A., Döpfner, M., Heiervang, E., Roessner, V., Steinhausen, H.-C., Rothenberger, A., 2008. Multicultural assessment of child and adolescent psychopathology with ASEBA and SDQ instruments: research findings, applications, and future directions. Journal of Child Psychology and Psychiatry 49, 251-275.

Adda, J., Björklund, A., Holmlund, H., 2011. The Role of Mothers and Fathers in Providing Skills: Evidence from Parental Deaths. IZA DP No. 5425.

Ahlburg, D., 1998. Intergenerational Transmission of Health. American Economic Review: Papers \& Proceedings 88, 265-270.

Alam, S.A., 2015. Parental health shocks, child labor and educational outcomes: Evidence from Tanzania. Journal of Health Economics 44, 161-175.

Allison, P.D., 2009. Fixed effects regression models: London : SAGE.

Anderson, M.L., 2008. Multiple Inference and Gender Differences in the Effects of Early Intervention: A Reevaluation of the Abecedarian, Perry Preschool, and Early Training Projects. Journal of the American Statistical Association 103, 1481-1495.

Arellano, M., Bover, O., 1995. Another look at the instrumental variable estimation of errorcomponents models. Journal of Econometrics 68, 29-51.

Becker, G.S., 1981. A Treatise on the Family, (enlarged edition) ed. Cambridge: Harvard University Press.

Becker, G.S., Tomes, N., 1979. An Equilibrium Theory of the Distribution of Income and Intergenerational Mobility. Journal of Political Economy 87, 1153-1189.

Becker, G.S., Tomes, N., 1986. Human Capital and the Rise and Fall of Families. Journal of Labor Economics 4, S1-S39.

Benjamini, Y., Hochberg, Y., 1995. Controlling the False Discovery Rate: A Practical and Powerful Approach to Multiple Testing. Journal of the Royal Statistical Society. Series B (Methodological) 57, 289-300.

Bertrand, M., Mullainathan, S., 2001. Do People Mean What They Say? Implications for Subjective Survey Data. American Economic Review: Papers \& Proceedings 91, 67-72.

Black, S.E., Devereux, P.J., 2011. Chapter 16 - Recent Developments in Intergenerational Mobility, In: Orley, A., David, C. (Eds.), Handbook of labor economics: Elsevier, pp. 1487-1541.

Blundell, R., Bond, S., 1998. Initial conditions and moment restrictions in dynamic panel data models. Journal of Econometrics 87, 115-143.

Bratti, M., Mendola, M., 2014. Parental health and child schooling. Journal of Health Economics 35, 94-108.

Cai, L., 2010. The relationship between health and labour force participation: Evidence from a panel data simultaneous equation model. Labour Economics 17, 77-90.

Cas, A., Frankenberg, E., Suriastini, W., Thomas, D., 2014. The Impact of Parental Death on Child Well-being: Evidence From the Indian Ocean Tsunami. Demography 51, 437-457.

Case, A., Ardington, C., 2006. The impact of parental death on school outcomes: Longitudinal evidence from South Africa. Demography 43, 401-420.

Chen, S.H., Chen, Y.-C., Liu, J.-T., 2009. The Impact of Unexpected Maternal Death on Education: First Evidence from Three National Administrative Data Links. American Economic Review Papers \& Proceedings 99, 149-153.

Cobb-Clark, D.A., Nguyen, T.-H., 2012. Educational Attainment Across Generations: The Role of Immigration Background. Economic Record 88, 554-575. 
Contoyannis, P., Jones, A.M., Rice, N., 2004. The dynamics of health in the British household panel survey. Journal of Applied Econometrics 19, 473-503.

Cunha, F., Heckman, J., 2007. The Technology of Skill Formation. The American Economic Review: Papers and Proceedings 97, 31-47.

Cunha, F., Heckman, J.J., 2008. Formulating, identifying and estimating the technology of cognitive and noncognitive skill formation. Journal of Human Resources 43, 738-782.

Cunha, F., Heckman, J.J., Schennach, S.M., 2010. Estimating the Technology of Cognitive and Noncognitive Skill Formation. Econometrica 78, 883-931.

Currie, J., 2009. Healthy, Wealthy, and Wise: Socioeconomic Status, Poor Health in Childhood, and Human Capital Development. Journal of Economic Literature 47, 87-122.

Daraganova, G., Edwards, B., Sipthorp, M., 2013. Using National Assessment Program-Literacy and Numeracy (NAPLAN) data in the Longitudinal Study of Australian Children (LSAC), LSAC Technical Paper No. 8. Australian Institute of Family Studies.

De Reyes, A.L., Kazdin, A.E., 2005. Informant discrepancies in the assessment of childhood psychopathology: A critical review, theoretical framework, and recommendations for further study. Psychological bulletin 131, 483-509.

De Witte, K., Cabus, S., Thyssen, G., Groot, W., van den Brink, H.M., 2013. A critical review of the literature on school dropout. Educational Research Review 10, 13-28.

Doiron, D., Fiebig, D.G., Johar, M., Suziedelyte, A., 2015. Does self-assessed health measure health? Applied Economics 47, 180-194.

Dunn, L.M., Dunn, L.M., 1997. Examiner's manual for the PPVT-III peabody picture vocabulary test: Form IIIA and Form IIIB: AGS.

Evans, D., Miguel, E., 2007. Orphans and schooling in Africa: a longitudinal analysis. Demography 44, 35-57.

Farahati, F., Marcotte, D.E., Wilcox-Gök, V., 2003. The effects of parents’ psychiatric disorders on children's high school dropout. Economics of Education Review 22, 167-178.

Figlio, D., Guryan, J., Karbownik, K., Roth, J., 2014. The Effects of Poor Neonatal Health on Children's Cognitive Development. American Economic Review 104, 3921-3955.

Fiorini, M., Keane, M.P., 2014. How the Allocation of Children's Time Affects Cognitive and Non-Cognitive Development. Journal of Labor Economics 3, 787-836.

Frank, R.G., Meara, E., 2009. The effect of maternal depression and substance abuse on child human capital development. National Bureau of Economic Research Working Paper No. 15314.

Frijters, P., Johnston, D.W., Shah, M., Shields, M.A., 2009. To Work or Not to Work? Child Development and Maternal Labor Supply. American Economic Journal: Applied Economics 1, 97-110.

Frijters, P., Johnston, D.W., Shields, M.A., 2014. The effect of mental health on employment: Evidence from Australian panel data. Health Economics 23, 1058-1071.

Furukawa, T.A., Kessler, R.C., Slade, T., Andrews, G., 2003. The performance of the K6 and K10 screening scales for psychological distress in the Australian National Survey of Mental Health and Well-Being. Psychological Medicine 33, 357-362.

Gertler, P., Levine, D.I., Ames, M., 2004. Schooling and Parental Death. Review of Economics and Statistics 86, 211-225.

Goodman, A., Goodman, R., 2009. Strengths and Difficulties Questionnaire as a Dimensional Measure of Child Mental Health. Journal of the American Academy of Child \& Adolescent Psychiatry 48, 400-403.

Goodman, R., 1997. The Strengths and Difficulties Questionnaire: A Research Note. Journal of Child Psychology and Psychiatry 38, 581-586.

Haveman, R., Wolfe, B., 1995. The Determinants of Children's Attainments: A Review of Methods and Findings. Journal of Economic Literature 33, 1829-1878. 
Heckman, J., Moon, S.H., Pinto, R., Savelyev, P., Yavitz, A., 2010. Analyzing social experiments as implemented: A reexamination of the evidence from the HighScope Perry Preschool Program. Quantitative economics 1, 1-46.

Heckman, J.J., 2007. The economics, technology, and neuroscience of human capability formation. Proceedings of the National Academy of Sciences 104, 13250-13255.

Heckman, J.J., Kautz, T., 2013. Fostering and measuring skills: Interventions that improve character and cognition, In: Heckman, J.J., Humphries, J.E., Kautz, T. (Eds.), The Myth of Achievement Tests: The GED and the Role of Character in American Life. Chicago, IL: The University of Chicago Press, pp. 341-430.

Heckman, J.J., Stixrud, J., Urzua, S., 2006. The Effects of Cognitive and Noncognitive Abilities on Labor Market Outcomes and Social Behavior. Journal of Labor Economics 24, 411-482.

Heitmueller, A., 2007. The chicken or the egg?. Endogeneity in labour market participation of informal carers in England. Journal of Health Economics 26, 536-559.

Hoynes, H., Schanzenbach, D.W., Almond, D., 2016. Long-Run Impacts of Childhood Access to the Safety Net. American Economic Review 106, 903-934.

Johnson, E., Reynolds, C.L., 2013. The effect of household hospitalizations on the educational attainment of youth. Economics of Education Review 37, 165-182.

Johnston, D., Propper, C., Pudney, S., Shields, M., 2014a. Child mental health and educational attainment: Multiple observers and the measurement error problem. Journal of Applied Econometrics 29, 880-900.

Johnston, D.W., Propper, C., Pudney, S.E., Shields, M.A., 2014b. The income gradient in childhood mental health: all in the eye of the beholder? Journal of the Royal Statistical Society: Series A (Statistics in Society) 177, 807-827.

Johnston, D.W., Schurer, S., Shields, M.A., 2013. Exploring the intergenerational persistence of mental health: Evidence from three generations. Journal of Health Economics 32, 1077-1089.

Kendler, K.S., Karkowski, L.M., Prescott, C.A., 1999. Causal relationship between stressful life events and the onset of major depression. American Journal of Psychiatry 156, 837-841.

Kessler, R.C., Green, J.G., Gruber, M.J., Sampson, N.A., Bromet, E., Cuitan, M., Furukawa, T.A., Gureje, O., Hinkov, H., Hu, C.-Y., Lara, C., Lee, S., Mneimneh, Z., Myer, L., Oakley-Browne, M., Posada-Villa, J., Sagar, R., Viana, M.C., Zaslavsky, A.M., 2010. Screening for serious mental illness in the general population with the K6 screening scale: results from the WHO World Mental Health (WMH) survey initiative. International Journal of Methods in Psychiatric Research 19, 422.

Kling, J.R., Liebman, J.B., Katz, L.F., 2007. Experimental analysis of neighborhood effects. Econometrica 75, 83-119.

Lawless, L., Drichoutis, A.C., Nayga Jr, R.M., 2013. Time preferences and health behaviour: a review. Agricultural and Food Economics 1, 1-19.

Le, H.T., Nguyen, H.T., 2015. The Impact of Maternal Mental Health Shocks on Child Health: Causal Estimates from Fixed Effects Instrumental Variables Models for two Cohorts of Australian Children. Bankwest Curtin Economics Centre working paper number 15/09.

Lucas, N., Nicholson, J.M., Maguire, B., 2010. 5 Parenting practices and behaviours, The Longitudinal Study of Australian Children: Annual statistical report 2010. Canberra: Australian Institute of Family Studies.

Morefield, B., 2010. Parental health events and children's skill development. University of North Carolina at Greensboro - Department of Economics Working Papers 10-11.

Mühlenweg, A., Westermaier, F., Morefield, B., 2015. Parental health and child behavior: evidence from parental health shocks. Review of Economics of the Household, 1-22.

Newson, R.B., 2010. Frequentist q-values for multiple-test procedures. Stata Journal 10, 568-584. 
Nghiem, H.S., Nguyen, H.T., Khanam, R., Connelly, L.B., 2015. Does School Type Affect Cognitive and Non-Cognitive Development in Children? Evidence from Australian Primary Schools. Labour Economics 33, 55-65.

Nguyen, H.T., 2015. The evolution of the gender test score gap through seventh grade: New insights from Australia using quantile regression and decomposition. Bankwest Curtin Economics Centre (BCEC) working paper number 15-07.

Nguyen, H.T., Connelly, L.B., 2014. The effect of unpaid caregiving intensity on labour force participation: Results from a multinomial endogenous treatment model. Social Science \& Medicine 100, 115-122.

Nielsen, T.H., 2016. The Relationship between Self-Rated Health and Hospital Records. Health Economics (United Kingdom) 25, 497-512.

Propper, C., Rigg, J., Burgess, S., 2007. Child health: evidence on the roles of family income and maternal mental health from a UK birth cohort. Health Economics 16, 1245-1269.

Richters, J.E., 1992. Depressed mothers as informants about their children: a critical review of the evidence for distortion. Psychological bulletin 112, 485.

Senne, J.-N., 2014. Death and schooling decisions over the short and long run in rural Madagascar. Journal of Population Economics 27, 497-528.

Simes, R.J., 1986. An improved Bonferroni procedure for multiple tests of significance. Biometrika 73, 751-754.

Stock, J.H., Yogo, M., 2005. Testing for Weak Instruments in Linear IV Regression, In: Andrews, D.W.K. (Ed.), Identification and Inference for Econometric Models. Identification and Inference for Econometric Models. New York: Cambridge University Press, pp. 80-108.

Sun, A., Yao, Y., 2010. Health shocks and children's school attainments in rural China. Economics of Education Review 29, 375-382.

Todd, P.E., Wolpin, K.I., 2007. The production of cognitive achievement in children: Home, school, and racial test score gaps. Journal of Human Capital 1, 91-136.

Vaillant, N., Wolff, F.-C., 2012. On the reliability of self-reported health: Evidence from Albanian data. Journal of Epidemiology and Global Health 2, 83-98.

Van Houtven, C.H., Coe, N.B., Skira, M.M., 2013. The effect of informal care on work and wages. Journal of Health Economics 32, 240-252.

Wagstaff, A., 2007. The economic consequences of health shocks: Evidence from Vietnam. Journal of Health Economics 26, 82-100.

Windmeijer, F., 2005. A finite sample correction for the variance of linear efficient two-step GMM estimators. Journal of Econometrics 126, 25-51.

Yamano, T., Jayne, T.S., 2005. Working-Age Adult Mortality and Primary School Attendance in Rural Kenya. Economic Development and Cultural Change 53, 619-653.

Yamauchi, C., 2010. Parental investment in children: Differential pathways of parental education and mental health. Economic Record 86, 210-226. 
Table 1: Parental health and child cognitive development - OLS versus FE specifications

\begin{tabular}{|c|c|c|c|c|c|c|c|c|c|c|c|c|c|c|c|c|}
\hline \multirow[b]{3}{*}{ Health measures } & \multicolumn{2}{|c|}{ PPVT } & \multicolumn{2}{|c|}{ MR } & \multicolumn{2}{|c|}{ Reading } & \multicolumn{2}{|c|}{ Writing } & \multicolumn{2}{|c|}{ Spelling } & \multicolumn{2}{|c|}{ Grammar } & \multicolumn{2}{|c|}{ "Numeracy } & \multicolumn{2}{|c|}{ Cognitive index } \\
\hline & OLS & $\mathrm{FE}$ & OLS & FE & OLS & $\mathrm{FE}$ & OLS & FE & OLS & FE & OLS & FE & OLS & FE & OLS & FE \\
\hline & (1) & (2) & (3) & (4) & (5) & (6) & (7) & (8) & (9) & (10) & (11) & (12) & (13) & (14) & (15) & (16) \\
\hline \multirow[t]{3}{*}{ Mother K6 (rev) } & $-0.05^{*}$ & 0.04 & 0.02 & $0.03 *$ & -0.27 & 0.28 & -0.27 & -0.39 & -0.30 & 0.29 & -0.30 & 0.35 & 0.10 & 0.12 & -0.18 & 0.15 \\
\hline & {$[0.03]$} & {$[0.03]$} & {$[0.01]$} & {$[0.02]$} & {$[0.41]$} & [0.38] & {$[0.35]$} & {$[0.42]$} & {$[0.37]$} & {$[0.27]$} & {$[0.43]$} & {$[0.45]$} & {$[0.41]$} & {$[0.38]$} & {$[0.28]$} & {$[0.18]$} \\
\hline & $\{0.14\}$ & $\{0.54\}$ & $\{0.20\}$ & $\{0.35\}$ & $\{0.56\}$ & $\{0.54\}$ & $\{0.56\}$ & $\{0.54\}$ & $\{0.56\}$ & $\{0.54\}$ & $\{0.56\}$ & $\{0.54\}$ & $\{0.82\}$ & $\{0.82\}$ & & \\
\hline \multirow[t]{3}{*}{ Father K6 (rev) } & 0.02 & $0.07 * *$ & 0.00 & -0.01 & 0.46 & -0.20 & 0.39 & 0.56 & 0.49 & 0.18 & 0.22 & 0.42 & 0.20 & -0.43 & 0.30 & 0.06 \\
\hline & {$[0.02]$} & {$[0.03]$} & {$[0.01]$} & {$[0.02]$} & {$[0.42]$} & {$[0.38]$} & {$[0.35]$} & {$[0.45]$} & {$[0.40]$} & {$[0.28]$} & {$[0.42]$} & {$[0.42]$} & {$[0.40]$} & {$[0.34]$} & {$[0.28]$} & {$[0.18]$} \\
\hline & $\{0.67\}$ & $\{0.14\}$ & $\{0.85\}$ & $\{0.86\}$ & $\{0.41\}$ & $\{0.80\}$ & $\{0.41\}$ & $\{0.52\}$ & $\{0.41\}$ & $\{0.78\}$ & $\{0.67\}$ & $\{0.63\}$ & $\{0.67\}$ & $\{0.52\}$ & & \\
\hline $\mathrm{P}$ t test & 0.10 & 0.48 & 0.36 & 0.14 & 0.25 & 0.38 & 0.21 & 0.11 & 0.17 & 0.79 & 0.42 & 0.91 & 0.87 & 0.28 & 0.25 & 0.71 \\
\hline No of observations & 5,089 & 5,089 & 6,474 & 6,474 & 5,172 & 5,172 & 5,152 & 5,152 & 5,163 & 5,163 & 5,161 & 5,161 & 5,134 & 5,134 & 5,054 & 5,054 \\
\hline No of individuals & 2,211 & 2,211 & 2,430 & 2,430 & 2,095 & 2,095 & 2,090 & 2,090 & 2,093 & 2,093 & 2,092 & 2,092 & 2,081 & 2,081 & 2,055 & 2,055 \\
\hline \multirow[t]{3}{*}{ Mother depressed } & -0.17 & -0.16 & 0.03 & $0.17 *$ & 0.08 & $-5.18^{* *}$ & -0.47 & -2.74 & -0.47 & 0.33 & 0.21 & 0.38 & 0.33 & -0.69 & -0.30 & -1.25 \\
\hline & [0.19] & {$[0.22]$} & [0.09] & {$[0.10]$} & {$[2.75]$} & [2.17] & [2.37] & {$[2.67]$} & [2.57] & [1.66] & {$[2.80]$} & {$[2.42]$} & [2.63] & [2.11] & {$[1.86]$} & [1.03] \\
\hline & $\{0.75\}$ & $\{0.88\}$ & $\{0.98\}$ & $\{0.48\}$ & $\{0.98\}$ & $\{0.20\}$ & $\{0.98\}$ & $\{0.73\}$ & $\{0.98\}$ & $\{0.88\}$ & $\{0.98\}$ & $\{0.88\}$ & $\{0.98\}$ & $\{0.88\}$ & & \\
\hline \multirow[t]{3}{*}{ Father depressed } & -0.03 & 0.17 & -0.03 & 0.09 & 1.04 & 0.25 & 0.33 & -0.12 & -0.16 & 1.83 & -1.05 & -0.07 & -1.34 & -1.56 & -0.19 & 0.29 \\
\hline & [0.19] & {$[0.22]$} & {$[0.09]$} & {$[0.10]$} & [2.63] & [2.10] & [2.35] & [2.44] & [2.53] & [1.45] & {$[2.73]$} & [2.42] & {$[2.54]$} & [1.99] & [1.81] & [0.95] \\
\hline & $\{0.95\}$ & $\{0.88\}$ & $\{0.95\}$ & $\{0.88\}$ & $\{0.95\}$ & $\{0.98\}$ & $\{0.95\}$ & $\{0.98\}$ & $\{0.95\}$ & $\{0.88\}$ & $\{0.95\}$ & $\{0.98\}$ & $\{0.95\}$ & $\{0.88\}$ & & \\
\hline $\mathrm{P}$ t test & 0.63 & 0.28 & 0.63 & 0.56 & 0.81 & 0.07 & 0.82 & 0.48 & 0.93 & 0.50 & 0.75 & 0.90 & 0.66 & 0.76 & 0.97 & 0.28 \\
\hline No of observations & 3,786 & 3,786 & 6,418 & 6,418 & 5,119 & 5,119 & 5,099 & 5,099 & 5,110 & 5,110 & 5,108 & 5,108 & 5,080 & 5,080 & 5,000 & 5,000 \\
\hline No of individuals & 1,893 & 1,893 & 2,420 & 2,420 & 2,078 & 2,078 & 2,073 & 2,073 & 2,076 & 2,076 & 2,075 & 2,075 & 2,063 & 2,063 & 2,037 & 2,037 \\
\hline \multirow[t]{3}{*}{ Mother general health } & 0.02 & -0.05 & 0.05 & $0.10^{*}$ & -1.10 & 0.49 & $-2.46^{* *}$ & -0.16 & $-3.65 * * *$ & 0.53 & -2.04 & 2.09 & -0.96 & 0.32 & -1.59 & 0.81 \\
\hline & {$[0.09]$} & {$[0.12]$} & {$[0.05]$} & {$[0.06]$} & {$[1.51]$} & {$[1.32]$} & {$[1.22]$} & {$[1.51]$} & [1.35] & {$[0.91]$} & [1.57] & {$[1.48]$} & {$[1.44]$} & {$[1.18]$} & {$[1.02]$} & {$[0.58]$} \\
\hline & $\{0.88\}$ & $\{0.92\}$ & $\{0.54\}$ & $\{0.55\}$ & $\{0.60\}$ & $\{0.92\}$ & $\{0.13\}$ & $\{0.92\}$ & $\{0.03\}$ & $\{0.92\}$ & $\{0.47\}$ & $\{0.64\}$ & $\{0.60\}$ & $\{0.92\}$ & & \\
\hline \multirow[t]{3}{*}{ Father general health } & 0.01 & -0.01 & 0.02 & 0.01 & 1.18 & -0.68 & 0.67 & 0.67 & -0.19 & 0.15 & 1.53 & $3.26 * *$ & 0.20 & -0.55 & 0.64 & 0.24 \\
\hline & {$[0.09]$} & {$[0.12]$} & {$[0.05]$} & {$[0.06]$} & {$[1.45]$} & [1.36] & [1.29] & {$[1.60]$} & {$[1.38]$} & {$[0.96]$} & {$[1.48]$} & {$[1.54]$} & {$[1.40]$} & {$[1.21]$} & {$[1.01]$} & {$[0.63]$} \\
\hline & $\{0.95\}$ & $\{0.98\}$ & $\{0.95\}$ & $\{0.98\}$ & $\{0.71\}$ & $\{0.98\}$ & $\{0.91\}$ & $\{0.98\}$ & $\{0.95\}$ & $\{0.98\}$ & $\{0.61\}$ & $\{0.41\}$ & $\{0.95\}$ & $\{0.98\}$ & & \\
\hline P t test & 0.90 & 0.85 & 0.69 & 0.31 & 0.32 & 0.53 & 0.09 & 0.72 & 0.09 & 0.77 & 0.12 & 0.60 & 0.58 & 0.61 & 0.14 & 0.52 \\
\hline No of observations & 5,089 & 5,089 & 6,474 & 6,474 & 5,172 & 5,172 & 5,152 & 5,152 & 5,163 & 5,163 & 5,161 & 5,161 & 5,134 & 5,134 & 5,054 & 5,054 \\
\hline No of individuals & 2,211 & 2,211 & 2,430 & 2,430 & 2,095 & 2,095 & 2,090 & 2,090 & 2,093 & 2,093 & 2,092 & 2,092 & 2,081 & 2,081 & 2,055 & 2,055 \\
\hline
\end{tabular}

Notes: OLS results are from the regression (1) while FE results are from the regression (2). Other explanatory variables include the child's characteristics (gender, age, migration status, Aboriginal status, birth weight, school sectors, and number of siblings), both parents' characteristics (age, education, and immigration status), local socio-economic background variables, state/territory dummies, year dummies, and survey quarters. NAPLAN test regressions also include test age and test years. $\mathrm{P} t$ test: $\mathrm{P}$ value of a $\mathrm{t}$ test for equality of maternal and paternal health estimates. Robust standard errors clustered at the individual level in square brackets. Adjusted $p$-values to account for multiple inference issue calculated using the Simes-Benjamini-Hochberg method are in curly brackets. The symbol *denotes unadjusted significance at the $10 \%$ level, **at the $5 \%$ level, and ***at the $1 \%$ level. 
Table 2: Parental health and child non-cognitive development - OLS versus FE specifications - Parents' reports

\begin{tabular}{|c|c|c|c|c|c|c|c|c|c|c|c|c|}
\hline \multirow[b]{3}{*}{ Health measures } & \multicolumn{2}{|c|}{ Prosociality } & \multicolumn{2}{|c|}{ Hyperactivity (rev.) } & \multicolumn{2}{|c|}{ Emotional (rev.) } & \multicolumn{2}{|c|}{ Conduct (rev.) } & \multicolumn{2}{|c|}{ Peer (rev.) } & \multicolumn{2}{|c|}{ Non-cognitive index } \\
\hline & OLS & $\mathrm{FE}$ & OLS & $\mathrm{FE}$ & OLS & $\mathrm{FE}$ & OLS & FE & OLS & FE & OLS & $\mathrm{FE}$ \\
\hline & (1) & (2) & (3) & (4) & (5) & (6) & (7) & (8) & (9) & (10) & (11) & (12) \\
\hline Mother K6 (rev) & $\begin{array}{c}-0.07 * * * \\
{[0.01]} \\
\{0.00\}\end{array}$ & $\begin{array}{c}-0.03 * * * \\
{[0.01]} \\
\{0.00\}\end{array}$ & $\begin{array}{c}-0.13 * * * \\
{[0.01]} \\
\{0.00\}\end{array}$ & $\begin{array}{c}-0.06^{* * *} \\
{[0.01]} \\
\{0.00\}\end{array}$ & $\begin{array}{c}-0.14^{* * *} \\
{[0.01]} \\
\{0.00\}\end{array}$ & $\begin{array}{c}-0.06^{* * *} \\
{[0.01]} \\
\{0.00\}\end{array}$ & $\begin{array}{c}-0.10 * * * \\
{[0.01]} \\
\{0.00\}\end{array}$ & $\begin{array}{c}-0.03 * * * \\
{[0.01]} \\
\{0.00\}\end{array}$ & $\begin{array}{c}-0.09 * * * \\
{[0.01]} \\
\{0.00\}\end{array}$ & $\begin{array}{c}-0.02^{* * *} \\
{[0.01]} \\
\{0.00\}\end{array}$ & $\begin{array}{c}-0.10^{* * *} \\
{[0.01]}\end{array}$ & $\begin{array}{c}-0.04^{* * *} \\
{[0.00]}\end{array}$ \\
\hline Father K6 (rev) & $\begin{array}{c}-0.03 * * * \\
{[0.01]} \\
\{0.00\}\end{array}$ & $\begin{array}{c}-0.00 \\
{[0.01]} \\
\{0.93\}\end{array}$ & $\begin{array}{c}-0.04 * * * \\
{[0.01]} \\
\{0.00\}\end{array}$ & $\begin{array}{c}0.00 \\
{[0.01]} \\
\{0.83\}\end{array}$ & $\begin{array}{c}-0.03 * * * \\
{[0.01]} \\
\{0.00\}\end{array}$ & $\begin{array}{c}-0.01 \\
{[0.01]} \\
\{0.66\}\end{array}$ & $\begin{array}{c}-0.03 * * * \\
{[0.01]} \\
\{0.00\}\end{array}$ & $\begin{array}{l}-0.01 \\
{[0.01]} \\
\{0.52\}\end{array}$ & $\begin{array}{c}-0.03 * * * \\
{[0.01]} \\
\{0.00\}\end{array}$ & $\begin{array}{l}-0.01 * \\
{[0.01]} \\
\{0.41\}\end{array}$ & $\begin{array}{c}-0.03^{* * *} \\
{[0.01]}\end{array}$ & $\begin{array}{c}-0.00 \\
{[0.00]}\end{array}$ \\
\hline P t test & 0.00 & 0.00 & 0.00 & 0.00 & 0.00 & 0.00 & 0.00 & 0.00 & 0.00 & 0.32 & 0.00 & 0.00 \\
\hline No of observations & 9,844 & 9,844 & 9,844 & 9,844 & 9,843 & 9,843 & 9,844 & 9,844 & 9,843 & 9,843 & 9,842 & 9,842 \\
\hline No of individuals & 2,774 & 2,774 & 2,774 & 2,774 & 2,774 & 2,774 & 2,774 & 2,774 & 2,774 & 2,774 & 2,774 & 2,774 \\
\hline Mother depressed & $\begin{array}{c}-0.16 * * * \\
{[0.05]} \\
\{0.01\}\end{array}$ & $\begin{array}{c}0.05 \\
{[0.04]} \\
\{0.46\}\end{array}$ & $\begin{array}{c}-0.52 * * * \\
{[0.07]} \\
\{0.00\}\end{array}$ & $\begin{array}{c}-0.12 * * \\
{[0.05]} \\
\{0.08\}\end{array}$ & $\begin{array}{c}-0.61 * * * \\
{[0.06]} \\
\{0.00\}\end{array}$ & $\begin{array}{c}-0.18 * * * \\
{[0.05]} \\
\{0.00\}\end{array}$ & $\begin{array}{c}-0.43 * * * \\
{[0.04]} \\
\{0.00\}\end{array}$ & $\begin{array}{c}-0.07 * * \\
{[0.03]} \\
\{0.11\}\end{array}$ & $\begin{array}{c}-0.47 * * * \\
{[0.05]} \\
\{0.00\}\end{array}$ & $\begin{array}{l}-0.08^{*} \\
{[0.04]} \\
\{0.16\}\end{array}$ & $\begin{array}{c}-0.44^{* * *} \\
{[0.04]}\end{array}$ & $\begin{array}{c}-0.08 * * * \\
{[0.03]}\end{array}$ \\
\hline Father depressed & $\begin{array}{c}-0.14^{* * *} \\
{[0.05]} \\
\{0.02\}\end{array}$ & $\begin{array}{l}-0.03 \\
{[0.04]} \\
\{0.88\}\end{array}$ & $\begin{array}{c}-0.28 * * * \\
{[0.07]} \\
\{0.00\}\end{array}$ & $\begin{array}{c}-0.11^{* *} \\
{[0.05]} \\
\{0.23\}\end{array}$ & $\begin{array}{c}-0.20 * * * \\
{[0.05]} \\
\{0.00\}\end{array}$ & $\begin{array}{c}0.01 \\
{[0.04]} \\
\{0.98\}\end{array}$ & $\begin{array}{c}-0.17^{* * *} \\
{[0.04]} \\
\{0.00\}\end{array}$ & $\begin{array}{l}-0.01 \\
{[0.03]} \\
\{0.98\}\end{array}$ & $\begin{array}{c}-0.17 * * * \\
{[0.05]} \\
\{0.00\}\end{array}$ & $\begin{array}{l}-0.02 \\
{[0.04]} \\
\{0.98\}\end{array}$ & $\begin{array}{c}-0.19 * * * \\
{[0.04]}\end{array}$ & $\begin{array}{c}-0.03 \\
{[0.02]}\end{array}$ \\
\hline $\mathrm{P}$ t test & 0.74 & 0.21 & 0.02 & 0.97 & 0.00 & 0.00 & 0.00 & 0.17 & 0.00 & 0.34 & 0.00 & 0.20 \\
\hline $\begin{array}{l}\text { No of observations } \\
\text { No of individuals }\end{array}$ & $\begin{array}{l}8,503 \\
2,602\end{array}$ & $\begin{array}{l}8,503 \\
2,602\end{array}$ & $\begin{array}{l}8,503 \\
2,602\end{array}$ & $\begin{array}{l}8,503 \\
2,602\end{array}$ & $\begin{array}{l}8,502 \\
2,602\end{array}$ & $\begin{array}{l}8,502 \\
2,602\end{array}$ & $\begin{array}{l}8,503 \\
2,602\end{array}$ & $\begin{array}{l}8,503 \\
2,602\end{array}$ & $\begin{array}{l}8,502 \\
2,602\end{array}$ & $\begin{array}{l}8,502 \\
2,602\end{array}$ & $\begin{array}{l}8,501 \\
2,602\end{array}$ & $\begin{array}{l}8,501 \\
2,602\end{array}$ \\
\hline Mother general health & $\begin{array}{c}-0.16^{* * *} \\
{[0.05]} \\
\{0.00\}\end{array}$ & $\begin{array}{c}0.05 \\
{[0.04]} \\
\{0.29\}\end{array}$ & $\begin{array}{c}-0.52 * * * \\
{[0.07]} \\
\{0.00\}\end{array}$ & $\begin{array}{c}-0.12^{* *} \\
{[0.05]} \\
\{0.84\}\end{array}$ & $\begin{array}{c}-0.61^{* * *} \\
{[0.06]} \\
\{0.00\}\end{array}$ & $\begin{array}{c}-0.18 * * * \\
{[0.05]} \\
\{0.00\}\end{array}$ & $\begin{array}{c}-0.43^{* * *} \\
{[0.04]} \\
\{0.00\}\end{array}$ & $\begin{array}{c}-0.07 * * \\
{[0.03]} \\
\{0.84\}\end{array}$ & $\begin{array}{c}-0.47 * * * \\
{[0.05]} \\
\{0.00\}\end{array}$ & $\begin{array}{l}-0.08 * \\
{[0.04]} \\
\{0.16\}\end{array}$ & $\begin{array}{c}-0.44^{* * *} \\
{[0.04]}\end{array}$ & $\begin{array}{c}-0.08 * * * \\
{[0.03]}\end{array}$ \\
\hline Father general health & $\begin{array}{c}-0.14^{* * *} \\
{[0.05]} \\
\{0.00\}\end{array}$ & $\begin{array}{l}-0.03 \\
{[0.04]} \\
\{0.10\}\end{array}$ & $\begin{array}{c}-0.28 * * * \\
{[0.07]} \\
\{0.00\}\end{array}$ & $\begin{array}{c}-0.11^{* *} \\
{[0.05]} \\
\{0.44\}\end{array}$ & $\begin{array}{c}-0.20 * * * \\
{[0.05]} \\
\{0.00\}\end{array}$ & $\begin{array}{c}0.01 \\
{[0.04]} \\
\{0.90\}\end{array}$ & $\begin{array}{c}-0.17^{* * * *} \\
{[0.04]} \\
\{0.00\}\end{array}$ & $\begin{array}{c}-0.01 \\
{[0.03]} \\
\{0.90\}\end{array}$ & $\begin{array}{c}-0.17 * * * \\
{[0.05]} \\
\{0.00\}\end{array}$ & $\begin{array}{l}-0.02 \\
{[0.04]} \\
\{0.90\}\end{array}$ & $\begin{array}{c}-0.19 * * * \\
{[0.04]}\end{array}$ & $\begin{array}{c}-0.03 \\
{[0.02]}\end{array}$ \\
\hline P t test & 0.74 & 0.21 & 0.02 & 0.97 & 0.00 & 0.00 & 0.00 & 0.17 & 0.00 & 0.34 & 0.00 & 0.20 \\
\hline No of observations & 8,503 & 8,503 & 8,503 & 8,503 & 8,502 & 8,502 & 8,503 & 8,503 & 8,502 & 8,502 & 8,501 & 8,501 \\
\hline No of individuals & 2,602 & 2,602 & 2,602 & 2,602 & 2,602 & 2,602 & 2,602 & 2,602 & 2,602 & 2,602 & 2,602 & 2,602 \\
\hline
\end{tabular}

Notes: OLS results are from the regression (1) while FE results are from the regression (2). Other explanatory variables include the child's characteristics (gender, age, migration status, Aboriginal status, birth weight, school sectors, and number of siblings), both parents' characteristics (age, education, and immigration status), local socio-economic background variables, state/territory dummies, year dummies, and survey quarters. $\mathrm{P} t$ test: $\mathrm{P}$ value of a t test for equality of maternal and paternal health estimates. Robust standard errors clustered at the individual level in square brackets. Adjusted $p$-values to account for multiple inference issue calculated using the Simes-Benjamini-Hochberg method are in curly brackets. The symbol $*$ denotes unadjusted significance at the $10 \%$ level, **at the $5 \%$ level, and ***at the $1 \%$ level. 
Table 3: Parental health and child non-cognitive development - OLS versus FE specifications - Teachers' reports

\begin{tabular}{|c|c|c|c|c|c|c|c|c|c|c|c|c|}
\hline \multirow[b]{3}{*}{ Health measures } & \multicolumn{2}{|c|}{ Prosociality } & \multicolumn{2}{|c|}{ Hyperactivity (rev.) } & \multicolumn{2}{|c|}{ Emotional (rev.) } & \multicolumn{2}{|c|}{ Conduct (rev.) } & \multicolumn{2}{|c|}{ Peer (rev.) } & \multicolumn{2}{|c|}{ Non-cognitive index } \\
\hline & OLS & $\mathrm{FE}$ & OLS & $\mathrm{FE}$ & OLS & FE & OLS & $\mathrm{FE}$ & OLS & $\mathrm{FE}$ & OLS & $\mathrm{FE}$ \\
\hline & (1) & (2) & (3) & (4) & (5) & (6) & (7) & (8) & (9) & (10) & (11) & (12) \\
\hline \multirow[t]{3}{*}{ Mother K6 (rev) } & $-0.02 *$ & -0.01 & $-0.04 * * *$ & $-0.03^{* *}$ & $-0.03 * * *$ & $-0.02 *$ & $-0.02 * *$ & -0.01 & $-0.03 * * *$ & -0.00 & $-0.03 * * *$ & $-0.01 *$ \\
\hline & {$[0.01]$} & {$[0.01]$} & {$[0.01]$} & {$[0.01]$} & {$[0.01]$} & {$[0.01]$} & {$[0.01]$} & {$[0.01]$} & [0.01] & {$[0.01]$} & [0.01] & {$[0.01]$} \\
\hline & $\{0.13\}$ & $\{0.54\}$ & $\{0.01\}$ & $\{0.20\}$ & $\{0.00\}$ & $\{0.35\}$ & $\{0.03\}$ & $\{0.54\}$ & $\{0.00\}$ & $\{0.94\}$ & & \\
\hline \multirow[t]{3}{*}{ Father K6 (rev) } & $-0.02 * *$ & 0.00 & $-0.04 * * *$ & $-0.03^{* *}$ & $-0.02 * * *$ & -0.01 & $-0.03^{* * *}$ & $-0.02 * *$ & $-0.02 * * *$ & 0.00 & $-0.03^{* * *}$ & -0.01 \\
\hline & {$[0.01]$} & {$[0.01]$} & {$[0.01]$} & {$[0.01]$} & {$[0.01]$} & {$[0.01]$} & {$[0.01]$} & {$[0.01]$} & {$[0.01]$} & {$[0.01]$} & [0.01] & {$[0.01]$} \\
\hline & $\{0.03\}$ & $\{0.90\}$ & $\{0.00\}$ & $\{0.14\}$ & $\{0.00\}$ & $\{0.78\}$ & $\{0.00\}$ & $\{0.14\}$ & $\{0.01\}$ & $\{0.90\}$ & & \\
\hline P t test & 0.76 & 0.51 & 0.88 & 0.96 & 0.38 & 0.43 & 0.39 & 0.21 & 0.36 & 0.86 & 0.95 & 0.74 \\
\hline No of observations & 8,008 & 8,008 & 8,030 & 8,030 & 8,018 & 8,018 & 8,028 & 8,028 & 8,013 & 8,013 & 7,994 & 7,994 \\
\hline No of individuals & 2,510 & 2,510 & 2,514 & 2,514 & 2,511 & 2,511 & 2,515 & 2,515 & 2,509 & 2,509 & 2,507 & 2,507 \\
\hline \multirow[t]{3}{*}{ Mother depressed } & -0.11 & 0.03 & $-0.17 * *$ & 0.03 & $-0.22 * * *$ & -0.02 & $-0.08^{* *}$ & 0.06 & $-0.24 * * *$ & -0.07 & $-0.16^{* * *}$ & 0.01 \\
\hline & {$[0.07]$} & {$[0.08]$} & {$[0.08]$} & {$[0.08]$} & {$[0.05]$} & {$[0.06]$} & {$[0.04]$} & {$[0.04]$} & [0.05] & {$[0.06]$} & [0.04] & {$[0.04]$} \\
\hline & $\{0.26\}$ & $\{0.88\}$ & $\{0.14\}$ & $\{0.88\}$ & $\{0.00\}$ & $\{0.88\}$ & $\{0.14\}$ & $\{0.55\}$ & $\{0.00\}$ & $\{0.61\}$ & & \\
\hline \multirow[t]{3}{*}{ Father depressed } & -0.06 & -0.02 & $-0.26 * * *$ & $-0.22 * * *$ & $-0.14^{* * *}$ & -0.07 & $-0.13^{* * *}$ & -0.01 & $-0.13^{* *}$ & -0.03 & $-0.15^{* * *}$ & $-0.07 *$ \\
\hline & {$[0.07]$} & {$[0.07]$} & [0.08] & {$[0.08]$} & [0.05] & {$[0.06]$} & [0.04] & {$[0.04]$} & {$[0.05]$} & {$[0.05]$} & {$[0.04]$} & {$[0.04]$} \\
\hline & $\{0.79\}$ & $\{0.98\}$ & $\{0.01\}$ & $\{0.04\}$ & $\{0.03\}$ & $\{0.88\}$ & $\{0.01\}$ & $\{0.98\}$ & $\{0.04\}$ & $\{0.98\}$ & & \\
\hline $\mathrm{P}$ t test & 0.65 & 0.64 & 0.42 & 0.02 & 0.27 & 0.57 & 0.44 & 0.23 & 0.18 & 0.56 & 0.87 & 0.15 \\
\hline No of observations & 7,041 & 7,041 & 7,064 & 7,064 & 7,050 & 7,050 & 7,061 & 7,061 & 7,045 & 7,045 & 7,025 & 7,025 \\
\hline No of individuals & 2,362 & 2,362 & 2,367 & 2,367 & 2,362 & 2,362 & 2,367 & 2,367 & 2,360 & 2,360 & 2,357 & 2,357 \\
\hline \multirow[t]{3}{*}{ Mother general health } & -0.03 & -0.03 & -0.04 & -0.02 & $-0.12 * * *$ & $-0.06^{*}$ & -0.00 & 0.01 & $-0.11^{* * *}$ & -0.00 & $-0.06^{* * *}$ & -0.02 \\
\hline & {$[0.03]$} & {$[0.04]$} & {$[0.04]$} & {$[0.04]$} & [0.02] & {$[0.03]$} & {$[0.02]$} & {$[0.02]$} & [0.03] & {$[0.03]$} & {$[0.02]$} & {$[0.02]$} \\
\hline & $\{0.53\}$ & $\{0.92\}$ & $\{0.53\}$ & $\{0.92\}$ & $\{0.00\}$ & $\{0.55\}$ & $\{0.95\}$ & $\{0.92\}$ & $\{0.00\}$ & $\{0.92\}$ & & \\
\hline \multirow[t]{3}{*}{ Father general health } & $-0.06 * *$ & 0.03 & $-0.12 * * *$ & -0.06 & -0.03 & -0.00 & $-0.06 * * *$ & -0.01 & $-0.07 * * *$ & 0.01 & $-0.07 * * *$ & -0.01 \\
\hline & {$[0.03]$} & {$[0.04]$} & [0.04] & {$[0.04]$} & {$[0.02]$} & {$[0.04]$} & [0.02] & {$[0.02]$} & [0.03] & {$[0.03]$} & {$[0.02]$} & {$[0.02]$} \\
\hline & $\{0.14\}$ & $\{0.98\}$ & $\{0.03\}$ & $\{0.82\}$ & $\{0.39\}$ & $\{0.98\}$ & $\{0.03\}$ & $\{0.98\}$ & $\{0.03\}$ & $\{0.98\}$ & & \\
\hline P t test & 0.52 & 0.35 & 0.20 & 0.50 & 0.02 & 0.21 & 0.06 & 0.47 & 0.28 & 0.75 & 0.70 & 0.75 \\
\hline No of observations & 8,008 & 8,008 & 8,030 & 8,030 & 8,018 & 8,018 & 8,028 & 8,028 & 8,013 & 8,013 & 7,994 & 7,994 \\
\hline No of individuals & 2,510 & 2,510 & 2,514 & 2,514 & 2,511 & 2,511 & 2,515 & 2,515 & 2,509 & 2,509 & 2,507 & 2,507 \\
\hline
\end{tabular}

Notes: OLS results are from the regression (1) while FE results are from the regression (2). Other explanatory variables include the child's characteristics (gender, age, migration status, Aboriginal status, birth weight, school sectors, and number of siblings), both parents' characteristics (age, education, and immigration status), local socio-economic background variables, state/territory dummies, year dummies, and survey quarters. $\mathrm{P} t$ test: $\mathrm{P}$ value of a t test for equality of maternal and paternal health estimates. Robust standard errors clustered at the individual level in square brackets. Adjusted $p$-values to account for multiple inference issue calculated using the Simes-Benjamini-Hochberg method are in curly brackets. The symbol *denotes unadjusted significance at the $10 \%$ level, **at the $5 \%$ level, and ***at the $1 \%$ level. 
APPENDIX TABLES (to be published online) 


\section{Appendix Table A1: Summary statistics}

\begin{tabular}{|c|c|c|c|c|c|}
\hline \multirow[t]{2}{*}{ Variable } & \multirow[t]{2}{*}{ Description } & \multirow[t]{2}{*}{ Mean } & \multicolumn{3}{|c|}{ Standard deviations } \\
\hline & & & Overall & Between & Within \\
\hline Maternal K6 (rev.) & As in the text & 8.94 & 3.17 & 2.65 & 1.82 \\
\hline Mother depressed (K6) & Dummy: $=1$ if maternal $\mathrm{K} 6$ is below $19,=0$ otherwise & 0.02 & 0.15 & 0.11 & 0.11 \\
\hline Paternal K6 (rev.) & As in the text & 8.78 & 3.03 & 2.52 & 1.77 \\
\hline Father depressed (K6) & Dummy: = 1 if paternal K6 is below $19,=0$ otherwise & 0.02 & 0.15 & 0.10 & 0.11 \\
\hline Mother depressed & $\begin{array}{l}\text { Dummy: }=1 \text { if mother was depressed for two weeks or more in the year prior to the survey } \\
\text { time, }=0 \text { otherwise }\end{array}$ & 0.24 & 0.43 & 0.33 & 0.29 \\
\hline Father depressed & $\begin{array}{l}\text { Dummy: }=1 \text { if father was depressed for two weeks or more in the year prior to the survey } \\
\text { time },=0 \text { otherwise }\end{array}$ & 0.26 & 0.44 & 0.34 & 0.29 \\
\hline Maternal general health & As in the text & 2.21 & 0.87 & 0.72 & 0.50 \\
\hline Mother poor health & Dummy: = 1 if maternal self-rated general health condition is "fair" or "poor", = 0 otherwise & 0.07 & 0.25 & 0.20 & 0.17 \\
\hline Paternal general health & As in the text & 2.30 & 0.89 & 0.75 & 0.49 \\
\hline Father poor health & Dummy: = 1 if paternal self-rated general health condition is "fair" or "poor", = 0 otherwise & 0.09 & 0.28 & 0.22 & 0.18 \\
\hline PPVT & Peabody Picture Vocabulary Test score & 74.70 & 6.91 & 5.05 & 4.94 \\
\hline MR & Matrix Reasoning score & 10.93 & 2.97 & 2.50 & 1.68 \\
\hline Reading & NAPLAN reading score & 513.63 & 93.31 & 78.69 & 55.33 \\
\hline Grammar & NAPLAN grammar score & 519.56 & 95.04 & 78.48 & 58.03 \\
\hline Numeracy & NAPLAN numeracy score & 508.59 & 90.56 & 73.59 & 57.01 \\
\hline Overall cognitive scale ${ }^{(a)}$ & Average of MR, reading, writing, spelling, grammar, and numeracy & 425.60 & 66.38 & 55.83 & 39.83 \\
\hline Prosociality ${ }^{(a)}$ & As in the text & 8.32 & 1.69 & 1.38 & 1.00 \\
\hline Hyperactivity (rev.) ${ }^{(a)}$ & As in the text & 7.02 & 2.27 & 2.00 & 1.12 \\
\hline Emotional (rev.) ${ }^{(a)}$ & As in the text & 8.43 & 1.70 & 1.37 & 1.03 \\
\hline Conduct (rev.) (a) & As in the text & 8.75 & 1.45 & 1.21 & 0.85 \\
\hline Peer (rev.) $)^{(\mathrm{a})}$ & As in the text & 8.67 & 1.56 & 1.27 & 0.92 \\
\hline Overall non-cognitive scale ${ }^{(a)}$ & As in the text & 8.24 & 1.17 & 1.04 & 0.56 \\
\hline Prosociality $^{(\mathrm{b})}$ & As in the text & 7.74 & 2.20 & 1.73 & 1.46 \\
\hline Hyperactivity (rev.) $^{(\mathrm{b})}$ & As in the text & 7.66 & 2.57 & 2.20 & 1.45 \\
\hline Emotional (rev.) ${ }^{(\mathrm{b})}$ & As in the text & 8.91 & 1.63 & 1.23 & 1.16 \\
\hline Conduct (rev.) (b) & As in the text & 9.37 & 1.32 & 1.11 & 0.83 \\
\hline Peer (rev.) ${ }^{(b)}$ & As in the text & 8.82 & 1.62 & 1.30 & 1.06 \\
\hline Overall non-cognitive scale ${ }^{(b)}$ & As in the text & 8.50 & 1.34 & 1.15 & 0.77 \\
\hline Native & Dummy: $=$ if child was born in Australia, $=0$ otherwise & 0.96 & 0.20 & 0.20 & 0.00 \\
\hline Aboriginal & Dummy: $=1$ if child has Aboriginal/Torres Strait Islander origin, $=0$ otherwise & 0.01 & 0.12 & 0.13 & 0.00 \\
\hline Low birth weight & Dummy: $=1$ Child's birth weight is 2500 grams or less, $=0$ otherwise & 0.06 & 0.24 & 0.25 & 0.00 \\
\hline Mother age & Mother age (years) & 40.03 & 5.28 & 4.81 & 2.42 \\
\hline Mother NESB & $\begin{array}{l}\text { Dummy: = } 1 \text { if mother was born in a Non-English Speaking Background (NESB) country, = } \\
0 \text { otherwise }\end{array}$ & 0.21 & 0.40 & 0.41 & 0.00 \\
\hline Mother ESB & $\begin{array}{l}\text { Dummy: = } 1 \text { if mother was born in an English Speaking Background (ESB) country, = } 0 \\
\text { otherwise }\end{array}$ & 0.16 & 0.36 & 0.37 & 0.00 \\
\hline Mother education: Certificate & Dummy: $=1$ if other has a certificate, $=0$ otherwise & 0.27 & 0.44 & 0.42 & 0.13 \\
\hline Mother education: Diploma & Dummy: $=1$ if mother has advanced diploma/diploma, $=0$ otherwise & 0.10 & 0.31 & 0.29 & 0.09 \\
\hline Mother education: Bachelor & Dummy: $=1$ if mother has a bachelor degree, $=0$ otherwise & 0.21 & 0.41 & 0.39 & 0.10 \\
\hline Mother education: Graduate & Dummy: $=1$ if mother has graduate diploma/certificate, $=0$ otherwise & 0.09 & 0.29 & 0.27 & 0.08 \\
\hline Mother education: Postgraduate & Dummy: $=1$ if mother has a postgraduate degree, $=0$ otherwise & 0.09 & 0.29 & 0.27 & 0.07 \\
\hline Father age & Father age (years) & 42.37 & 6.20 & 5.84 & 2.43 \\
\hline Father NESB & Dummy: $=1$ if father was born in a NESB country, $=0$ otherwise & 0.24 & 0.42 & 0.43 & 0.00 \\
\hline Father ESB & Dummy: = 1 if father was born in an ESB country, $=0$ otherwise & 0.17 & 0.38 & 0.38 & 0.00 \\
\hline Father education: Certificate & Dummy: $=1$ if other has a certificate, $=0$ otherwise & 0.36 & 0.48 & 0.47 & 0.11 \\
\hline Father education: Diploma & Dummy: $=1$ if father has advanced diploma/diploma, $=0$ otherwise & 0.10 & 0.30 & 0.28 & 0.07 \\
\hline Father education: Bachelor & Dummy: $=1$ if father has a bachelor degree, $=0$ otherwise & 0.17 & 0.38 & 0.36 & 0.08 \\
\hline Father education: Graduate & Dummy: $=1$ if father has graduate diploma/certificate, $=0$ otherwise & 0.07 & 0.26 & 0.25 & 0.07 \\
\hline Father education: Postgraduate & Dummy: $=1$ if father has a postgraduate degree, $=0$ otherwise & 0.11 & 0.31 & 0.30 & 0.06 \\
\hline Catholic school & Dummy: $=1$ if child attends a Catholic school, $=0$ otherwise & 0.23 & 0.42 & 0.38 & 0.19 \\
\hline Independent school & Dummy: $=1$ if child attends an Independent school, $=0$ otherwise & 0.17 & 0.37 & 0.31 & 0.20 \\
\hline Number of older siblings & Number of older siblings & 0.80 & 0.88 & 0.87 & 0.18 \\
\hline Number of younger siblings & Number of younger siblings & 0.74 & 0.81 & 0.80 & 0.19 \\
\hline Number of same age siblings & Number of same age siblings & 0.03 & 0.19 & 0.19 & 0.00 \\
\hline
\end{tabular}

Notes: Figures are calculated using a regression sample of overall non-cognitive skill index reported by parents on parental K6 measure. ${ }^{\text {(a) }}$ denotes reports from parents while ${ }^{(b)}$ represents reports from teachers. 
Appendix Table A2: Correlation structure

\begin{tabular}{|c|c|c|c|c|c|c|c|c|c|c|c|c|c|c|c|c|c|c|c|c|c|c|c|c|c|c|c|c|c|c|c|}
\hline & 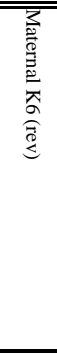 & 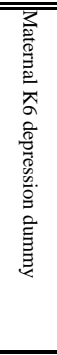 & 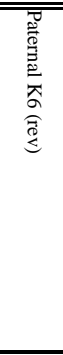 & 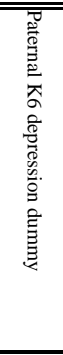 & 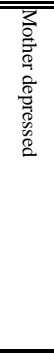 & 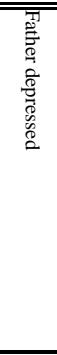 & 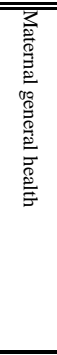 & 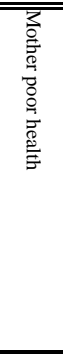 & 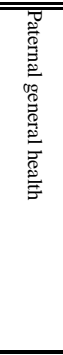 & 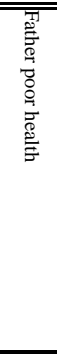 & 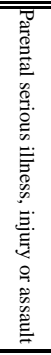 & 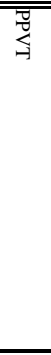 & 言 & 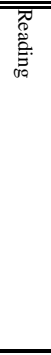 & 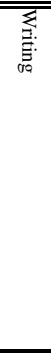 & 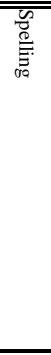 & 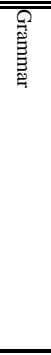 & 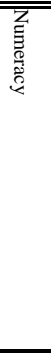 & 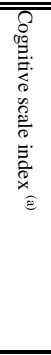 & 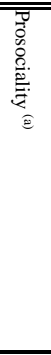 & 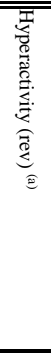 & 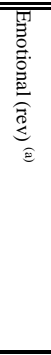 & 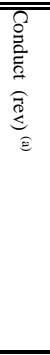 & 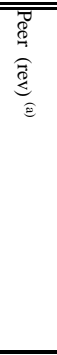 & 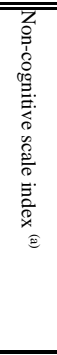 & 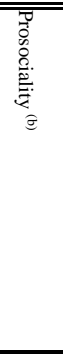 & 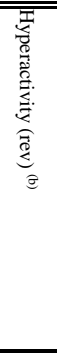 & 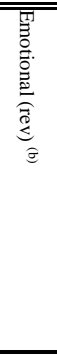 & 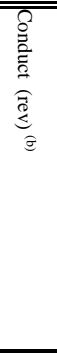 & 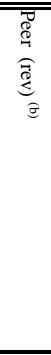 & 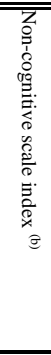 \\
\hline Maternal K6 (rev) & 1.0 & & & & & & & & & & & & & & & & & & & & & & & & & & & & & & \\
\hline Maternal K6 depression dummy & 0.6 & 1.0 & & & & & & & & & & & & & & & & & & & & & & & & & & & & & \\
\hline Paternal K6 (rev) & 0.2 & 0.1 & 1.0 & & & & & & & & & & & & & & & & & & & & & & & & & & & & \\
\hline Paternal K6 depression dummy & 0.1 & 0.0 & 0.6 & 1.0 & & & & & & & & & & & & & & & & & & & & & & & & & & & \\
\hline Mother depressed & 0.5 & 0.2 & 0.1 & 0.0 & 1.0 & & & & & & & & & & & & & & & & & & & & & & & & & & \\
\hline Father depressed & 0.1 & 0.1 & 0.5 & 0.2 & 0.1 & 1.0 & & & & & & & & & & & & & & & & & & & & & & & & & \\
\hline Maternal general health & 0.4 & 0.2 & 0.1 & 0.1 & 0.3 & 0.1 & 1.0 & & & & & & & & & & & & & & & & & & & & & & & & \\
\hline Mother poor health & 0.3 & 0.2 & 0.1 & 0.0 & 0.2 & 0.1 & 0.6 & 1.0 & & & & & & & & & & & & & & & & & & & & & & & \\
\hline Paternal general health & 0.1 & 0.1 & 0.3 & 0.2 & 0.1 & 0.2 & 0.2 & 0.1 & 1.0 & & & & & & & & & & & & & & & & & & & & & & \\
\hline Father poor health & 0.1 & 0.1 & 0.3 & 0.2 & 0.1 & 0.2 & 0.1 & 0.1 & 0.6 & 1.0 & & & & & & & & & & & & & & & & & & & & & \\
\hline Parental serious illness, injury or assault & 0.1 & 0.1 & 0.1 & 0.0 & 0.1 & 0.1 & 0.2 & 0.2 & 0.1 & 0.1 & 1.0 & & & & & & & & & & & & & & & & & & & & \\
\hline PPVT & -0.1 & -0.1 & & & & & 0.0 & & -0.1 & 0.0 & & 1.0 & & & & & & & & & & & & & & & & & & & \\
\hline MR & & & & & & & & & 0.0 & 0.0 & & 0.3 & 1.0 & & & & & & & & & & & & & & & & & & \\
\hline Reading & & 0.0 & 0.0 & 0.0 & & -0.1 & 0.0 & & 0.0 & 0.0 & & 0.5 & 0.4 & 1.0 & & & & & & & & & & & & & & & & & \\
\hline Writing & & & & 0.0 & & -0.1 & 0.0 & & 0.0 & -0.1 & & 0.4 & 0.3 & 0.7 & 1.0 & & & & & & & & & & & & & & & & \\
\hline Spelling & & & & & & -0.1 & 0.0 & & 0.0 & 0.0 & & 0.4 & 0.3 & 0.7 & 0.7 & 1.0 & & & & & & & & & & & & & & & \\
\hline Grammar & & & 0.0 & 0.0 & & -0.1 & 0.0 & & & 0.0 & & 0.5 & 0.4 & 0.8 & 0.7 & 0.8 & 1.0 & & & & & & & & & & & & & & \\
\hline Numeracy & & & 0.0 & 0.0 & & -0.1 & & & & 0.0 & & 0.5 & 0.4 & 0.8 & 0.7 & 0.7 & 0.8 & 1.0 & & & & & & & & & & & & & \\
\hline Cognitive scale index ${ }^{(a)}$ & & & 0.0 & 0.0 & & -0.1 & 0.0 & & 0.0 & -0.1 & & 0.5 & 0.4 & 0.9 & 0.8 & 0.9 & 0.9 & 0.9 & 1.0 & & & & & & & & & & & & \\
\hline Prosociality ${ }^{(a)}$ & -0.2 & -0.1 & -0.1 & 0.0 & 0.0 & -0.1 & -0.1 & 0.0 & -0.1 & -0.1 & 0.0 & 0.1 & 0.0 & 0.1 & 0.1 & 0.1 & 0.1 & 0.0 & 0.1 & 1.0 & & & & & & & & & & & \\
\hline Hyperactivity (rev) ${ }^{(a)}$ & -0.2 & -0.1 & -0.1 & -0.1 & -0.1 & -0.1 & -0.1 & -0.1 & -0.1 & -0.1 & & 0.1 & 0.2 & 0.2 & 0.2 & 0.2 & 0.2 & 0.2 & 0.2 & 0.3 & 1.0 & & & & & & & & & & \\
\hline Emotional (rev) ${ }^{(a)}$ & -0.3 & -0.1 & -0.1 & 0.0 & -0.2 & -0.1 & -0.2 & -0.1 & -0.1 & -0.1 & -0.1 & 0.1 & 0.1 & 0.0 & 0.1 & 0.0 & 0.0 & 0.0 & 0.1 & 0.1 & 0.3 & 1.0 & & & & & & & & & \\
\hline Conduct (rev) ${ }^{(a)}$ & -0.2 & -0.1 & -0.1 & -0.1 & -0.1 & -0.1 & -0.1 & -0.1 & -0.1 & -0.1 & 0.0 & 0.2 & 0.1 & 0.2 & 0.2 & 0.1 & 0.2 & 0.1 & 0.2 & 0.4 & 0.5 & 0.3 & 1.0 & & & & & & & & \\
\hline Peer (rev) ${ }^{(a)}$ & -0.2 & -0.1 & -0.1 & -0.1 & -0.1 & -0.1 & -0.2 & -0.1 & -0.1 & -0.1 & 0.0 & 0.1 & 0.0 & 0.1 & 0.1 & 0.1 & 0.1 & 0.1 & 0.1 & 0.3 & 0.3 & 0.4 & 0.3 & 1.0 & & & & & & & \\
\hline Non-cognitive scale index ${ }^{(a)}$ & -0.3 & -0.2 & -0.1 & -0.1 & -0.2 & -0.1 & -0.2 & -0.1 & -0.1 & -0.1 & 0.0 & 0.2 & 0.1 & 0.2 & 0.2 & 0.2 & 0.2 & 0.1 & 0.2 & 0.6 & 0.8 & 0.6 & 0.7 & 0.6 & 1.0 & & & & & & \\
\hline Prosociality ${ }^{(b)}$ & -0.1 & 0.0 & -0.1 & 0.0 & 0.0 & 0.0 & 0.0 & 0.0 & -0.1 & 0.0 & & 0.1 & 0.1 & 0.1 & 0.2 & 0.1 & 0.1 & 0.1 & 0.1 & 0.3 & 0.3 & 0.1 & 0.2 & 0.2 & 0.3 & 1.0 & & & & & \\
\hline Hyperactivity (rev) ${ }^{(b)}$ & -0.1 & 0.0 & -0.1 & 0.0 & 0.0 & -0.1 & 0.0 & & -0.1 & 0.0 & & 0.1 & 0.2 & 0.3 & 0.3 & 0.3 & 0.3 & 0.2 & 0.3 & 0.2 & 0.5 & 0.1 & 0.3 & 0.2 & 0.4 & 0.5 & 1.0 & & & & \\
\hline Emotional (rev) ${ }^{(b)}$ & -0.1 & 0.0 & -0.1 & 0.0 & -0.1 & 0.0 & -0.1 & -0.1 & 0.0 & 0.0 & 0.0 & 0.1 & 0.1 & 0.1 & 0.1 & 0.2 & 0.1 & 0.2 & 0.2 & 0.1 & 0.2 & 0.3 & 0.1 & 0.2 & 0.3 & 0.2 & 0.2 & 1.0 & & & \\
\hline Conduct (rev) ${ }^{(b)}$ & -0.1 & 0.0 & -0.1 & -0.1 & 0.0 & -0.1 & 0.0 & 0.0 & -0.1 & -0.1 & & 0.1 & 0.1 & 0.1 & 0.2 & 0.1 & 0.1 & 0.1 & 0.2 & 0.2 & 0.3 & 0.1 & 0.3 & 0.2 & 0.3 & 0.6 & 0.6 & 0.2 & 1.0 & & \\
\hline Peer (rev) ${ }^{(\mathrm{b})}$ & -0.1 & 0.0 & -0.1 & 0.0 & -0.1 & -0.1 & -0.1 & -0.1 & -0.1 & -0.1 & & 0.1 & 0.1 & 0.0 & 0.1 & 0.1 & 0.1 & 0.1 & 0.1 & 0.2 & 0.2 & 0.2 & 0.2 & 0.4 & 0.3 & 0.4 & 0.3 & 0.4 & 0.4 & 1.0 & \\
\hline Non-cognitive scale index ${ }^{(b)}$ & -0.1 & 0.0 & -0.1 & -0.1 & -0.1 & -0.1 & -0.1 & 0.0 & -0.1 & -0.1 & & 0.1 & 0.1 & 0.2 & 0.3 & 0.2 & 0.2 & 0.2 & 0.3 & 0.3 & 0.4 & 0.2 & 0.3 & 0.3 & 0.5 & 0.8 & 0.8 & 0.5 & 0.7 & 0.7 & 1.0 \\
\hline
\end{tabular}

Notes: Figures are calculated using a regression sample of overall non-cognitive skill index reported by parents on parental K6 measure. ${ }^{\text {(a) }}$ denotes reports from parents while ${ }^{\text {(b) }}$ represents reports from teachers. Only correlation with statistical significance level of $5 \%$ or higher is listed. 
Appendix Table A3: Differences between original and selected samples

\begin{tabular}{|c|c|c|c|c|c|}
\hline & Wave 1 & Wave 2 & Wave 3 & Wave 4 & Wave 5 \\
\hline & (1) & (2) & (3) & (4) & (5) \\
\hline Male & $-0.05^{* * *}$ & -0.01 & $-0.02 *$ & -0.00 & 0.00 \\
\hline Child age & $0.04 * * *$ & $-0.00 * *$ & -0.00 & $-0.00 * *$ & 0.00 \\
\hline Native & -0.07 & $0.06^{*}$ & 0.04 & 0.05 & $0.06^{*}$ \\
\hline Aboriginal & -0.04 & $-0.11^{* * *}$ & $-0.07^{*}$ & $-0.08^{*}$ & $-0.08 * *$ \\
\hline Mother's age & -0.00 & $0.00 * *$ & $0.00 * * *$ & $0.01^{* * *}$ & $0.00 * * *$ \\
\hline Mother NESB migrant ${ }^{(a)}$ & -0.03 & 0.03 & -0.01 & -0.03 & $0.08 * * *$ \\
\hline Mother ESB migrant ${ }^{\text {(a) }}$ & 0.03 & 0.02 & -0.01 & -0.01 & 0.00 \\
\hline Mother education: Certificate ${ }^{(b)}$ & $-0.04 *$ & -0.02 & -0.01 & -0.00 & 0.01 \\
\hline Mother education: Diploma ${ }^{(b)}$ & -0.01 & 0.03 & -0.02 & 0.01 & 0.01 \\
\hline Mother education: Bachelor (b) & $-0.05^{*}$ & $0.06^{* * *}$ & $0.03 *$ & $0.04 * *$ & 0.02 \\
\hline Mother education: Graduate ${ }^{(b)}$ & -0.02 & $0.08^{* * *}$ & 0.04 & 0.03 & 0.03 \\
\hline Mother education: Postgraduate ${ }^{(b)}$ & $-0.07^{*}$ & 0.03 & -0.03 & -0.01 & 0.03 \\
\hline Maternal K6 (rev) & -0.00 & 0.00 & 0.00 & 0.00 & 0.00 \\
\hline Maternal general health & -0.00 & -0.01 & -0.01 & $-0.02 * *$ & -0.01 \\
\hline Father's age & 0.00 & 0.00 & 0.00 & 0.00 & 0.00 \\
\hline Father NESB migrant ${ }^{(a)}$ & 0.01 & -0.04 & 0.03 & 0.03 & -0.01 \\
\hline Father ESB migrant ${ }^{(a)}$ & 0.03 & 0.00 & -0.00 & 0.00 & 0.00 \\
\hline Father education: Certificate ${ }^{(b)}$ & 0.03 & 0.01 & $0.05 * * *$ & $0.04 * * *$ & 0.01 \\
\hline Father education: Diploma ${ }^{(b)}$ & $0.08 * *$ & $0.05^{*}$ & $0.06 * * *$ & $0.07 * * *$ & $0.05^{*}$ \\
\hline Father education: Bachelor ${ }^{(b)}$ & 0.02 & 0.03 & $0.06^{* * *}$ & 0.03 & 0.01 \\
\hline Father education: Graduate ${ }^{(b)}$ & 0.04 & -0.03 & $0.08 * * *$ & $0.09 * * *$ & 0.05 \\
\hline Father education: Postgraduate ${ }^{(b)}$ & 0.02 & 0.04 & $0.07 * * *$ & $0.06^{* *}$ & $0.05^{*}$ \\
\hline Paternal K6 (rev) & $-0.01^{* *}$ & -0.00 & -0.00 & -0.00 & -0.00 \\
\hline Paternal general health & 0.01 & -0.01 & -0.01 & $-0.02 * *$ & -0.00 \\
\hline Number of siblings & $0.02 *$ & -0.00 & -0.00 & $-0.02 * * *$ & -0.01 \\
\hline Observations & 3,036 & 2,675 & 2,491 & 2,487 & 2,126 \\
\hline Number in selected sample & 1079 & 2355 & 2269 & 2223 & 1916 \\
\hline Pseudo R2 & 0.05 & 0.05 & 0.06 & 0.06 & 0.05 \\
\hline P t test & 0.18 & 0.25 & 0.23 & 0.02 & 0.23 \\
\hline
\end{tabular}

Notes: Results (marginal effects) are from a probit model. Marginal effects are calculated at the means of continuous variables. The dependent variable is equal to one if the child is in our sample and zero otherwise. Original sample is derived from a FE regression sample of overall non-cognitive skill index reported by parents on parental K6 and general health. ${ }^{\text {(a) }}$ and ${ }^{\text {(b) }}$ denote native and no qualification as the base group, respectively. $\mathrm{P}$ t test: $\mathrm{P}$ value of a t test for whether all maternal and paternal health estimates are equal to zero. The parental depression dummies are not included because they are not available in wave 1 . The symbol *denotes significance at the $10 \%$ level, **at the $5 \%$ level, and $* * *$ at the $1 \%$ level. 
Appendix Table A4: Robustness checks - Reverse causality

\begin{tabular}{|c|c|c|c|c|c|c|}
\hline \multirow[b]{3}{*}{ Lag one wave of } & \multicolumn{2}{|c|}{ K6 (rev) } & \multicolumn{2}{|c|}{ Depressed } & \multicolumn{2}{|c|}{ General health } \\
\hline & Mother & Father & Mother & Father & Mother & Father \\
\hline & (1) & (2) & (3) & (4) & (5) & (6) \\
\hline \multirow{2}{*}{ PPVT } & 0.00 & -0.01 & -0.00 & 0.00 & -0.00 & 0.00 \\
\hline & {$[0.01]$} & {$[0.01]$} & {$[0.00]$} & {$[0.00]$} & {$[0.00]$} & {$[0.00]$} \\
\hline \multirow[t]{2}{*}{ MR } & 0.01 & -0.01 & 0.00 & -0.00 & 0.01 & 0.00 \\
\hline & {$[0.02]$} & {$[0.02]$} & {$[0.00]$} & {$[0.00]$} & {$[0.00]$} & {$[0.00]$} \\
\hline \multirow[t]{2}{*}{ Reading } & 0.00 & -0.00 & 0.00 & -0.00 & 0.00 & 0.00 \\
\hline & {$[0.00]$} & {$[0.00]$} & {$[0.00]$} & {$[0.00]$} & {$[0.00]$} & {$[0.00]$} \\
\hline \multirow[t]{2}{*}{ Writing } & 0.00 & 0.00 & -0.00 & -0.00 & -0.00 & -0.00 \\
\hline & {$[0.00]$} & {$[0.00]$} & {$[0.00]$} & {$[0.00]$} & {$[0.00]$} & {$[0.00]$} \\
\hline \multirow[t]{2}{*}{ Spelling } & -0.00 & 0.00 & 0.00 & 0.00 & -0.00 & 0.00 \\
\hline & {$[0.00]$} & {$[0.00]$} & {$[0.00]$} & {$[0.00]$} & {$[0.00]$} & {$[0.00]$} \\
\hline \multirow[t]{2}{*}{ Grammar } & $-0.00 *$ & 0.00 & -0.00 & -0.00 & 0.00 & -0.00 \\
\hline & {$[0.00]$} & {$[0.00]$} & {$[0.00]$} & {$[0.00]$} & {$[0.00]$} & {$[0.00]$} \\
\hline \multirow[t]{2}{*}{ Numeracy } & -0.00 & 0.00 & -0.00 & -0.00 & 0.00 & $-0.00^{*}$ \\
\hline & {$[0.00]$} & {$[0.00]$} & {$[0.00]$} & {$[0.00]$} & {$[0.00]$} & {$[0.00]$} \\
\hline \multirow[t]{2}{*}{ Cognitive skill index } & -0.00 & $0.00 *$ & 0.00 & -0.00 & 0.00 & -0.00 \\
\hline & {$[0.00]$} & {$[0.00]$} & {$[0.00]$} & {$[0.00]$} & {$[0.00]$} & {$[0.00]$} \\
\hline \multirow[t]{2}{*}{ Prosociality } & 0.02 & -0.01 & $0.00 *$ & -0.00 & 0.00 & -0.00 \\
\hline & {$[0.02]$} & {$[0.02]$} & {$[0.00]$} & {$[0.00]$} & {$[0.00]$} & {$[0.00]$} \\
\hline \multirow{2}{*}{ Hyperactivity (rev) } & -0.00 & -0.00 & -0.01 & -0.00 & 0.00 & -0.01 \\
\hline & {$[0.02]$} & {$[0.02]$} & {$[0.00]$} & {$[0.00]$} & {$[0.00]$} & {$[0.00]$} \\
\hline \multirow[t]{2}{*}{ Emotional (rev) } & $-0.05^{* *}$ & 0.02 & $-0.01^{*}$ & -0.00 & -0.01 & 0.00 \\
\hline & {$[0.02]$} & {$[0.02]$} & {$[0.00]$} & {$[0.00]$} & {$[0.01]$} & {$[0.01]$} \\
\hline \multirow[t]{2}{*}{ Conduct (rev) } & -0.01 & 0.00 & $-0.01 * *$ & 0.00 & $-0.01 *$ & -0.01 \\
\hline & {$[0.03]$} & {$[0.03]$} & {$[0.00]$} & [0.01] & {$[0.01]$} & {$[0.01]$} \\
\hline \multirow[t]{2}{*}{ Peer (rev) } & 0.01 & -0.01 & 0.00 & -0.00 & 0.00 & -0.01 \\
\hline & {$[0.02]$} & {$[0.02]$} & {$[0.00]$} & {$[0.00]$} & {$[0.01]$} & {$[0.01]$} \\
\hline \multirow[t]{2}{*}{ Non-cognitive skill index } & -0.01 & 0.00 & -0.00 & -0.00 & -0.01 & -0.01 \\
\hline & {$[0.03]$} & {$[0.04]$} & {$[0.01]$} & [0.01] & {$[0.01]$} & {$[0.01]$} \\
\hline
\end{tabular}

Notes: Each estimate is from a separate FE regression of each of parental health measures on one wave lag of each of child development outcomes. Teachers' evaluations of child non-cognitive skills are used as independent variables. Other explanatory variables include the child's characteristics (age, school sectors, and number of siblings), both parents' characteristics (age and education), local socio-economic background variables, state/territory dummies, year dummies, and survey quarters. NAPLAN test regressions also include test age and test years. Robust standard errors clustered at the individual level in square brackets. The symbol *denotes significance at the $10 \%$ level, **at the $5 \%$ level, and ***at the $1 \%$ level. 
Appendix Table A5: Maternal mental health and child development - Results from fixed effects instrumental variables models

\begin{tabular}{|c|c|c|c|c|c|c|c|c|c|c|c|c|c|c|}
\hline & $\overline{P \text { PPVT }}$ & MR & Reading & Writing & Spelling & Grammar & " Numeracy & $\begin{array}{c}\text { Cognitive } \\
\text { index }\end{array}$ & "Prosociality & $\begin{array}{c}\text { Hyperactivity } \\
\text { (rev) }\end{array}$ & $\begin{array}{c}\text { Emotional } \\
\text { (rev) }\end{array}$ & $\begin{array}{c}\text { Conduct } \\
\text { (rev) }\end{array}$ & Peer (rev) & $\begin{array}{c}\text { Non- } \\
\text { cognitive } \\
\text { index }\end{array}$ \\
\hline \multirow{4}{*}{$\frac{\text { Health variables }}{\text { Maternal K6 (rev) }}$} & (1) & (2) & (3) & (4) & (5) & (6) & (7) & (8) & (9) & (10) & (11) & (12) & (13) & (14) \\
\hline & -1.05 & 0.01 & 2.79 & $11.71 *$ & 0.18 & 4.90 & -2.73 & 3.31 & 0.00 & 0.19 & -0.26 & -0.08 & 0.06 & -0.02 \\
\hline & {$[0.84]$} & {$[0.20]$} & {$[4.33]$} & [6.17] & [3.24] & {$[5.42]$} & {$[4.25]$} & {$[2.33]$} & {$[0.18]$} & [0.19] & {$[0.16]$} & {$[0.11]$} & {$[0.13]$} & {$[0.10]$} \\
\hline & $\{0.79\}$ & $\{1.00\}$ & $\{0.79\}$ & $\{0.72\}$ & $\{1.00\}$ & $\{0.79\}$ & $\{0.79\}$ & & $\{1.00\}$ & $\{0.79\}$ & $\{0.72\}$ & $\{0.79\}$ & $\{0.87\}$ & \\
\hline $\mathrm{F}$ test & 2.71 & 8.84 & 7.71 & 6.87 & 6.83 & 6.83 & 6.87 & 6.42 & 9.28 & 8.95 & 8.86 & 8.94 & 8.95 & 8.77 \\
\hline P Sargan-Hansen & 0.48 & 0.75 & 0.84 & 0.45 & 0.48 & 0.38 & 0.01 & 0.26 & 0.92 & 0.57 & 0.47 & 0.85 & 0.51 & 0.84 \\
\hline No of observations & 7,090 & 9,967 & 7,843 & 7,831 & 7,848 & 7,846 & 7,793 & 7,646 & 12,447 & 12,483 & 12,471 & 12,477 & 12,452 & 12,423 \\
\hline No of individuals & 3,053 & 3,708 & 3,162 & 3,159 & 3,165 & 3,164 & 3,147 & 3,095 & 3,756 & 3,761 & 3,759 & 3,761 & 3,754 & 3,751 \\
\hline \multirow[t]{3}{*}{ Mother depressed } & -1.66 & 0.12 & 11.66 & $52.58^{*}$ & -1.13 & 21.78 & -20.94 & 12.66 & 0.12 & 0.49 & -0.88 & 0.01 & 0.06 & -0.05 \\
\hline & {$[2.72]$} & [1.03] & [22.39] & [27.09] & {$[15.22]$} & [25.32] & [21.93] & [10.64] & {$[0.80]$} & {$[0.82]$} & {$[0.70]$} & {$[0.47]$} & [0.59] & {$[0.43]$} \\
\hline & $\{0.99\}$ & $\{0.99\}$ & $\{0.99\}$ & $\{0.72\}$ & $\{0.99\}$ & $\{0.99\}$ & $\{0.99\}$ & & $\{0.99\}$ & $\{0.99\}$ & $\{0.99\}$ & $\{0.99\}$ & $\{0.99\}$ & \\
\hline F test & 5.84 & 13.55 & 11.13 & 12.31 & 12.12 & 12.12 & 10.34 & 11.02 & 17.39 & 17.44 & 17.08 & 17.28 & 17.72 & 17.03 \\
\hline P Sargan-Hansen & 0.23 & 0.77 & 0.79 & 0.57 & 0.45 & 0.31 & 0.01 & 0.19 & 0.76 & 0.41 & 0.15 & 0.91 & 0.50 & 0.90 \\
\hline No of observations & 5,284 & 9,933 & 7,808 & 7,796 & 7,813 & 7,811 & 7,760 & 7,613 & 11,231 & 11,268 & 11,255 & 11,260 & 11,236 & 11,205 \\
\hline No of individuals & 2,642 & 3,700 & 3,150 & 3,147 & 3,153 & 3,152 & 3,136 & 3,084 & 3,648 & 3,654 & 3,651 & 3,652 & 3,646 & 3,641 \\
\hline
\end{tabular}

Notes: Results for each cell are estimated from a separate FE-IV regression. Non-cognitive skills are reported by teachers. Instruments: death of close friend and illness to close relative (of the mother). Other explanatory variables include the child's characteristics (age, school sectors, number of siblings, living with both parents), the mother's characteristics (age and education), local socio-economic background variables, state/territory dummies, year dummies, and survey quarters. NAPLAN test regressions also include test age and test years. F test denotes the F statistic for the excluded instrument in the first stage regression and p Sargan-Hansen denotes results from the Sargan-Hansen test for over identification restrictions. Robust standard errors clustered at the individual level in square brackets. Adjusted $p$-values to account for multiple inference issue calculated using the Simes-Benjamini-Hochberg method are in curly brackets. The symbol *denotes unadjusted significance at the $10 \%$ level, **at the $5 \%$ level, and ***at the $1 \%$ level. 
Appendix Table A6: Parental health and child development - cut-off points and interactions of parental health variables

\begin{tabular}{|c|c|c|c|c|c|c|c|c|c|c|c|c|c|c|}
\hline & 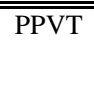 & 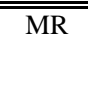 & "Reading & "Writing & "Spelling & Grammar & Numeracy & $\begin{array}{c}\text { Cognitive } \\
\text { index }\end{array}$ & $\begin{array}{c}\text { Prosocialit } \\
\mathrm{y}\end{array}$ & $\begin{array}{c}\text { Hyperactivit } \\
\text { y (rev) }\end{array}$ & $\begin{array}{c}\text { Emotional } \\
\text { (rev) }\end{array}$ & $\begin{array}{c}\begin{array}{c}\text { Conduct } \\
\text { (rev) }\end{array}\end{array}$ & Peer (rev) & $\begin{array}{c}\text { Non- } \\
\text { cognitive } \\
\text { index }\end{array}$ \\
\hline Health measures & (1) & (2) & (3) & (4) & (5) & (6) & (7) & (8) & (9) & $(10)$ & (11) & $(12)$ & (13) & (14) \\
\hline Maternal depression (K6) & $\begin{array}{c}-0.40 \\
{[0.47]} \\
\{0.77\}\end{array}$ & $\begin{array}{c}0.48 \\
{[0.31]} \\
\{0.57\}\end{array}$ & $\begin{array}{l}-0.36 \\
{[6.57]} \\
\{0.96\}\end{array}$ & $\begin{array}{c}2.02 \\
{[6.95]} \\
\{0.87\}\end{array}$ & $\begin{array}{c}5.76 \\
{[3.95]} \\
\{0.57\}\end{array}$ & $\begin{array}{c}-4.98 \\
{[8.16]} \\
\{0.81\}\end{array}$ & $\begin{array}{c}6.37 \\
{[8.37]} \\
\{0.77\}\end{array}$ & $\begin{array}{c}1.28 \\
{[3.55]}\end{array}$ & $\begin{array}{c}0.27 \\
{[0.21]} \\
\{0.57\}\end{array}$ & $\begin{array}{c}-0.26 \\
{[0.20]} \\
\{0.57\}\end{array}$ & $\begin{array}{c}0.05 \\
{[0.19]} \\
\{0.87\}\end{array}$ & $\begin{array}{c}0.05 \\
{[0.11]} \\
\{0.85\}\end{array}$ & $\begin{array}{c}0.20 \\
{[0.18]} \\
\{0.63\}\end{array}$ & $\begin{array}{c}0.08 \\
{[0.11]}\end{array}$ \\
\hline Paternal depression (K6) & $\begin{array}{l}1.20^{* *} \\
{[0.52]} \\
\{0.09\}\end{array}$ & $\begin{array}{c}0.21 \\
{[0.27]} \\
\{0.67\}\end{array}$ & $\begin{array}{l}-1.48 \\
{[7.19]} \\
\{0.99\}\end{array}$ & $\begin{array}{c}-2.93 \\
{[7.32]} \\
\{0.92\}\end{array}$ & $\begin{array}{c}-5.34 \\
{[4.29]} \\
\{0.63\}\end{array}$ & $\begin{array}{l}-6.65 \\
{[7.53]} \\
\{0.65\}\end{array}$ & $\begin{array}{c}-13.65^{* * * *} \\
{[5.27]} \\
\{0.09\}\end{array}$ & $\begin{array}{c}-5.79 * \\
{[3.02]}\end{array}$ & $\begin{array}{c}-0.21 \\
{[0.21]} \\
\{0.63\}\end{array}$ & $\begin{array}{c}-0.27 \\
{[0.24]} \\
\{0.63\}\end{array}$ & $\begin{array}{c}0.02 \\
{[0.19]} \\
\{0.99\}\end{array}$ & $\begin{array}{c}-0.39 * * \\
{[0.16]} \\
\{0.09\}\end{array}$ & $\begin{array}{c}-0.00 \\
{[0.17]} \\
\{0.99\}\end{array}$ & $\begin{array}{c}-0.17 \\
{[0.14]}\end{array}$ \\
\hline Interaction & $\begin{array}{l}-1.11 \\
{[1.99]} \\
\{0.82\}\end{array}$ & $\begin{array}{l}-1.91 * \\
{[1.08]} \\
\{0.82\}\end{array}$ & $\begin{array}{c}-10.42 \\
{[20.50]} \\
\{0.82\}\end{array}$ & $\begin{array}{c}-0.03 \\
{[18.90]} \\
\{1.00\}\end{array}$ & $\begin{array}{c}-23.23 \\
{[16.06]} \\
\{0.82\}\end{array}$ & $\begin{array}{c}-16.18 \\
{[17.59]} \\
\{0.82\}\end{array}$ & $\begin{array}{c}11.37 \\
{[12.73]} \\
\{0.82\}\end{array}$ & $\begin{array}{c}-5.66 \\
{[8.88]}\end{array}$ & $\begin{array}{l}-0.00 \\
{[0.77]} \\
\{1.00\}\end{array}$ & $\begin{array}{l}-0.45 \\
{[0.58]} \\
\{0.82\}\end{array}$ & $\begin{array}{c}0.37 \\
{[0.44]} \\
\{0.82\}\end{array}$ & $\begin{array}{c}0.20 \\
{[0.52]} \\
\{0.83\}\end{array}$ & $\begin{array}{l}-0.40 \\
{[0.61]} \\
\{0.82\}\end{array}$ & $\begin{array}{c}-0.06 \\
{[0.41]}\end{array}$ \\
\hline Mother depressed & $\begin{array}{c}-0.23 \\
{[0.26]} \\
\{0.81\}\end{array}$ & $\begin{array}{c}0.08 \\
{[0.11]} \\
\{0.81\}\end{array}$ & $\begin{array}{c}-4.03 \\
{[2.55]} \\
\{0.81\}\end{array}$ & $\begin{array}{c}-3.52 \\
{[3.20]} \\
\{0.81\}\end{array}$ & $\begin{array}{c}0.15 \\
{[1.97]} \\
\{0.97\}\end{array}$ & $\begin{array}{c}2.22 \\
{[2.82]} \\
\{0.81\}\end{array}$ & $\begin{array}{l}-1.13 \\
{[2.47]} \\
\{0.86\}\end{array}$ & $\begin{array}{l}-1.17 \\
{[1.22]}\end{array}$ & $\begin{array}{c}0.02 \\
{[0.09]} \\
\{0.97\}\end{array}$ & $\begin{array}{l}-0.00 \\
{[0.09]} \\
\{0.97\}\end{array}$ & $\begin{array}{c}-0.04 \\
{[0.07]} \\
\{0.81\}\end{array}$ & $\begin{array}{c}0.06 \\
{[0.05]} \\
\{0.81\}\end{array}$ & $\begin{array}{c}-0.07 \\
{[0.06]} \\
\{0.81\}\end{array}$ & $\begin{array}{c}-0.00 \\
{[0.05]}\end{array}$ \\
\hline Father depressed & $\begin{array}{c}0.12 \\
{[0.24]} \\
\{0.88\}\end{array}$ & $\begin{array}{c}0.01 \\
{[0.11]} \\
\{0.93\}\end{array}$ & $\begin{array}{l}1.28 \\
{[2.45]} \\
\{0.88\}\end{array}$ & $\begin{array}{l}-0.82 \\
{[2.89]} \\
\{0.88\}\end{array}$ & $\begin{array}{c}1.67 \\
{[1.68]} \\
\{0.88\}\end{array}$ & $\begin{array}{c}1.59 \\
{[2.78]} \\
\{0.88\}\end{array}$ & $\begin{array}{l}-1.96 \\
{[2.31]} \\
\{0.88\}\end{array}$ & $\begin{array}{c}0.58 \\
{[1.13]}\end{array}$ & $\begin{array}{l}-0.03 \\
{[0.08]} \\
\{0.88\}\end{array}$ & $\begin{array}{c}-0.25 * * * \\
{[0.09]} \\
\{0.04\}\end{array}$ & $\begin{array}{l}-0.09 \\
{[0.06]} \\
\{0.88\}\end{array}$ & $\begin{array}{l}-0.01 \\
{[0.05]} \\
\{0.88\}\end{array}$ & $\begin{array}{l}-0.03 \\
{[0.06]} \\
\{0.88\}\end{array}$ & $\begin{array}{l}-0.08 * \\
{[0.05]}\end{array}$ \\
\hline Interaction & $\begin{array}{c}0.19 \\
{[0.39]} \\
\{0.98\}\end{array}$ & $\begin{array}{c}0.27 \\
{[0.19]} \\
\{0.98\}\end{array}$ & $\begin{array}{l}-3.75 \\
{[4.14]} \\
\{0.98\}\end{array}$ & $\begin{array}{c}2.55 \\
{[4.85]} \\
\{0.98\}\end{array}$ & $\begin{array}{c}0.59 \\
{[2.95]} \\
\{0.98\}\end{array}$ & $\begin{array}{l}-6.03 \\
{[4.79]} \\
\{0.98\}\end{array}$ & $\begin{array}{c}1.44 \\
{[4.05]} \\
\{0.98\}\end{array}$ & $\begin{array}{l}-0.74 \\
{[1.91]}\end{array}$ & $\begin{array}{c}0.03 \\
{[0.14]} \\
\{0.98\}\end{array}$ & $\begin{array}{c}0.10 \\
{[0.14]} \\
\{0.98\}\end{array}$ & $\begin{array}{c}0.07 \\
{[0.12]} \\
\{0.98\}\end{array}$ & $\begin{array}{c}0.01 \\
{[0.08]} \\
\{0.98\}\end{array}$ & $\begin{array}{c}0.00 \\
{[0.11]} \\
\{0.98\}\end{array}$ & $\begin{array}{c}0.04 \\
{[0.07]}\end{array}$ \\
\hline Maternal poor health & $\begin{array}{l}-0.25 \\
{[0.40]} \\
\{0.65\}\end{array}$ & $\begin{array}{c}0.17 \\
{[0.20]} \\
\{0.65\}\end{array}$ & $\begin{array}{l}-5.88 \\
{[4.80]} \\
\{0.65\}\end{array}$ & $\begin{array}{c}-3.81 \\
{[4.94]} \\
\{0.65\}\end{array}$ & $\begin{array}{l}-2.03 \\
{[3.21]} \\
\{0.65\}\end{array}$ & $\begin{array}{l}8.78^{*} \\
{[5.04]} \\
\{0.65\}\end{array}$ & $\begin{array}{c}3.67 \\
{[4.13]} \\
\{0.65\}\end{array}$ & $\begin{array}{c}0.18 \\
{[2.16]}\end{array}$ & $\begin{array}{c}0.03 \\
{[0.14]} \\
\{0.91\}\end{array}$ & $\begin{array}{c}0.01 \\
{[0.13]} \\
\{0.96\}\end{array}$ & $\begin{array}{c}-0.08 \\
{[0.12]} \\
\{0.65\}\end{array}$ & $\begin{array}{l}-0.06 \\
{[0.08]} \\
\{0.65\}\end{array}$ & $\begin{array}{c}-0.07 \\
{[0.10]} \\
\{0.65\}\end{array}$ & $\begin{array}{c}-0.02 \\
{[0.07]}\end{array}$ \\
\hline Paternal poor health & $\begin{array}{c}0.51 \\
{[0.32]} \\
\{0.88\}\end{array}$ & $\begin{array}{c}-0.08 \\
{[0.17]} \\
\{0.88\}\end{array}$ & $\begin{array}{c}-1.90 \\
{[3.59]} \\
\{0.88\}\end{array}$ & $\begin{array}{c}1.11 \\
{[4.87]} \\
\{0.89\}\end{array}$ & $\begin{array}{c}-0.99 \\
{[3.25]} \\
\{0.89\}\end{array}$ & $\begin{array}{c}4.07 \\
{[4.15]} \\
\{0.88\}\end{array}$ & $\begin{array}{c}-4.54 \\
{[3.40]} \\
\{0.88\}\end{array}$ & $\begin{array}{c}-0.32 \\
{[1.83]}\end{array}$ & $\begin{array}{c}0.08 \\
{[0.12]} \\
\{0.88\}\end{array}$ & $\begin{array}{c}0.08 \\
{[0.13]} \\
\{0.88\}\end{array}$ & $\begin{array}{c}-0.07 \\
{[0.10]} \\
\{0.88\}\end{array}$ & $\begin{array}{c}-0.00 \\
{[0.08]} \\
\{0.99\}\end{array}$ & $\begin{array}{c}-0.05 \\
{[0.10]} \\
\{0.88\}\end{array}$ & $\begin{array}{c}0.01 \\
{[0.07]}\end{array}$ \\
\hline Interaction & $\begin{array}{l}-1.21^{*} \\
{[0.72]} \\
\{0.49\}\end{array}$ & $\begin{array}{c}0.53 \\
{[0.38]} \\
\{0.49\}\end{array}$ & $\begin{array}{c}2.46 \\
{[10.04]} \\
\{0.88\}\end{array}$ & $\begin{array}{c}0.07 \\
{[9.87]} \\
\{0.99\}\end{array}$ & $\begin{array}{l}-4.44 \\
{[9.03]} \\
\{0.83\}\end{array}$ & $\begin{array}{c}-9.84 \\
{[10.13]} \\
\{0.60\}\end{array}$ & $\begin{array}{c}6.73 \\
{[10.54]} \\
\{0.79\}\end{array}$ & $\begin{array}{c}0.19 \\
{[4.69]}\end{array}$ & $\begin{array}{c}-0.43 \\
{[0.31]} \\
\{0.49\}\end{array}$ & $\begin{array}{c}-0.61^{*} \\
{[0.32]} \\
\{0.49\}\end{array}$ & $\begin{array}{c}0.23 \\
{[0.25]} \\
\{0.60\}\end{array}$ & $\begin{array}{c}0.06 \\
{[0.18]} \\
\{0.88\}\end{array}$ & $\begin{array}{c}-0.24 \\
{[0.25]} \\
\{0.60\}\end{array}$ & $\begin{array}{c}-0.20 \\
{[0.16]}\end{array}$ \\
\hline
\end{tabular}

Notes: FE results are from the regression (2). Non-cognitive skills are reported by teachers. Other explanatory variables include the child's characteristics (age, school sectors, and number of siblings), both parents' characteristics (age and education), local socio-economic background variables, state/territory dummies, year dummies, and survey quarters. NAPLAN test regressions also include test age and test years. Robust standard errors clustered at the individual level in square brackets. Adjusted $p$-values to account for multiple inference issue calculated using the Simes-Benjamini-Hochberg method are in curly brackets. The symbol *denotes unadjusted significance at the $10 \%$ level, $* *$ at the $5 \%$ level, and $* * *$ at the $1 \%$ level 
Appendix Table A7: Parental health and child development - One-wave lag of parental health variables

\begin{tabular}{|c|c|c|c|c|c|c|c|c|c|c|c|c|c|c|}
\hline & PPVT & MR & Reading & Writing & Spelling & Grammar & Numeracy & $\begin{array}{l}\text { Cognitive } \\
\text { index }\end{array}$ & Prosociality & $\begin{array}{l}\text { Hyperactivity } \\
\text { (rev) }\end{array}$ & $\begin{array}{l}\text { Emotional } \\
\text { (rev) }\end{array}$ & $\begin{array}{c}\text { Conduct } \\
\text { (rev) }\end{array}$ & Peer (rev) & $\begin{array}{c}\text { Non- } \\
\text { cognitive } \\
\text { index }\end{array}$ \\
\hline One-wave lag of & (1) & (2) & (3) & (4) & (5) & (6) & (7) & (8) & (9) & (10) & (11) & (12) & (13) & (14) \\
\hline \multirow[t]{3}{*}{ Mother K6 (rev) } & -0.02 & -0.01 & 0.08 & 0.54 & 0.14 & 0.31 & $\begin{array}{l}-0.59 \\
\end{array}$ & $\begin{array}{l}-0.00 \\
\end{array}$ & $\begin{array}{l}-0.01 \\
\end{array}$ & 0.01 & 0.01 & 0.00 & 0.01 & 0.00 \\
\hline & {$[0.04]$} & {$[0.02]$} & {$[0.43]$} & {$[0.46]$} & [0.29] & {$[0.47]$} & {$[0.36]$} & [0.19] & {$[0.01]$} & {$[0.01]$} & {$[0.01]$} & {$[0.01]$} & {$[0.01]$} & {$[0.01]$} \\
\hline & $\{0.78\}$ & $\{0.78\}$ & $\{0.86\}$ & $\{0.78\}$ & $\{0.78\}$ & $\{0.78\}$ & $\{0.78\}$ & & $\{0.78\}$ & $\{0.78\}$ & $\{0.78\}$ & $\{0.86\}$ & $\{0.78\}$ & \\
\hline \multirow[t]{3}{*}{ Father K6 (rev) } & -0.04 & -0.02 & -0.52 & -0.54 & -0.12 & -0.22 & 0.12 & -0.31 & -0.00 & 0.00 & -0.02 & 0.01 & -0.00 & -0.00 \\
\hline & {$[0.04]$} & {$[0.02]$} & {$[0.40]$} & {$[0.46]$} & {$[0.27]$} & {$[0.50]$} & {$[0.34]$} & {$[0.19]$} & {$[0.01]$} & {$[0.01]$} & {$[0.01]$} & {$[0.01]$} & {$[0.01]$} & {$[0.01]$} \\
\hline & $\{0.74\}$ & $\{0.74\}$ & $\{0.74\}$ & $\{0.74\}$ & $\{0.91\}$ & $\{0.91\}$ & $\{0.91\}$ & & $\{0.91\}$ & $\{0.91\}$ & $\{0.74\}$ & $\{0.91\}$ & $\{0.91\}$ & \\
\hline $\mathrm{P} t$ test & 0.75 & 0.73 & 0.29 & 0.10 & 0.49 & 0.43 & 0.16 & 0.23 & 0.92 & 0.64 & 0.12 & 0.76 & 0.59 & 0.58 \\
\hline No of observations & 3,422 & 5,329 & 4,331 & 4,316 & 4,323 & 4,323 & 4,304 & 4,247 & 6,055 & 6,071 & 6,062 & 6,066 & 6,059 & 6,041 \\
\hline No of individuals & 1,711 & 1,934 & 1,724 & 1,722 & 1,723 & 1,723 & 1,715 & 1,700 & 2,018 & 2,021 & 2,018 & 2,020 & 2,017 & 2,013 \\
\hline \multirow[t]{3}{*}{ Mother depressed } & & -0.03 & 2.65 & 4.69 & 1.22 & -0.60 & $-4.30 *$ & 0.51 & 0.14 & 0.12 & -0.01 & 0.04 & 0.07 & 0.07 \\
\hline & & {$[0.15]$} & [2.81] & [3.67] & [1.93] & {$[3.55]$} & {$[2.50]$} & [1.31] & {$[0.10]$} & {$[0.10]$} & {$[0.08]$} & {$[0.05]$} & {$[0.07]$} & {$[0.05]$} \\
\hline & & $\{0.90\}$ & $\{0.63\}$ & $\{0.63\}$ & $\{0.72\}$ & $\{0.90\}$ & $\{0.63\}$ & & $\{0.63\}$ & $\{0.63\}$ & $\{0.90\}$ & $\{0.66\}$ & $\{0.63\}$ & \\
\hline \multirow[t]{2}{*}{ Father depressed } & & 0.06 & 1.05 & 3.64 & -1.56 & -0.52 & -3.25 & -0.05 & $-0.25 * *$ & -0.14 & -0.09 & $-0.15^{* *}$ & -0.07 & $-0.14^{* *}$ \\
\hline & & {$[0.14]$} & [2.78] & [3.54] & [1.83] & [3.47] & {$[2.31]$} & [1.23] & {$[0.10]$} & {$[0.10]$} & {$[0.07]$} & {$[0.06]$} & {$[0.07]$} & {$[0.06]$} \\
\hline No of observations & & 3,328 & 2,784 & 2,764 & 2,772 & 2,772 & 2,750 & 2,690 & 4,144 & 4,159 & 4,154 & 4,157 & 4,151 & 4,136 \\
\hline No of individuals & & 1,664 & 1,392 & 1,382 & 1,386 & 1,386 & 1,375 & 1,345 & 1,643 & 1,647 & 1,646 & 1,647 & 1,644 & 1,640 \\
\hline \multirow[t]{3}{*}{ Mother general health } & -0.05 & -0.02 & -1.01 & -0.09 & 0.22 & $3.73^{* *}$ & -0.65 & 0.15 & 0.00 & 0.04 & -0.02 & 0.02 & -0.01 & 0.01 \\
\hline & {$[0.14]$} & {$[0.06]$} & [1.46] & [1.65] & {$[1.08]$} & {$[1.62]$} & {$[1.37]$} & {$[0.68]$} & {$[0.05]$} & {$[0.05]$} & {$[0.04]$} & {$[0.03]$} & {$[0.03]$} & {$[0.03]$} \\
\hline & $\{0.96\}$ & $\{0.96\}$ & $\{0.96\}$ & $\{0.96\}$ & $\{0.96\}$ & $\{0.25\}$ & $\{0.96\}$ & & $\{0.96\}$ & $\{0.96\}$ & $\{0.96\}$ & $\{0.96\}$ & $\{0.96\}$ & \\
\hline \multirow[t]{3}{*}{ Father general health } & 0.05 & -0.10 & -0.11 & 1.94 & 0.09 & 0.17 & -0.09 & 0.47 & -0.01 & -0.03 & -0.03 & 0.03 & 0.03 & -0.00 \\
\hline & {$[0.13]$} & {$[0.06]$} & [1.32] & [1.57] & {$[0.97]$} & [1.63] & [1.32] & {$[0.60]$} & {$[0.05]$} & {$[0.05]$} & {$[0.04]$} & {$[0.03]$} & {$[0.03]$} & {$[0.02]$} \\
\hline & $\{0.95\}$ & $\{0.88\}$ & $\{0.95\}$ & $\{0.88\}$ & $\{0.95\}$ & $\{0.95\}$ & $\{0.95\}$ & & $\{0.95\}$ & $\{0.95\}$ & $\{0.95\}$ & $\{0.88\}$ & $\{0.95\}$ & \\
\hline $\mathrm{P}$ t test & 0.60 & 0.42 & 0.66 & 0.41 & 0.94 & 0.12 & 0.77 & 0.73 & 0.88 & 0.28 & 0.80 & 0.76 & 0.48 & 0.80 \\
\hline No of observations & 3,594 & 5,556 & 4,508 & 4,491 & 4,502 & 4,502 & 4,477 & 4,418 & 6,243 & 6,260 & 6,251 & 6,254 & 6,248 & 6,230 \\
\hline No of individuals & 1,797 & 2,015 & 1,792 & 1,789 & 1,792 & 1,792 & 1,781 & 1,765 & 2,068 & 2,072 & 2,069 & 2,070 & 2,068 & 2,064 \\
\hline
\end{tabular}

Notes: FE results are from the regression (2). Non-cognitive skills are reported by teachers. Other explanatory variables include the child's characteristics (age, school sectors, and number of siblings), both parents' characteristics (age and education), local socio-economic background variables, state/territory dummies, year dummies, and survey quarters. NAPLAN test regressions also include test age and test years. $\mathrm{P} t$ test: $\mathrm{P}$ value of a $\mathrm{t}$ test for equality of maternal and paternal health estimates. Robust standard errors clustered at the individual level in square brackets. Adjusted $p$-values to account for multiple inference issue calculated using the Simes-Benjamini-Hochberg method are in curly brackets. The symbol *denotes unadjusted significance at the $10 \%$ level, **at the $5 \%$ level, and ***at the $1 \%$ level. 
Appendix Table A8: Parental health and child development - dynamic child development models

\begin{tabular}{|c|c|c|c|c|c|c|c|c|c|c|c|c|c|c|}
\hline & PPVT & MR & Reading & Writing & Spelling & Grammar & Numeracy & $\begin{array}{l}\text { Cognitive } \\
\text { index }\end{array}$ & Prosociality & $\begin{array}{c}\text { Hyperactivity } \\
\text { (rev) }\end{array}$ & $\begin{array}{c}\text { Emotional } \\
\text { (rev) }\end{array}$ & $\begin{array}{l}\text { Conduct } \\
\text { (rev) }\end{array}$ & Peer (rev) & $\begin{array}{c}\text { Non- } \\
\text { cognitive } \\
\text { index }\end{array}$ \\
\hline Health measures & (1) & (2) & (3) & (4) & (5) & (6) & (7) & (8) & (9) & (10) & (11) & (12) & (13) & (14) \\
\hline \multirow[t]{3}{*}{ Lag of outcome } & $0.13^{* * *}$ & $0.15^{* * *}$ & $0.23^{* * *}$ & $0.13^{* *}$ & 0.13 & 0.05 & $0.47 * * *$ & $0.42 * * *$ & $0.07 * * *$ & $0.23^{* * *}$ & $0.12 * * *$ & $0.09 * *$ & $0.13^{* * *}$ & $0.16^{* * * *}$ \\
\hline & {$[0.04]$} & {$[0.04]$} & {$[0.06]$} & {$[0.05]$} & [0.11] & {$[0.06]$} & {$[0.05]$} & {$[0.09]$} & {$[0.03]$} & {$[0.03]$} & {$[0.03]$} & {$[0.04]$} & {$[0.03]$} & {$[0.03]$} \\
\hline & $\{0.01\}$ & $\{0.00\}$ & $\{0.00\}$ & $\{0.01\}$ & $\{0.27\}$ & $\{0.40\}$ & $\{0.00\}$ & & $\{0.01\}$ & $\{0.00\}$ & $\{0.00\}$ & $\{0.04\}$ & $\{0.00\}$ & \\
\hline \multirow{3}{*}{ Mother K6 (rev) } & -0.00 & $0.02 *$ & 0.11 & -0.27 & -0.07 & 0.02 & 0.33 & 0.04 & -0.00 & -0.01 & -0.01 & -0.00 & $-0.02 *$ & -0.01 \\
\hline & {$[0.02]$} & {$[0.01]$} & {$[0.36]$} & {$[0.35]$} & {$[0.30]$} & {$[0.43]$} & {$[0.32]$} & {$[0.18]$} & {$[0.01]$} & {$[0.01]$} & {$[0.01]$} & {$[0.01]$} & {$[0.01]$} & {$[0.01]$} \\
\hline & $\{0.96\}$ & $\{0.33\}$ & $\{0.96\}$ & $\{0.89\}$ & $\{0.96\}$ & $\{0.97\}$ & $\{0.80\}$ & & $\{0.96\}$ & $\{0.80\}$ & $\{0.80\}$ & $\{0.96\}$ & $\{0.33\}$ & \\
\hline \multirow[t]{3}{*}{ Father K6 (rev) } & $0.04 *$ & 0.01 & $0.79 * *$ & 0.29 & 0.32 & 0.51 & 0.48 & 0.27 & -0.00 & -0.02 & -0.01 & $-0.02 * *$ & -0.01 & $-0.01 *$ \\
\hline & {$[0.02]$} & {$[0.02]$} & {$[0.36]$} & {$[0.38]$} & {$[0.34]$} & {$[0.48]$} & {$[0.32]$} & {$[0.20]$} & {$[0.01]$} & {$[0.01]$} & {$[0.01]$} & {$[0.01]$} & {$[0.01]$} & {$[0.01]$} \\
\hline & $\{0.31\}$ & $\{0.47\}$ & $\{0.18\}$ & $\{0.47\}$ & $\{0.47\}$ & $\{0.43\}$ & $\{0.34\}$ & & $\{0.80\}$ & $\{0.32\}$ & $\{0.34\}$ & $\{0.18\}$ & $\{0.34\}$ & \\
\hline No of observations & 4,419 & 4,323 & 3,285 & 3,268 & 3,279 & 3,278 & 3,250 & 3,179 & 6,025 & 6,038 & 6,029 & 6,036 & 6,024 & 6,009 \\
\hline No of individuals & 2,707 & 2,630 & 2,249 & 2,241 & 2,248 & 2,247 & 2,226 & 2,183 & 2,650 & 2,656 & 2,653 & 2,654 & 2,650 & 2,645 \\
\hline \multirow[t]{3}{*}{ Mother depressed } & -0.24 & 0.05 & -0.21 & 0.88 & -1.75 & 2.22 & 1.21 & 0.34 & -0.01 & 0.02 & -0.02 & 0.02 & $-0.12 * *$ & -0.02 \\
\hline & {$[0.16]$} & {$[0.10]$} & {$[2.41]$} & [2.53] & [1.99] & [2.75] & {$[2.38]$} & [1.19] & {$[0.07]$} & {$[0.08]$} & [0.05] & {$[0.04]$} & [0.05] & {$[0.04]$} \\
\hline & $\{0.87\}$ & $\{0.91\}$ & $\{0.93\}$ & $\{0.91\}$ & $\{0.91\}$ & $\{0.91\}$ & $\{0.91\}$ & & $\{0.91\}$ & $\{0.91\}$ & $\{0.91\}$ & $\{0.91\}$ & $\{0.32\}$ & \\
\hline \multirow{2}{*}{ Father depressed } & 0.15 & -0.05 & 3.57 & 0.39 & 1.44 & 1.05 & 1.17 & 1.52 & 0.02 & $-0.14 *$ & $-0.10^{*}$ & -0.02 & -0.08 & -0.06 \\
\hline & [0.15] & {$[0.10]$} & [2.37] & {$[2.58]$} & [2.11] & [2.79] & [2.23] & [1.24] & {$[0.07]$} & {$[0.07]$} & {$[0.06]$} & {$[0.04]$} & {$[0.05]$} & {$[0.04]$} \\
\hline No of observations & $\{0.81\}$ & $\{0.82\}$ & $\{0.40\}$ & $\{0.88\}$ & $\{0.82\}$ & $\{0.82\}$ & $\{0.82\}$ & & $\{0.82\}$ & $\{0.40\}$ & $\{0.40\}$ & $\{0.82\}$ & $\{0.40\}$ & \\
\hline No of individuals & ה ו ו & T, & $0,<00$ & | & 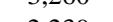 & 3,253 & 3,231 & 3,100 & , ,504 & ( & (5,J50 & (2,905 & (35) & 5,938 \\
\hline & & $2,0<1$ & 2,240 & 2,202 & 2,203 & 2,200 & 2,217 & $2,1 / 4$ & 2,005 & $2,0+J$ & & 2,043 & & \\
\hline \multirow[t]{3}{*}{ Mother general health } & 0.10 & 0.01 & -0.81 & -2.05 & -1.88 & -2.03 & -1.31 & -1.10 & 0.02 & 0.02 & -0.04 & 0.02 & -0.04 & -0.00 \\
\hline & {$[0.08]$} & {$[0.05]$} & [1.31] & [1.31] & [1.17] & [1.55] & [1.35] & {$[0.67]$} & {$[0.04]$} & {$[0.04]$} & {$[0.03]$} & {$[0.02]$} & {$[0.03]$} & {$[0.02]$} \\
\hline & $\{0.44\}$ & $\{0.84\}$ & $\{0.67\}$ & $\{0.44\}$ & $\{0.44\}$ & $\{0.44\}$ & $\{0.50\}$ & & $\{0.67\}$ & $\{0.77\}$ & $\{0.44\}$ & $\{0.50\}$ & $\{0.44\}$ & \\
\hline \multirow{3}{*}{ Father general health } & 0.02 & 0.03 & 0.99 & 1.72 & -0.28 & 2.23 & 1.35 & 0.97 & -0.00 & -0.02 & -0.01 & -0.01 & -0.03 & -0.02 \\
\hline & {$[0.08]$} & {$[0.05]$} & {$[1.24]$} & [1.40] & [1.14] & [1.49] & [1.12] & {$[0.64]$} & {$[0.04]$} & {$[0.04]$} & {$[0.03]$} & {$[0.02]$} & {$[0.03]$} & {$[0.02]$} \\
\hline & $\{0.93\}$ & $\{0.92\}$ & $\{0.92\}$ & $\{0.73\}$ & $\{0.93\}$ & $\{0.73\}$ & $\{0.73\}$ & & $\{0.94\}$ & $\{0.92\}$ & $\{0.92\}$ & $\{0.93\}$ & $\{0.73\}$ & \\
\hline No of observations & 4,387 & 4,292 & 3,266 & 3,249 & 3,260 & 3,259 & 3,231 & 3,160 & 5,954 & 5,967 & 5,958 & 5,965 & 5,953 & 5,938 \\
\hline No of individuals & 2,645 & 2,700 & 2,621 & 2,240 & 2,232 & 2,239 & 2,238 & 2,217 & 2,174 & 2,639 & 2,645 & 2,642 & 2,643 & 2,639 \\
\hline
\end{tabular}

Notes: Results for each column and each panel are from separate system GMM estimations. Non-cognitive skills are reported by teachers. Other explanatory variables include the child's characteristics (age, self-reported general health, school sectors, and number of siblings), both parents' characteristics (age and education), parental investment in child development (family income, both parents' labour supply, out-of-home activities index, and parenting styles), local socio-economic background variables, state/territory dummies, year dummies, and survey quarters. NAPLAN test regressions also include test age and test years. Estimates of lag of outcomes are skipped in the second and third panel because they are almost the same as those reported in the first panel. Robust standard errors clustered at the individual level in square brackets. Adjusted $p$-values to account for multiple inference issue calculated using the Simes-Benjamini-Hochberg method are in curly brackets. The symbol *denotes unadjusted significance at the $10 \%$ level, **at the $5 \%$ level, and ***at the $1 \%$ level. 
Appendix Table A9: Maternal health and child development - single mothers

\begin{tabular}{|c|c|c|c|c|c|c|c|c|c|c|c|c|c|c|}
\hline & $\begin{array}{l}\text { PPVT } \\
\end{array}$ & MR & Reading & Writing & $\overline{\text { Spelling }}$ & Grammar & Numeracy & $\begin{array}{l}\text { Cognitive } \\
\text { index }\end{array}$ & Prosociality & $\begin{array}{l}\text { Hyperactivity } \\
\text { (rev) }\end{array}$ & $\begin{array}{c}\text { Emotional } \\
\text { (rev) }\end{array}$ & $\begin{array}{l}\text { Conduct } \\
\text { (rev) }\end{array}$ & $\begin{array}{l}\text { Peer } \\
\text { (rev) }\end{array}$ & $\begin{array}{c}\text { Non- } \\
\text { cognitive } \\
\text { index }\end{array}$ \\
\hline \multirow{4}{*}{$\begin{array}{l}\text { Health measures } \\
\text { Maternal K6 (rev) }\end{array}$} & (1) & (2) & (3) & (4) & (5) & (6) & (7) & (8) & (9) & (10) & (11) & $(12)$ & (13) & (14) \\
\hline & -0.00 & -0.03 & 0.02 & 0.30 & -0.13 & -0.08 & $-0.83^{*}$ & -0.27 & -0.02 & $-0.05^{* *}$ & $-0.04 * *$ & -0.02 & $-0.03 * *$ & $-0.03 * * *$ \\
\hline & {$[0.05]$} & {$[0.02]$} & {$[0.51]$} & {$[0.59]$} & {$[0.40]$} & {$[0.59]$} & {$[0.47]$} & {$[0.23]$} & {$[0.02]$} & {$[0.02]$} & {$[0.02]$} & {$[0.01]$} & {$[0.01]$} & {$[0.01]$} \\
\hline & $\{0.97\}$ & $\{0.34\}$ & $\{0.97\}$ & $\{0.93\}$ & $\{0.97\}$ & $\{0.97\}$ & $\{0.24\}$ & & $\{0.35\}$ & $\{0.10\}$ & $\{0.10\}$ & $\{0.35\}$ & $\{0.12\}$ & \\
\hline No of observations & 1,223 & 1,903 & 1,374 & 1,375 & 1,378 & 1,376 & 1,368 & 1,329 & 2,277 & 2,291 & 2,287 & 2,288 & 2,282 & 2,272 \\
\hline No of individuals & 543 & 738 & 580 & 579 & 580 & 580 & 578 & 565 & 769 & 773 & 772 & 772 & 771 & 768 \\
\hline \multirow[t]{3}{*}{ Mother depressed } & -0.56 & -0.20 & -1.46 & 5.26 & -0.20 & -2.25 & -2.60 & -0.05 & -0.17 & $-0.24 *$ & -0.13 & -0.09 & -0.12 & $-0.15^{* *}$ \\
\hline & {$[0.38]$} & {$[0.15]$} & [3.98] & [3.93] & {$[2.62]$} & {$[4.27]$} & {$[3.48]$} & {$[1.78]$} & {$[0.12]$} & {$[0.12]$} & {$[0.12]$} & {$[0.09]$} & {$[0.11]$} & {$[0.07]$} \\
\hline & $\{0.44\}$ & $\{0.44\}$ & $\{0.78\}$ & $\{0.44\}$ & $\{0.94\}$ & $\{0.72\}$ & $\{0.61\}$ & & $\{0.44\}$ & $\{0.44\}$ & $\{0.44\}$ & $\{0.48\}$ & $\{0.44\}$ & \\
\hline No of observations & 1,004 & 1,940 & 1,388 & 1,389 & 1,392 & 1,390 & 1,384 & 1,345 & 2,119 & 2,131 & 2,126 & 2,128 & 2,122 & 2,113 \\
\hline No of individuals & 502 & 750 & 585 & 584 & 585 & 585 & 584 & 571 & 747 & 750 & 749 & 749 & 748 & 746 \\
\hline \multirow[t]{3}{*}{ Maternal general health } & 0.11 & -0.10 & -2.88 & -2.09 & -0.50 & $-4.97 *$ & -0.00 & $-2.28 *$ & -0.02 & -0.06 & -0.12 & -0.09 & $-0.12 *$ & -0.08 \\
\hline & {$[0.28]$} & {$[0.10]$} & {$[2.31]$} & {$[2.66]$} & {$[1.66]$} & [2.93] & {$[2.56]$} & {$[1.17]$} & {$[0.08]$} & {$[0.09]$} & {$[0.07]$} & {$[0.06]$} & {$[0.07]$} & {$[0.05]$} \\
\hline & $\{0.84\}$ & $\{0.65\}$ & $\{0.51\}$ & $\{0.74\}$ & $\{0.84\}$ & $\{0.42\}$ & $\{1.00\}$ & & $\{0.84\}$ & $\{0.77\}$ & $\{0.42\}$ & $\{0.50\}$ & $\{0.42\}$ & \\
\hline No of observations & 1,011 & 1,679 & 1,230 & 1,234 & 1,239 & 1,239 & 1,223 & 1,191 & 2,103 & 2,117 & 2,114 & 2,113 & 2,107 & 2,099 \\
\hline No of individuals & 449 & 666 & 528 & 528 & 531 & 531 & 526 & 514 & 722 & 726 & 726 & 725 & 724 & 722 \\
\hline
\end{tabular}

Notes: FE results are from the regression (2). Non-cognitive skills are reported by teachers. Other explanatory variables include the child's characteristics (age, school sectors, and number of siblings), mother's characteristics (age and education), local socio-economic background variables, state/territory dummies, year dummies, and survey quarters. Robust standard errors clustered at the individual level in square brackets. Adjusted $p$-values to account for multiple inference issue calculated using the Simes-Benjamini-Hochberg method are in curly brackets. The symbol *denotes unadjusted significance at the $10 \%$ level, **at the $5 \%$ level, and ***at the $1 \%$ level. 
Appendix Table A10: Parental health and child cognitive development - Heterogeneity by gender of the child

\begin{tabular}{|c|c|c|c|c|c|c|c|c|c|c|c|c|c|c|c|c|}
\hline \multirow[b]{3}{*}{ Health measures } & \multicolumn{2}{|c|}{ 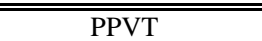 } & \multicolumn{2}{|c|}{$\overline{\mathrm{MR}}$} & \multicolumn{2}{|c|}{ Reading } & \multicolumn{2}{|c|}{$\begin{array}{l}\text { Writing } \\
\end{array}$} & \multicolumn{2}{|c|}{ Spelling } & \multicolumn{2}{|c|}{ Grammar } & \multicolumn{2}{|c|}{ Numeracy } & \multicolumn{2}{|c|}{ Cognitive index } \\
\hline & Daughter & Son & Daughter & Son & Daughter & Son & Daughter & Son & Daughter & Son & Daughter & Son & Daughter & Son & Daughter & Son \\
\hline & (1) & (2) & (3) & (4) & (5) & (6) & (7) & (8) & (9) & (10) & (11) & (12) & (13) & (14) & (15) & (16) \\
\hline \multirow[t]{3}{*}{ Mother K6 (rev) } & 0.02 & 0.05 & -0.00 & $0.06^{* *}$ & 0.29 & 0.17 & -0.33 & -0.33 & 0.18 & 0.32 & -0.31 & 0.79 & -0.16 & 0.29 & 0.08 & 0.21 \\
\hline & {$[0.05]$} & [0.05] & {$[0.02]$} & {$[0.02]$} & {$[0.49]$} & {$[0.57]$} & {$[0.58]$} & {$[0.62]$} & {$[0.36]$} & {$[0.41]$} & {$[0.62]$} & {$[0.65]$} & {$[0.44]$} & {$[0.61]$} & {$[0.23]$} & {$[0.29]$} \\
\hline & $\{0.77\}$ & $\{0.66\}$ & $\{1.00\}$ & $\{0.15\}$ & $\{0.77\}$ & $\{0.83\}$ & $\{0.77\}$ & $\{0.76\}$ & $\{0.77\}$ & $\{0.74\}$ & $\{0.77\}$ & $\{0.66\}$ & $\{0.77\}$ & $\{0.76\}$ & & \\
\hline \multirow[t]{3}{*}{ Father K6 (rev) } & $0.09 * *$ & 0.04 & -0.02 & 0.01 & -0.41 & -0.08 & -0.10 & $1.26^{*}$ & -0.34 & $0.69 *$ & 0.08 & 0.48 & $-0.91 * *$ & 0.29 & -0.31 & $0.55^{* *}$ \\
\hline & {$[0.05]$} & {$[0.04]$} & {$[0.02]$} & {$[0.03]$} & {$[0.54]$} & {$[0.53]$} & {$[0.59]$} & {$[0.66]$} & {$[0.37]$} & {$[0.41]$} & {$[0.56]$} & {$[0.63]$} & {$[0.46]$} & {$[0.52]$} & {$[0.22]$} & {$[0.28]$} \\
\hline & $\{0.29\}$ & $\{0.55\}$ & $\{0.63\}$ & $\{0.84\}$ & $\{0.66\}$ & $\{0.89\}$ & $\{0.95\}$ & $\{0.27\}$ & $\{0.63\}$ & $\{0.27\}$ & $\{0.95\}$ & $\{0.67\}$ & $\{0.29\}$ & $\{0.78\}$ & & \\
\hline $\mathrm{P}$ t test & 0.27 & 0.94 & 0.52 & 0.17 & 0.35 & 0.76 & 0.77 & 0.09 & 0.33 & 0.54 & 0.65 & 0.74 & 0.25 & 1.00 & 0.23 & 0.42 \\
\hline No of observations & 2,541 & 2,548 & 3,201 & 3,273 & 2,594 & 2,578 & 2,585 & 2,567 & 2,589 & 2,574 & 2,590 & 2,571 & 2,577 & 2,557 & 2,533 & 2,521 \\
\hline No of individuals & 1,097 & 1,114 & 1,195 & 1,235 & 1,047 & 1,048 & 1,044 & 1,046 & 1,045 & 1,048 & 1,045 & 1,047 & 1,042 & 1,039 & 1,026 & 1,029 \\
\hline \multirow[t]{3}{*}{ Mother depressed } & -0.44 & 0.03 & 0.23 & 0.10 & $-4.97 *$ & $-6.27 *$ & -1.56 & -3.90 & 1.26 & -1.05 & -3.17 & 3.40 & -2.17 & 0.81 & -1.66 & -1.22 \\
\hline & {$[0.28]$} & [0.34] & {$[0.14]$} & {$[0.13]$} & [2.90] & [3.22] & [3.64] & {$[3.83]$} & [2.43] & {$[2.28]$} & [3.64] & [3.21] & [2.91] & {$[3.04]$} & [1.44] & [1.46] \\
\hline & $\{0.34\}$ & $\{0.93\}$ & $\{0.34\}$ & $\{0.75\}$ & $\{0.34\}$ & $\{0.62\}$ & $\{0.80\}$ & $\{0.75\}$ & $\{0.80\}$ & $\{0.77\}$ & $\{0.66\}$ & $\{0.75\}$ & $\{0.69\}$ & $\{0.86\}$ & & \\
\hline \multirow[t]{3}{*}{ Father depressed } & 0.47 & -0.02 & 0.07 & 0.13 & 2.06 & -1.48 & -3.70 & 3.17 & 1.02 & 2.45 & 2.23 & -1.83 & -3.01 & -0.62 & -0.45 & 0.74 \\
\hline & {$[0.31]$} & {$[0.30]$} & {$[0.14]$} & {$[0.14]$} & {$[3.07]$} & {$[2.90]$} & [3.24] & {$[3.66]$} & [2.20] & [1.95] & [3.28] & [3.55] & [2.75] & {$[2.88]$} & [1.30] & [1.42] \\
\hline & $\{0.51\}$ & $\{0.95\}$ & $\{0.64\}$ & $\{0.77\}$ & $\{0.60\}$ & $\{0.81\}$ & $\{0.55\}$ & $\{0.77\}$ & $\{0.64\}$ & $\{0.77\}$ & $\{0.60\}$ & $\{0.81\}$ & $\{0.55\}$ & $\{0.94\}$ & & \\
\hline $\mathrm{P} t$ test & 0.03 & 0.92 & 0.43 & 0.84 & 0.10 & 0.27 & 0.67 & 0.19 & 0.94 & 0.25 & 0.27 & 0.27 & 0.84 & 0.73 & 0.54 & 0.33 \\
\hline No of observations & 1,876 & 1,910 & 3,178 & 3,240 & 2,570 & 2,549 & 2,561 & 2,538 & 2,565 & 2,545 & 2,566 & 2,542 & 2,552 & 2,528 & 2,508 & 2,492 \\
\hline No of individuals & 938 & 955 & 1,193 & 1,227 & 1,039 & 1,039 & 1,036 & 1,037 & 1,037 & 1,039 & 1,037 & 1,038 & 1,033 & 1,030 & 1,017 & 1,020 \\
\hline \multirow[t]{3}{*}{ Mother general health } & -0.02 & -0.16 & 0.11 & 0.11 & 0.59 & -0.25 & 0.04 & -0.54 & 1.46 & -0.71 & -0.15 & $4.25 *$ & -0.56 & 1.60 & 0.20 & 1.03 \\
\hline & {$[0.17]$} & {$[0.16]$} & {$[0.09]$} & {$[0.08]$} & [1.87] & [1.83] & [2.04] & {$[2.23]$} & {$[1.28]$} & [1.29] & [2.02] & {$[2.21]$} & [1.63] & {$[1.71]$} & {$[0.80]$} & {$[0.89]$} \\
\hline & $\{0.98\}$ & $\{0.62\}$ & $\{0.76\}$ & $\{0.62\}$ & $\{0.98\}$ & $\{0.89\}$ & $\{0.98\}$ & $\{0.89\}$ & $\{0.76\}$ & $\{0.78\}$ & $\{0.98\}$ & $\{0.62\}$ & $\{0.98\}$ & $\{0.62\}$ & & \\
\hline \multirow[t]{3}{*}{ Father general health } & 0.17 & -0.17 & 0.01 & 0.03 & 0.87 & -1.82 & $4.56^{* *}$ & -3.58 & 0.59 & -0.30 & 3.41 & 3.34 & -2.72 & 1.78 & 1.04 & -0.55 \\
\hline & {$[0.16]$} & {$[0.18]$} & {$[0.09]$} & {$[0.08]$} & [1.80] & {$[2.01]$} & {$[2.24]$} & {$[2.32]$} & [1.33] & {$[1.38]$} & {$[2.11]$} & {$[2.22]$} & [1.71] & [1.73] & [0.84] & {$[0.92]$} \\
\hline & $\{0.72\}$ & $\{0.63\}$ & $\{0.94\}$ & $\{0.83\}$ & $\{0.94\}$ & $\{0.63\}$ & $\{0.33\}$ & $\{0.53\}$ & $\{0.94\}$ & $\{0.83\}$ & $\{0.33\}$ & $\{0.53\}$ & $\{0.33\}$ & $\{0.63\}$ & & \\
\hline $\mathrm{P} t$ test & 0.42 & 0.94 & 0.43 & 0.47 & 0.91 & 0.56 & 0.15 & 0.36 & 0.64 & 0.83 & 0.25 & 0.78 & 0.38 & 0.94 & 0.48 & 0.22 \\
\hline No of observations & 2,541 & 2,548 & 3,201 & 3,273 & 2,594 & 2,578 & 2,585 & 2,567 & 2,589 & 2,574 & 2,590 & 2,571 & 2,577 & 2,557 & 2,533 & 2,521 \\
\hline No of individuals & 1,097 & 1,114 & 1,195 & 1,235 & 1,047 & 1,048 & 1,044 & 1,046 & 1,045 & 1,048 & 1,045 & 1,047 & 1,042 & 1,039 & 1,026 & 1,029 \\
\hline
\end{tabular}

Notes: FE results are from the regression (2). Non-cognitive skills are reported by teachers. Other explanatory variables include the child's characteristics (age, school sectors, and number of siblings), both parents' characteristics (age and education), local socio-economic background variables, state/territory dummies, year dummies, and survey quarters. NAPLAN test regressions also include test age and test years. P t test: P value of a t test for equality of maternal and paternal health estimates. Robust standard errors clustered at the individual level in square brackets. Adjusted $p$-values to account for multiple inference issue calculated using the Simes-Benjamini-Hochberg method are in curly brackets. The symbol *denotes unadjusted significance at the $10 \%$ level, **at the $5 \%$ level, and $* * *$ at the $1 \%$ level. 
Appendix Table A11: Parental health and child non-cognitive development - Heterogeneity by gender of the child

\begin{tabular}{|c|c|c|c|c|c|c|c|c|c|c|c|c|}
\hline \multirow[b]{3}{*}{ Health measures } & \multicolumn{2}{|c|}{$\begin{array}{l}\text { Prosociality } \\
\end{array}$} & \multicolumn{2}{|c|}{ "Hyperactivity (rev) } & \multicolumn{2}{|c|}{ Emotional (rev) } & \multicolumn{2}{|c|}{ Conduct (rev) } & \multicolumn{2}{|c|}{ Peer (rev) } & \multicolumn{2}{|c|}{ Non-cognitive index } \\
\hline & Daughter & Son & Daughter & Son & Daughter & Son & Daughter & Son & Daughter & Son & Daughter & Son \\
\hline & (1) & (2) & (3) & (4) & (5) & (6) & (7) & (8) & (9) & (10) & (11) & (12) \\
\hline Mother K6 (rev) & $\begin{array}{l}-0.03^{*} \\
{[0.02]} \\
\{0.38\}\end{array}$ & $\begin{array}{c}0.01 \\
{[0.02]} \\
\{0.76\}\end{array}$ & $\begin{array}{c}-0.03^{* *} \\
{[0.01]} \\
\{0.34\}\end{array}$ & $\begin{array}{c}-0.02 \\
{[0.02]} \\
\{0.66\}\end{array}$ & $\begin{array}{l}-0.02 * \\
{[0.01]} \\
\{0.38\}\end{array}$ & $\begin{array}{c}-0.01 \\
{[0.01]} \\
\{0.73\}\end{array}$ & $\begin{array}{l}-0.01 \\
{[0.01]} \\
\{0.38\}\end{array}$ & $\begin{array}{l}-0.00 \\
{[0.01]} \\
\{0.94\}\end{array}$ & $\begin{array}{l}-0.02 \\
{[0.01]} \\
\{0.56\}\end{array}$ & $\begin{array}{c}0.01 \\
{[0.01]} \\
\{0.66\}\end{array}$ & $\begin{array}{c}-0.02 * * * \\
{[0.01]}\end{array}$ & $\begin{array}{c}-0.00 \\
{[0.01]}\end{array}$ \\
\hline Father K6 (rev) & $\begin{array}{c}0.00 \\
{[0.02]} \\
\{0.95\}\end{array}$ & $\begin{array}{c}0.00 \\
{[0.02]} \\
\{0.89\}\end{array}$ & $\begin{array}{l}-0.01 \\
{[0.02]} \\
\{0.71\}\end{array}$ & $\begin{array}{c}-0.04 * * \\
{[0.02]} \\
\{0.27\}\end{array}$ & $\begin{array}{c}0.02 \\
{[0.01]} \\
\{0.57\}\end{array}$ & $\begin{array}{l}-0.02 * \\
{[0.01]} \\
\{0.27\}\end{array}$ & $\begin{array}{l}-0.02 \\
{[0.01]} \\
\{0.37\}\end{array}$ & $\begin{array}{l}-0.02 \\
{[0.01]} \\
\{0.33\}\end{array}$ & $\begin{array}{c}0.02 \\
{[0.01]} \\
\{0.37\}\end{array}$ & $\begin{array}{l}-0.02 \\
{[0.01]} \\
\{0.54\}\end{array}$ & $\begin{array}{c}0.00 \\
{[0.01]}\end{array}$ & $\begin{array}{c}-0.02 * \\
{[0.01]}\end{array}$ \\
\hline $\mathrm{Pt}$ test & 0.18 & 0.81 & 0.31 & 0.48 & 0.04 & 0.62 & 0.70 & 0.28 & 0.04 & 0.12 & 0.04 & 0.25 \\
\hline No of observations & 4,010 & 3,997 & 4,022 & 4,007 & 4,014 & 4,003 & 4,022 & 4,005 & 4,009 & 4,003 & 4,002 & 3,991 \\
\hline No of individuals & 1,251 & 1,259 & 1,254 & 1,260 & 1,252 & 1,259 & 1,255 & 1,260 & 1,249 & 1,260 & 1,249 & 1,258 \\
\hline Mother depressed & $\begin{array}{l}-0.01 \\
{[0.10]} \\
\{0.98\}\end{array}$ & $\begin{array}{c}0.07 \\
{[0.12]} \\
\{0.75\}\end{array}$ & $\begin{array}{c}0.13 \\
{[0.09]} \\
\{0.34\}\end{array}$ & $\begin{array}{l}-0.08 \\
{[0.12]} \\
\{0.75\}\end{array}$ & $\begin{array}{c}0.00 \\
{[0.09]} \\
\{0.99\}\end{array}$ & $\begin{array}{c}-0.05 \\
{[0.08]} \\
\{0.75\}\end{array}$ & $\begin{array}{l}0.09 * \\
{[0.05]} \\
\{0.34\}\end{array}$ & $\begin{array}{c}0.04 \\
{[0.07]} \\
\{0.75\}\end{array}$ & $\begin{array}{l}-0.08 \\
{[0.08]} \\
\{0.57\}\end{array}$ & $\begin{array}{l}-0.06 \\
{[0.08]} \\
\{0.75\}\end{array}$ & $\begin{array}{c}0.03 \\
{[0.05]}\end{array}$ & $\begin{array}{c}-0.01 \\
{[0.06]}\end{array}$ \\
\hline Father depressed & $\begin{array}{l}-0.13 \\
{[0.10]} \\
\{0.55\}\end{array}$ & $\begin{array}{c}0.07 \\
{[0.11]} \\
\{0.81\}\end{array}$ & $\begin{array}{l}-0.21^{* *} \\
{[0.09]} \\
\{0.25\}\end{array}$ & $\begin{array}{c}-0.26 * * \\
{[0.12]} \\
\{0.35\}\end{array}$ & $\begin{array}{l}-0.05 \\
{[0.08]} \\
\{0.60\}\end{array}$ & $\begin{array}{c}-0.08 \\
{[0.08]} \\
\{0.77\}\end{array}$ & $\begin{array}{c}-0.10^{* *} \\
{[0.05]} \\
\{0.25\}\end{array}$ & $\begin{array}{c}0.08 \\
{[0.06]} \\
\{0.77\}\end{array}$ & $\begin{array}{l}-0.07 \\
{[0.08]} \\
\{0.60\}\end{array}$ & $\begin{array}{c}0.01 \\
{[0.08]} \\
\{0.94\}\end{array}$ & $\begin{array}{c}-0.12 * * \\
{[0.05]}\end{array}$ & $\begin{array}{c}-0.03 \\
{[0.06]}\end{array}$ \\
\hline P t test & 0.40 & 1.00 & 0.01 & 0.30 & 0.65 & 0.75 & 0.01 & 0.70 & 0.89 & 0.51 & 0.05 & 0.75 \\
\hline No of observations & 3,504 & 3,536 & 3,517 & 3,546 & 3,507 & 3,542 & 3,516 & 3,544 & 3,502 & 3,542 & 3,494 & 3,530 \\
\hline No of individuals & 1,169 & 1,193 & 1,173 & 1,194 & 1,169 & 1,193 & 1,173 & 1,194 & 1,166 & 1,194 & 1,165 & 1,192 \\
\hline Mother general health & $\begin{array}{l}-0.04 \\
{[0.05]} \\
\{0.94\}\end{array}$ & $\begin{array}{l}-0.01 \\
{[0.06]} \\
\{0.89\}\end{array}$ & $\begin{array}{c}-0.10^{* *} \\
{[0.05]} \\
\{0.54\}\end{array}$ & $\begin{array}{c}0.06 \\
{[0.07]} \\
\{0.62\}\end{array}$ & $\begin{array}{l}-0.06 \\
{[0.05]} \\
\{0.76\}\end{array}$ & $\begin{array}{l}-0.06 \\
{[0.05]} \\
\{0.62\}\end{array}$ & $\begin{array}{l}-0.02 \\
{[0.03]} \\
\{0.98\}\end{array}$ & $\begin{array}{c}0.04 \\
{[0.04]} \\
\{0.62\}\end{array}$ & $\begin{array}{l}-0.03 \\
{[0.04]} \\
\{0.94\}\end{array}$ & $\begin{array}{c}0.02 \\
{[0.04]} \\
\{0.78\}\end{array}$ & $\begin{array}{l}-0.05 * \\
{[0.03]}\end{array}$ & $\begin{array}{c}0.01 \\
{[0.03]}\end{array}$ \\
\hline Father general health & $\begin{array}{l}0.09^{*} \\
{[0.06]} \\
\{0.33\}\end{array}$ & $\begin{array}{l}-0.05 \\
{[0.06]} \\
\{0.70\}\end{array}$ & $\begin{array}{c}0.02 \\
{[0.05]} \\
\{0.94\}\end{array}$ & $\begin{array}{c}-0.15^{* *} \\
{[0.07]} \\
\{0.27\}\end{array}$ & $\begin{array}{c}0.01 \\
{[0.05]} \\
\{0.94\}\end{array}$ & $\begin{array}{c}-0.02 \\
{[0.05]} \\
\{0.83\}\end{array}$ & $\begin{array}{c}0.01 \\
{[0.03]} \\
\{0.94\}\end{array}$ & $\begin{array}{l}-0.04 \\
{[0.04]} \\
\{0.63\}\end{array}$ & $\begin{array}{c}0.01 \\
{[0.05]} \\
\{0.94\}\end{array}$ & $\begin{array}{c}0.01 \\
{[0.04]} \\
\{0.83\}\end{array}$ & $\begin{array}{c}0.02 \\
{[0.03]}\end{array}$ & $\begin{array}{c}-0.05 \\
{[0.03]}\end{array}$ \\
\hline $\mathrm{P} t$ test & 0.10 & 0.67 & 0.10 & 0.03 & 0.32 & 0.50 & 0.61 & 0.16 & 0.52 & 0.87 & 0.10 & 0.21 \\
\hline No of observations & 4,010 & 3,997 & 4,022 & 4,007 & 4,014 & 4,003 & 4,022 & 4,005 & 4,009 & 4,003 & 4,002 & 3,991 \\
\hline No of individuals & 1,251 & 1,259 & 1,254 & 1,260 & 1,252 & 1,259 & 1,255 & 1,260 & 1,249 & 1,260 & 1,249 & 1,258 \\
\hline
\end{tabular}

Notes: FE results are from the regression (2). Non-cognitive skills are reported by teachers. Other explanatory variables include the child's characteristics (age, school sectors, and number of siblings), both parents' characteristics (age and education), local socio-economic background variables, state/territory dummies, year dummies, and survey quarters. $\mathrm{P} t$ test: $\mathrm{P}$ value of a $\mathrm{t}$ test for equality of maternal and paternal health estimates. Robust standard errors clustered at the individual level in square brackets. Adjusted $p$-values to account for multiple inference issue calculated using the Simes-Benjamini-Hochberg method are in curly brackets. The symbol *denotes unadjusted significance at the $10 \%$ level, **at the $5 \%$ level, and ***at the $1 \%$ level. 
Appendix Table A12: Heterogeneity of parental mental health K6 effects by survey waves

\begin{tabular}{|c|c|c|c|c|c|c|c|c|c|c|c|c|c|c|c|}
\hline & Estimates & PPVT & MR & "Reading & "Writing & "Spelling & Grammar & Numeracy & $\begin{array}{c}\text { Cognitive } \\
\text { index }\end{array}$ & "Prosociality & $\begin{array}{l}\begin{array}{l}\text { Hyperactivity } \\
\text { (rev) }\end{array}\end{array}$ & $\begin{array}{c}\text { Emotional } \\
\text { (rev) }\end{array}$ & $\begin{array}{c}\begin{array}{c}\text { Conduct } \\
\text { (rev) }\end{array}\end{array}$ & Peer (rev) & $\begin{array}{c}\text { Non- } \\
\text { cognitive } \\
\text { index }\end{array}$ \\
\hline & from & (1) & (2) & (3) & (4) & (5) & (6) & (7) & (8) & (9) & $(10)$ & (11) & (12) & (13) & (14) \\
\hline \multirow{12}{*}{ 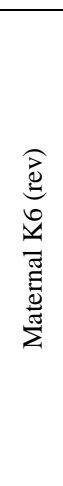 } & Wave 2 & -0.00 & & & & & & & & -0.04 & -0.02 & 0.00 & -0.03 & $-0.05^{*}$ & -0.03 \\
\hline & & {$[0.06]$} & & & & & & & & {$[0.04]$} & {$[0.03]$} & {$[0.03]$} & {$[0.02]$} & {$[0.03]$} & {$[0.02]$} \\
\hline & & $\{1.00\}$ & & & & & & & & $\{0.63\}$ & $\{0.85\}$ & $\{1.00\}$ & $\{0.57\}$ & $\{0.34\}$ & \\
\hline & Wave 3 & 0.01 & 0.04 & 0.25 & -0.37 & 0.34 & 0.34 & 0.04 & 0.13 & 0.00 & -0.03 & 0.00 & -0.00 & 0.01 & -0.00 \\
\hline & & {$[0.04]$} & [0.03] & {$[0.74]$} & [0.69] & {$[0.45]$} & {$[0.80]$} & {$[0.67]$} & [0.33] & {$[0.02]$} & {$[0.02]$} & {$[0.02]$} & {$[0.01]$} & {$[0.02]$} & {$[0.01]$} \\
\hline & & $\{0.95\}$ & $\{0.95\}$ & $\{0.95\}$ & $\{0.95\}$ & $\{0.95\}$ & $\{0.95\}$ & $\{0.95\}$ & & $\{0.95\}$ & $\{0.95\}$ & $\{0.95\}$ & $\{0.95\}$ & $\{0.95\}$ & \\
\hline & Wave 4 & & 0.02 & 0.52 & -0.86 & $0.51^{*}$ & 0.69 & 0.53 & 0.20 & -0.01 & -0.02 & -0.03 & 0.01 & 0.01 & -0.01 \\
\hline & & & {$[0.02]$} & {$[0.43]$} & {$[0.53]$} & {$[0.28]$} & {$[0.54]$} & [0.37] & {$[0.20]$} & {$[0.02]$} & {$[0.02]$} & {$[0.02]$} & {$[0.01]$} & {$[0.02]$} & {$[0.01]$} \\
\hline & & & $\{0.47\}$ & $\{0.46\}$ & $\{0.42\}$ & $\{0.42\}$ & $\{0.46\}$ & $\{0.45\}$ & & $\{0.71\}$ & $\{0.57\}$ & $\{0.42\}$ & $\{0.59\}$ & $\{0.79\}$ & \\
\hline & Wave 5 & & & & & & & & & 0.02 & -0.00 & -0.01 & 0.02 & 0.02 & 0.01 \\
\hline & & & & & & & & & & [0.03] & {$[0.03]$} & {$[0.02]$} & {$[0.01]$} & {$[0.02]$} & {$[0.01]$} \\
\hline & & & & & & & & & & $\{0.80\}$ & $\{0.85\}$ & $\{0.85\}$ & $\{0.65\}$ & $\{0.65\}$ & \\
\hline \multirow{12}{*}{ 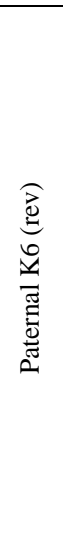 } & Wave 2 & $0.17^{* *}$ & & & & & & & & $-0.08^{* *}$ & $-0.12^{* *}$ & -0.03 & $-0.05^{*}$ & 0.00 & $-0.06^{* *}$ \\
\hline & & {$[0.07]$} & & & & & & & & {$[0.04]$} & {$[0.05]$} & {$[0.03]$} & {$[0.03]$} & {$[0.03]$} & {$[0.02]$} \\
\hline & & $\{0.05\}$ & & & & & & & & $\{0.06\}$ & $\{0.05\}$ & $\{0.38\}$ & $\{0.09\}$ & $\{0.89\}$ & \\
\hline & Wave 3 & 0.04 & -0.02 & -0.17 & 0.36 & -0.08 & -0.28 & $-1.14^{* *}$ & -0.16 & 0.02 & 0.01 & -0.01 & $-0.03^{* *}$ & 0.00 & -0.00 \\
\hline & & [0.03] & {$[0.02]$} & [0.57] & [0.67] & {$[0.40]$} & {$[0.65]$} & {$[0.56]$} & {$[0.28]$} & {$[0.02]$} & {$[0.02]$} & {$[0.02]$} & {$[0.01]$} & {$[0.02]$} & {$[0.01]$} \\
\hline & & $\{0.84\}$ & $\{0.84\}$ & $\{0.84\}$ & $\{0.84\}$ & $\{0.84\}$ & $\{0.84\}$ & $\{0.26\}$ & & $\{0.84\}$ & $\{0.84\}$ & $\{0.84\}$ & $\{0.16\}$ & $\{0.84\}$ & \\
\hline & Wave 4 & & 0.03 & 0.12 & 0.35 & 0.24 & 0.71 & 0.38 & 0.24 & $0.05^{* *}$ & 0.01 & $0.04^{*}$ & 0.01 & 0.02 & $0.03 * *$ \\
\hline & & & {$[0.03]$} & [0.51] & [0.59] & [0.39] & [0.59] & {$[0.42]$} & {$[0.24]$} & {$[0.03]$} & {$[0.02]$} & {$[0.02]$} & {$[0.01]$} & {$[0.02]$} & {$[0.01]$} \\
\hline & & & $\{0.63\}$ & $\{0.81\}$ & $\{0.66\}$ & $\{0.66\}$ & $\{0.63\}$ & $\{0.63\}$ & & $\{0.33\}$ & $\{0.69\}$ & $\{0.33\}$ & $\{0.66\}$ & $\{0.63\}$ & \\
\hline & Wave 5 & & & & & & & & & -0.01 & -0.05 & -0.02 & -0.02 & 0.02 & -0.02 \\
\hline & & & & & & & & & & [0.03] & [0.03] & {$[0.02]$} & {$[0.02]$} & {$[0.02]$} & {$[0.02]$} \\
\hline & & & & & & & & & & $\{0.91\}$ & $\{0.66\}$ & $\{0.84\}$ & $\{0.84\}$ & $\{0.84\}$ & \\
\hline
\end{tabular}

Notes: FE results are from the regression (2). Respective estimates for maternal and paternal health variables are from the same regressions. Non-cognitive skills are reported by teachers. Other explanatory variables include the child's characteristics (age, school sectors, and number of siblings), both parents' characteristics (age and education), local socio-economic background variables, state/territory dummies, year dummies, and survey quarters. NAPLAN test regressions also include test age and test years. Robust standard errors clustered at the individual level in square brackets. Adjusted $p$-values to account for multiple inference issue calculated using the Simes-Benjamini-Hochberg method are in curly brackets. The symbol *denotes unadjusted significance at the $10 \%$ level, **at the $5 \%$ level, and ***at the $1 \%$ level. 
Appendix Table A13: Heterogeneity of parental depression effects by survey waves

\begin{tabular}{|c|c|c|c|c|c|c|c|c|c|c|c|c|c|c|c|}
\hline & & $\begin{array}{l}\text { PPVT } \\
\end{array}$ & MR & Reading & Writing & Spelling & Grammar & "Numeracy & $\begin{array}{c}\text { Cognitive } \\
\text { index }\end{array}$ & Prosociality & $\begin{array}{c}\text { Hyperactivity } \\
\text { (rev) }\end{array}$ & $\begin{array}{c}\text { Emotional } \\
\text { (rev) }\end{array}$ & $\begin{array}{c}\text { Conduct } \\
\text { (rev) }\end{array}$ & Peer (rev) & $\begin{array}{c}\text { Non- } \\
\text { cognitive } \\
\text { index }\end{array}$ \\
\hline & $\begin{array}{c}\text { Estimates } \\
\text { from }\end{array}$ & (1) & (2) & (3) & (4) & (5) & (6) & (7) & (8) & (9) & (10) & (11) & (12) & (13) & (14) \\
\hline \multirow{9}{*}{ 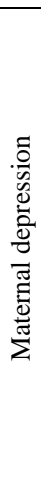 } & Waye 3 & -0.17 & 0.15 & $-7.47^{* *}$ & -2.71 & -2.97 & -4.55 & 0.19 & $-2.73^{*}$ & -0.07 & -0.08 & $0.22^{* *}$ & $\begin{array}{l}-0.02 \\
\end{array}$ & -0.08 & -0.00 \\
\hline & & {$[0.22]$} & [0.15] & [3.79] & [3.92] & [2.77] & [3.97] & [3.82] & [1.60] & [0.13] & {$[0.12]$} & {$[0.11]$} & {$[0.08]$} & {$[0.09]$} & {$[0.07]$} \\
\hline & & $\{0.66\}$ & $\{0.66\}$ & $\{0.29\}$ & $\{0.66\}$ & $\{0.66\}$ & $\{0.66\}$ & $\{0.96\}$ & & $\{0.73\}$ & $\{0.66\}$ & $\{0.29\}$ & $\{0.86\}$ & $\{0.66\}$ & \\
\hline & Waye 4 & & 0.17 & -2.48 & -0.08 & 0.73 & 3.15 & 3.16 & 0.66 & 0.05 & 0.12 & -0.09 & $0.12^{*}$ & -0.06 & 0.03 \\
\hline & & & {$[0.14]$} & {$[2.65]$} & [3.49] & [1.78] & [3.27] & [2.45] & [1.23] & {$[0.14]$} & [0.13] & {$[0.11]$} & {$[0.07]$} & {$[0.11]$} & {$[0.08]$} \\
\hline & & & $\{0.64\}$ & $\{0.64\}$ & $\{0.98\}$ & $\{0.78\}$ & $\{0.64\}$ & $\{0.64\}$ & & $\{0.78\}$ & $\{0.64\}$ & $\{0.64\}$ & $\{0.64\}$ & $\{0.78\}$ & \\
\hline & Waye 5 & & & & & & & & & 0.09 & $0.29 *$ & 0.03 & $0.15^{*}$ & -0.06 & 0.10 \\
\hline & & & & & & & & & & [0.15] & {$[0.15]$} & {$[0.11]$} & [0.09] & {$[0.11]$} & {$[0.08]$} \\
\hline & & & & & & & & & & $\{0.71\}$ & $\{0.21\}$ & $\{0.78\}$ & $\{0.21\}$ & $\{0.71\}$ & \\
\hline \multirow{9}{*}{ 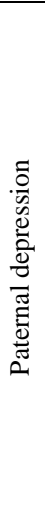 } & Wave 3 & 0.17 & 0.21 & -0.05 & 0.05 & -0.76 & 1.97 & -2.89 & 0.26 & 0.20 & 0.05 & $-0.16^{*}$ & 0.06 & 0.08 & 0.04 \\
\hline & & [0.22] & [0.14] & [3.24] & [3.46] & [2.19] & [3.88] & [3.05] & [1.37] & [0.12] & [0.12] & [0.09] & {$[0.07]$} & {$[0.09]$} & {$[0.07]$} \\
\hline & & $\{0.75\}$ & $\{0.53\}$ & $\{0.99\}$ & $\{0.99\}$ & $\{0.87\}$ & $\{0.87\}$ & $\{0.75\}$ & & $\{0.53\}$ & $\{0.87\}$ & $\{0.53\}$ & $\{0.75\}$ & $\{0.75\}$ & \\
\hline & Wave 4 & & -0.06 & -1.21 & -4.45 & $3.55^{*}$ & -0.44 & 0.68 & -0.11 & 0.13 & -0.02 & -0.02 & $0.13^{*}$ & 0.02 & 0.05 \\
\hline & & & {$[0.15]$} & [2.73] & [3.31] & [1.91] & [3.24] & {$[2.42]$} & {$[1.27]$} & {$[0.13]$} & {$[0.13]$} & {$[0.11]$} & {$[0.07]$} & {$[0.10]$} & {$[0.07]$} \\
\hline & & & $\{0.89\}$ & $\{0.89\}$ & $\{0.66\}$ & $\{0.47\}$ & $\{0.89\}$ & $\{0.89\}$ & & $\{0.89\}$ & $\{0.89\}$ & $\{0.89\}$ & $\{0.47\}$ & $\{0.89\}$ & \\
\hline & Wave 5 & & & & & & & & & 0.01 & $-0.30^{* *}$ & 0.02 & -0.10 & -0.00 & -0.07 \\
\hline & & & & & & & & & & [0.15] & {$[0.15]$} & {$[0.12]$} & [0.09] & {$[0.11]$} & {$[0.08]$} \\
\hline & & & & & & & & & & $\{0.99\}$ & $\{0.24\}$ & $\{0.99\}$ & $\{0.59\}$ & $\{0.99\}$ & \\
\hline
\end{tabular}

Notes: FE results are from the regression (2). Respective estimates for maternal and paternal health variables are from the same regressions. Non-cognitive skills are reported by teachers. Other explanatory variables include the child's characteristics (age, school sectors, and number of siblings), both parents' characteristics (age and education), local socio-economic background variables, state/territory dummies, year dummies, and survey quarters. NAPLAN test regressions also include test age and test years. Robust standard errors clustered at the individual level in square brackets. Adjusted $p$-values to account for multiple inference issue calculated using the Simes-Benjamini-Hochberg method are in curly brackets. The symbol *denotes unadjusted significance at the $10 \%$ level, **at the $5 \%$ level, and ***at the $1 \%$ level. 
Appendix Table A14: Heterogeneity of parental general health effects by survey waves

\begin{tabular}{|c|c|c|c|c|c|c|c|c|c|c|c|c|c|c|c|}
\hline & & $\begin{array}{l}\text { PPVT } \\
\end{array}$ & MR & Reading & Writing & "Spelling & Grammar & Numeracy & $\begin{array}{c}\text { Cognitive } \\
\text { index }\end{array}$ & Prosociality & $\begin{array}{c}\text { Hyperactivity } \\
\text { (rev) }\end{array}$ & $\begin{array}{c}\text { Emotional } \\
\text { (rev) }\end{array}$ & $\begin{array}{c}\begin{array}{c}\text { Conduct } \\
\text { (rev) }\end{array}\end{array}$ & Peer (rev) & $\begin{array}{c}\text { Non- } \\
\text { cognitive } \\
\text { index }\end{array}$ \\
\hline & from & (1) & (2) & (3) & (4) & (5) & (6) & (7) & (8) & (9) & (10) & (11) & (12) & (13) & (14) \\
\hline \multirow{12}{*}{ 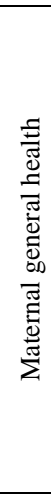 } & Wave 2 & 0.04 & & & & & & & & $0.24^{*}$ & 0.04 & 0.08 & $0.17^{* *}$ & $0.20 * *$ & $0.15^{* *}$ \\
\hline & & {$[0.24]$} & & & & & & & & {$[0.13]$} & {$[0.13]$} & [0.11] & {$[0.08]$} & {$[0.09]$} & {$[0.07]$} \\
\hline & & $\{0.88\}$ & & & & & & & & $\{0.12\}$ & $\{0.88\}$ & $\{0.75\}$ & $\{0.11\}$ & $\{0.11\}$ & \\
\hline & Wave 3 & 0.01 & 0.05 & 2.77 & 2.13 & 1.08 & 3.66 & 0.80 & $1.94 * *$ & 0.07 & 0.00 & 0.01 & 0.04 & -0.04 & 0.01 \\
\hline & & [0.13] & [0.09] & [2.23] & {$[2.27]$} & [1.48] & [2.57] & [2.05] & [0.98] & {$[0.08]$} & {$[0.08]$} & {$[0.07]$} & {$[0.05]$} & {$[0.06]$} & {$[0.04]$} \\
\hline & & $\{1.00\}$ & $\{0.93\}$ & $\{0.84\}$ & $\{0.84\}$ & $\{0.84\}$ & $\{0.84\}$ & $\{0.93\}$ & & $\{0.84\}$ & $\{1.00\}$ & $\{1.00\}$ & $\{0.84\}$ & $\{0.84\}$ & \\
\hline & Wave 4 & & 0.04 & -2.04 & -1.79 & 0.65 & -1.87 & 0.36 & -0.60 & -0.05 & -0.02 & -0.05 & -0.01 & 0.02 & -0.02 \\
\hline & & & {$[0.08]$} & [1.69] & [1.97] & [1.11] & [1.98] & [1.48] & [0.72] & {$[0.08]$} & {$[0.09]$} & {$[0.07]$} & [0.04] & {$[0.06]$} & {$[0.04]$} \\
\hline & & & $\{0.88\}$ & $\{0.88\}$ & $\{0.88\}$ & $\{0.88\}$ & $\{0.88\}$ & $\{0.88\}$ & & $\{0.88\}$ & $\{0.88\}$ & $\{0.88\}$ & $\{0.88\}$ & $\{0.88\}$ & \\
\hline & Wave 5 & & & & & & & & & -0.07 & 0.05 & -0.03 & 0.05 & 0.05 & 0.01 \\
\hline & & & & & & & & & & [0.09] & [0.09] & {$[0.07]$} & [0.05] & {$[0.07]$} & {$[0.05]$} \\
\hline & & & & & & & & & & $\{0.66\}$ & $\{0.66\}$ & $\{0.66\}$ & $\{0.66\}$ & $\{0.66\}$ & \\
\hline \multirow{12}{*}{ 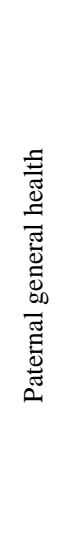 } & Wave 2 & 0.17 & & & & & & & & -0.10 & -0.06 & 0.16 & -0.07 & 0.06 & -0.00 \\
\hline & & {$[0.24]$} & & & & & & & & {$[0.14]$} & [0.13] & [0.11] & [0.09] & {$[0.10]$} & {$[0.08]$} \\
\hline & & $\{0.65\}$ & & & & & & & & $\{0.65\}$ & $\{0.65\}$ & $\{0.65\}$ & $\{0.65\}$ & $\{0.65\}$ & \\
\hline & Wave 3 & -0.05 & 0.08 & -3.27 & -1.35 & -0.06 & 3.00 & 1.61 & -0.42 & -0.04 & -0.00 & 0.12 & -0.03 & 0.10 & 0.02 \\
\hline & & {$[0.14]$} & [0.09] & [2.34] & {$[2.34]$} & [1.61] & [2.56] & [2.08] & [0.99] & {$[0.08]$} & {$[0.08]$} & {$[0.07]$} & [0.05] & {$[0.06]$} & {$[0.04]$} \\
\hline & & $\{0.88\}$ & $\{0.78\}$ & $\{0.65\}$ & $\{0.83\}$ & $\{0.97\}$ & $\{0.73\}$ & $\{0.78\}$ & & $\{0.83\}$ & $\{0.97\}$ & $\{0.65\}$ & $\{0.78\}$ & $\{0.65\}$ & \\
\hline & Wave 4 & & 0.11 & 0.01 & 0.90 & 0.81 & 2.68 & 0.80 & 0.57 & 0.05 & 0.04 & -0.09 & 0.00 & -0.07 & -0.01 \\
\hline & & & {$[0.09]$} & [1.60] & {$[2.24]$} & [1.12] & [1.99] & [1.46] & {$[0.76]$} & {$[0.08]$} & {$[0.08]$} & {$[0.07]$} & [0.04] & {$[0.07]$} & {$[0.04]$} \\
\hline & & & $\{0.81\}$ & $\{1.00\}$ & $\{0.84\}$ & $\{0.84\}$ & $\{0.81\}$ & $\{0.84\}$ & & $\{0.84\}$ & $\{0.84\}$ & $\{0.81\}$ & $\{1.00\}$ & $\{0.84\}$ & \\
\hline & Wave 5 & & & & & & & & & 0.12 & -0.07 & -0.09 & -0.00 & 0.03 & -0.01 \\
\hline & & & & & & & & & & {$[0.09]$} & [0.10] & {$[0.07]$} & {$[0.05]$} & {$[0.06]$} & {$[0.05]$} \\
\hline & & & & & & & & & & $\{0.52\}$ & $\{0.73\}$ & $\{0.52\}$ & $\{0.96\}$ & $\{0.76\}$ & \\
\hline
\end{tabular}

Notes: FE results are from the regression (2). Respective estimates for maternal and paternal health variables are from the same regressions. Non-cognitive skills are reported by teachers. Other explanatory variables include the child's characteristics (age, school sectors, and number of siblings), both parents' characteristics (age and education), local socio-economic background variables, state/territory dummies, year dummies, and survey quarters. NAPLAN test regressions also include test age and test years. Robust standard errors clustered at the individual level in square brackets. Adjusted $p$-values to account for multiple inference issue calculated using the Simes-Benjamini-Hochberg method are in curly brackets. The symbol *denotes unadjusted significance at the $10 \%$ level, **at the $5 \%$ level, and ***at the $1 \%$ level. 
Appendix Table A15: Parental health and child cognitive development - Heterogeneity by household income

\begin{tabular}{|c|c|c|c|c|c|c|c|c|c|c|c|c|c|c|c|c|}
\hline \multirow[b]{3}{*}{ Health measures } & \multicolumn{2}{|c|}{$\begin{array}{l}\text { PPVT } \\
\end{array}$} & \multicolumn{2}{|c|}{ MR } & \multicolumn{2}{|c|}{ Reading } & \multicolumn{2}{|c|}{ Writing } & \multicolumn{2}{|c|}{ Spelling } & \multicolumn{2}{|c|}{ Grammar } & \multicolumn{2}{|c|}{ Numeracy } & \multicolumn{2}{|c|}{ Cognitive index } \\
\hline & Low & High & Low & High & Low & High & Low & High & Low & High & Low & High & Low & High & Low & High \\
\hline & (1) & (2) & (3) & (4) & (5) & (6) & (7) & (8) & (9) & (10) & (11) & (12) & (13) & (14) & (15) & (16) \\
\hline \multirow[t]{2}{*}{ Mother K6 (rev) } & 0.04 & -0.00 & 0.03 & 0.02 & 0.07 & 0.55 & -0.63 & -0.55 & -0.39 & $1.05^{* * *}$ & 0.66 & 0.96 & 0.04 & 0.51 & -0.06 & $0.41^{*}$ \\
\hline & {$[0.05]$} & {$[0.06]$} & {$[0.02]$} & {$[0.03]$} & {$[0.62]$} & {$[0.55]$} & {$[0.66]$} & {$[0.65]$} & {$[0.44]$} & {$[0.39]$} & {$[0.70]$} & {$[0.73]$} & {$[0.53]$} & {$[0.55]$} & {$[0.31]$} & {$[0.25]$} \\
\hline \multirow[t]{3}{*}{ Father K6 (rev) } & $0.11^{* *}$ & 0.04 & -0.03 & -0.00 & -0.18 & -0.35 & 0.11 & 0.72 & -0.30 & 0.51 & 0.16 & 0.30 & -0.52 & -0.72 & -0.11 & 0.09 \\
\hline & {$[0.05]$} & {$[0.05]$} & {$[0.02]$} & {$[0.03]$} & [0.59] & {$[0.60]$} & {$[0.76]$} & {$[0.65]$} & {$[0.46]$} & {$[0.39]$} & {$[0.65]$} & {$[0.68]$} & {$[0.50]$} & {$[0.57]$} & {$[0.30]$} & {$[0.26]$} \\
\hline & $\{0.38\}$ & $\{0.68\}$ & $\{0.67\}$ & $\{0.95\}$ & $\{0.88\}$ & $\{0.88\}$ & $\{0.88\}$ & $\{0.63\}$ & $\{0.88\}$ & $\{0.63\}$ & $\{0.88\}$ & $\{0.88\}$ & $\{0.73\}$ & $\{0.63\}$ & & \\
\hline $\mathrm{Pt}$ test & 0.32 & 0.49 & 0.12 & 0.53 & 0.78 & 0.26 & 0.45 & 0.16 & 0.90 & 0.33 & 0.63 & 0.52 & 0.44 & 0.12 & 0.91 & 0.36 \\
\hline No of observations & 2,460 & 2,629 & 3,135 & 3,339 & 2,482 & 2,690 & 2,473 & 2,679 & 2,477 & 2,686 & 2,477 & 2,684 & 2,465 & 2,669 & 2,433 & 2,621 \\
\hline No of individuals & 1,377 & 1,447 & 1,568 & 1,610 & 1,309 & 1,364 & 1,306 & 1,358 & 1,307 & 1,360 & 1,306 & 1,359 & 1,302 & 1,353 & 1,284 & 1,326 \\
\hline \multirow[t]{3}{*}{ Mother depressed } & -0.01 & -0.47 & 0.07 & 0.20 & $-8.73^{* *}$ & -0.87 & -5.20 & -0.93 & 0.22 & 1.32 & 1.55 & -1.99 & -2.66 & 1.23 & -2.82 & -0.46 \\
\hline & {$[0.34]$} & {$[0.36]$} & {$[0.15]$} & {$[0.16]$} & [3.71] & {$[3.24]$} & {$[4.58]$} & {$[3.87]$} & {$[2.84]$} & {$[2.39]$} & {$[3.90]$} & [3.91] & {$[3.42]$} & {$[3.37]$} & {$[1.78]$} & [1.44] \\
\hline & $\{0.98\}$ & $\{0.63\}$ & $\{0.88\}$ & $\{0.63\}$ & $\{0.23\}$ & $\{0.81\}$ & $\{0.88\}$ & $\{0.81\}$ & $\{0.98\}$ & $\{0.81\}$ & $\{0.88\}$ & $\{0.81\}$ & $\{0.88\}$ & $\{0.81\}$ & & \\
\hline \multirow[t]{3}{*}{ Father depressed } & 0.17 & 0.34 & 0.02 & 0.07 & 0.95 & -0.65 & 3.44 & -1.66 & 2.06 & 2.42 & 3.42 & -1.54 & -1.97 & 0.49 & 1.72 & -0.07 \\
\hline & {$[0.36]$} & {$[0.34]$} & {$[0.14]$} & {$[0.17]$} & [3.38] & {$[3.35]$} & {$[3.86]$} & [3.68] & {$[2.26]$} & [2.27] & {$[3.76]$} & {$[3.77]$} & [3.39] & [3.13] & [1.59] & [1.42] \\
\hline & $\{0.91\}$ & $\{0.83\}$ & $\{0.91\}$ & $\{0.83\}$ & $\{0.91\}$ & $\{0.87\}$ & $\{0.91\}$ & $\{0.83\}$ & $\{0.91\}$ & $\{0.83\}$ & $\{0.91\}$ & $\{0.83\}$ & $\{0.91\}$ & $\{0.87\}$ & & \\
\hline $\mathrm{P}$ t test & 0.73 & 0.09 & 0.79 & 0.59 & 0.04 & 0.96 & 0.14 & 0.90 & 0.60 & 0.75 & 0.73 & 0.94 & 0.88 & 0.88 & 0.05 & 0.85 \\
\hline No of observations & 1,847 & 1,939 & 3,106 & 3,312 & 2,457 & 2,662 & 2,448 & 2,651 & 2,452 & 2,658 & 2,452 & 2,656 & 2,439 & 2,641 & 2,407 & 2,593 \\
\hline No of individuals & 1,123 & 1,169 & 1,560 & 1,602 & 1,298 & 1,352 & 1,295 & 1,346 & 1,296 & 1,348 & 1,295 & 1,347 & 1,290 & 1,341 & 1,272 & 1,314 \\
\hline \multirow[t]{3}{*}{ Mother general health } & -0.04 & 0.02 & 0.12 & 0.08 & -0.05 & 1.29 & -1.59 & 1.24 & -0.64 & 1.66 & $3.99 *$ & 3.53 & 1.89 & 0.19 & 1.10 & 1.27 \\
\hline & {$[0.19]$} & {$[0.18]$} & {$[0.09]$} & {$[0.10]$} & [2.12] & {$[2.07]$} & {$[2.60]$} & {$[2.14]$} & {$[1.54]$} & [1.32] & {$[2.12]$} & {$[2.40]$} & [1.79] & {$[1.84]$} & {$[0.97]$} & {$[0.90]$} \\
\hline & $\{0.93\}$ & $\{0.92\}$ & $\{0.68\}$ & $\{0.76\}$ & $\{0.98\}$ & $\{0.76\}$ & $\{0.92\}$ & $\{0.76\}$ & $\{0.92\}$ & $\{0.68\}$ & $\{0.36\}$ & $\{0.68\}$ & $\{0.88\}$ & $\{0.92\}$ & & \\
\hline \multirow{3}{*}{ Father general health } & -0.14 & $0.34 * *$ & 0.03 & 0.01 & -0.06 & -0.97 & $4.90 *$ & $-4.36 *$ & 0.40 & 0.57 & 2.19 & 3.43 & 0.17 & -1.94 & 0.91 & -0.71 \\
\hline & {$[0.21]$} & {$[0.17]$} & {$[0.09]$} & {$[0.10]$} & [2.10] & {$[2.16]$} & {$[2.67]$} & [2.36] & [1.66] & {$[1.36]$} & {$[2.50]$} & {$[2.41]$} & [1.97] & {$[1.90]$} & {$[1.02]$} & {$[0.94]$} \\
\hline & $\{0.98\}$ & $\{0.39\}$ & $\{0.98\}$ & $\{0.95\}$ & $\{0.98\}$ & $\{0.85\}$ & $\{0.80\}$ & $\{0.39\}$ & $\{0.98\}$ & $\{0.85\}$ & $\{0.98\}$ & $\{0.62\}$ & $\{0.98\}$ & $\{0.74\}$ & & \\
\hline $\mathrm{Pt}$ test & 0.73 & 0.19 & 0.47 & 0.60 & 1.00 & 0.42 & 0.10 & 0.08 & 0.65 & 0.54 & 0.61 & 0.98 & 0.53 & 0.41 & 0.90 & 0.10 \\
\hline No of observations & 2,460 & 2,629 & 3,135 & 3,339 & 2,482 & 2,690 & 2,473 & 2,679 & 2,477 & 2,686 & 2,477 & 2,684 & 2,465 & 2,669 & 2,433 & 2,621 \\
\hline No of individuals & 1,377 & 1,447 & 1,568 & 1,610 & 1,309 & 1,364 & 1,306 & 1,358 & 1,307 & 1,360 & 1,306 & 1,359 & 1,302 & 1,353 & 1,284 & 1,326 \\
\hline
\end{tabular}

Notes: FE results are from the regression (2). "Low" ("High”) refers to a sub-sample of children from households with income below (not below) the median. Other explanatory variables include the child's characteristics (age, school sectors, and number of siblings), both parents' characteristics (age and education), local socio-economic background variables, state/territory dummies, year dummies, and survey quarters. NAPLAN test regressions also include test age and test years. P t test: $\mathrm{P}$ value of a t test for equality of maternal and paternal health estimates. Robust standard errors clustered at the individual level in square brackets. Adjusted $p$-values to account for multiple inference issue calculated using the Simes-Benjamini-Hochberg method are in curly brackets. The symbol *denotes unadjusted significance at the $10 \%$ level, **at the $5 \%$ level, and ***at the $1 \%$ level. 
Appendix Table A16: Parental health and child non-cognitive development - Heterogeneity by household annual income

\begin{tabular}{|c|c|c|c|c|c|c|c|c|c|c|c|c|}
\hline \multirow[b]{3}{*}{ Health measures } & \multicolumn{2}{|c|}{ Prosociality } & \multicolumn{2}{|c|}{ Hyperactivity (rev) } & \multicolumn{2}{|c|}{ Emotional (rev) } & \multicolumn{2}{|c|}{$\begin{array}{l}\text { Conduct (rev) } \\
\end{array}$} & \multicolumn{2}{|c|}{$\begin{array}{l}\text { Peer (rev) } \\
\text { Per }\end{array}$} & \multicolumn{2}{|c|}{$\begin{array}{l}\text { Non-cognitive index } \\
\end{array}$} \\
\hline & Low & High & Low & High & Low & High & Low & High & Low & High & Low & High \\
\hline & (1) & (2) & (3) & (4) & (5) & (6) & (7) & (8) & (9) & (10) & (11) & (12) \\
\hline \multirow[t]{3}{*}{ Mother K6 (rev) } & -0.00 & -0.02 & -0.01 & $-0.04 * *$ & $-0.03 * *$ & 0.00 & -0.00 & -0.01 & 0.01 & 0.01 & -0.01 & -0.01 \\
\hline & {$[0.02]$} & {$[0.02]$} & {$[0.02]$} & {$[0.02]$} & {$[0.02]$} & {$[0.02]$} & {$[0.01]$} & {$[0.01]$} & {$[0.01]$} & {$[0.02]$} & {$[0.01]$} & {$[0.01$} \\
\hline & $\{0.94\}$ & $\{0.51\}$ & $\{0.74\}$ & $\{0.28\}$ & $\{0.57\}$ & $\{0.89\}$ & $\{0.94\}$ & $\{0.51\}$ & $\{0.94\}$ & $\{0.51\}$ & & \\
\hline \multirow[t]{3}{*}{ Father K6 (rev) } & 0.01 & -0.00 & -0.03 & -0.03 & -0.01 & -0.01 & $-0.02 *$ & $-0.03^{*}$ & -0.01 & 0.01 & -0.01 & -0.01 \\
\hline & {$[0.02]$} & {$[0.02]$} & {$[0.02]$} & {$[0.02]$} & {$[0.01]$} & {$[0.01]$} & {$[0.01]$} & {$[0.01]$} & {$[0.01]$} & {$[0.02]$} & {$[0.01]$} & {$[0.01$} \\
\hline & $\{0.88\}$ & $\{0.95\}$ & $\{0.62\}$ & $\{0.63\}$ & $\{0.88\}$ & $\{0.88\}$ & $\{0.46\}$ & $\{0.63\}$ & $\{0.88\}$ & $\{0.91\}$ & & \\
\hline $\mathrm{P} t$ test & 0.68 & 0.50 & 0.61 & 0.59 & 0.27 & 0.59 & 0.21 & 0.29 & 0.53 & 0.72 & 0.87 & 0.98 \\
\hline No of observations & 3,843 & 4,165 & 3,857 & 4,173 & 3,854 & 4,164 & 3,856 & 4,172 & 3,848 & 4,165 & 3,839 & 4,155 \\
\hline No of individuals & 1,730 & 1,743 & 1,734 & 1,745 & 1,733 & 1,742 & 1,735 & 1,744 & 1,729 & 1,740 & 1,727 & 1,739 \\
\hline \multirow[t]{3}{*}{ Mother depressed } & -0.06 & 0.17 & 0.06 & -0.06 & -0.05 & 0.02 & 0.03 & 0.08 & -0.04 & -0.06 & -0.01 & 0.05 \\
\hline & {$[0.12]$} & [0.11] & {$[0.12]$} & {$[0.12]$} & {$[0.09]$} & {$[0.09]$} & {$[0.07]$} & {$[0.06]$} & {$[0.09]$} & {$[0.09]$} & {$[0.07]$} & {$[0.06$} \\
\hline & $\{0.88\}$ & $\{0.63\}$ & $\{0.88\}$ & $\{0.81\}$ & $\{0.88\}$ & $\{0.81\}$ & $\{0.88\}$ & $\{0.63\}$ & $\{0.88\}$ & $\{0.81\}$ & & \\
\hline \multirow[t]{3}{*}{ Father depressed } & 0.03 & 0.06 & $-0.20 *$ & $-0.24 * *$ & 0.03 & $-0.19 * *$ & -0.01 & -0.05 & -0.06 & 0.04 & -0.04 & -0.08 \\
\hline & {$[0.12]$} & [0.12] & {$[0.12]$} & {$[0.11]$} & {$[0.10]$} & {$[0.08]$} & {$[0.06]$} & {$[0.07]$} & {$[0.09]$} & {$[0.08]$} & {$[0.07]$} & {$[0.06$} \\
\hline & $\{0.91\}$ & $\{0.83\}$ & $\{0.91\}$ & $\{0.17\}$ & $\{0.91\}$ & $\{0.17\}$ & $\{0.91\}$ & $\{0.83\}$ & $\{0.91\}$ & $\{0.83\}$ & & \\
\hline $\mathrm{P} t$ test & 0.61 & 0.51 & 0.14 & 0.25 & 0.57 & 0.08 & 0.74 & 0.15 & 0.87 & 0.41 & 0.79 & 0.12 \\
\hline No of observations & 3,395 & 3,646 & 3,362 & 3,702 & 3,359 & 3,691 & 3,359 & 3,702 & 3,351 & 3,694 & 3,342 & 3,683 \\
\hline No of individuals & 1,594 & 1,590 & 1,576 & 1,600 & 1,575 & 1,595 & 1,576 & 1,600 & 1,570 & 1,595 & 1,568 & 1,593 \\
\hline \multirow[t]{3}{*}{ Mother general health } & 0.03 & -0.04 & -0.03 & -0.01 & $-0.10^{*}$ & -0.07 & 0.01 & 0.04 & -0.02 & 0.03 & -0.02 & -0.01 \\
\hline & {$[0.06]$} & {$[0.07]$} & {$[0.06]$} & {$[0.07]$} & {$[0.05]$} & {$[0.05]$} & {$[0.03]$} & {$[0.04]$} & {$[0.05]$} & {$[0.05]$} & {$[0.03]$} & {$[0.03$} \\
\hline & $\{0.92\}$ & $\{0.76\}$ & $\{0.92\}$ & $\{0.92\}$ & $\{0.36\}$ & $\{0.68\}$ & $\{0.93\}$ & $\{0.68\}$ & $\{0.92\}$ & $\{0.76\}$ & & \\
\hline \multirow[t]{3}{*}{ Father general health } & 0.06 & 0.08 & -0.04 & -0.04 & 0.01 & 0.02 & 0.01 & 0.01 & 0.07 & 0.02 & 0.01 & 0.02 \\
\hline & {$[0.06]$} & [0.07] & {$[0.06]$} & {$[0.07]$} & {$[0.06]$} & {$[0.05]$} & {$[0.04]$} & {$[0.04]$} & {$[0.05]$} & {$[0.05]$} & {$[0.04]$} & {$[0.04$} \\
\hline & $\{0.98\}$ & $\{0.73\}$ & $\{0.98\}$ & $\{0.85\}$ & $\{0.98\}$ & $\{0.85\}$ & $\{0.98\}$ & $\{0.85\}$ & $\{0.98\}$ & $\{0.85\}$ & & \\
\hline $\mathrm{P} t$ test & 0.75 & 0.22 & 0.90 & 0.79 & 0.18 & 0.20 & 0.91 & 0.55 & 0.22 & 0.86 & 0.48 & 0.55 \\
\hline No of observations & 3,843 & 4,165 & 3,857 & 4,173 & 3,854 & 4,164 & 3,856 & 4,172 & 3,848 & 4,165 & 3,839 & 4,155 \\
\hline No of individuals & 1,730 & 1,743 & 1,734 & 1,745 & 1,733 & 1,742 & 1,735 & 1,744 & 1,729 & 1,740 & 1,727 & 1,739 \\
\hline
\end{tabular}

Notes: FE results are from the regression (2). "Low" ("High”) refers to a sub-sample of children from households with annual income below (not below) the median. Non-cognitive skills are reported by teachers. Other explanatory variables include the child's characteristics (age, school sectors, and number of siblings), both parents' characteristics (age and education), local socioeconomic background variables, state/territory dummies, year dummies, and survey quarters. P t test: P value of a t test for equality of maternal and paternal health estimates. Robust standard errors clustered at the individual level in square brackets. Adjusted $p$-values to account for multiple inference issue calculated using the Simes-Benjamini-Hochberg method are in curly brackets. The symbol *denotes unadjusted significance at the $10 \%$ level, **at the $5 \%$ level, and ***at the $1 \%$ level. 
Appendix Table A17: Parental depression and child development - Transition in and out of depression

\begin{tabular}{|c|c|c|c|c|c|c|c|c|c|c|c|c|c|}
\hline & 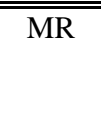 & Reading & "Writing & Spelling & "Grammar & " Numeracy & $\begin{array}{c}\text { Cognitive } \\
\text { index }\end{array}$ & " Prosociality & $\begin{array}{c}\text { Hyperactivity } \\
\text { (rev) }\end{array}$ & $\begin{array}{c}\text { Emotional } \\
\text { (rev) }\end{array}$ & $\begin{array}{c}\begin{array}{c}\text { Conduct } \\
\text { (rev) }\end{array}\end{array}$ & $\begin{array}{l}\begin{array}{l}\text { Peer } \\
\text { (rev) }\end{array}\end{array}$ & $\begin{array}{c}\text { Non- } \\
\text { cognitive } \\
\text { index }\end{array}$ \\
\hline & (1) & (2) & (3) & (4) & (5) & (6) & (7) & (8) & (9) & (10) & $\begin{array}{l}(11) \\
\end{array}$ & (12) & (13) \\
\hline \multirow[t]{3}{*}{ Maternal transition in } & $0.65 *$ & -3.26 & 9.24 & 4.81 & 3.51 & -1.61 & 0.32 & 0.14 & 0.09 & -0.01 & $0.25 * * *$ & 0.07 & 0.11 \\
\hline & {$[0.39]$} & {$[6.80]$} & [7.37] & [3.89] & [7.18] & {$[6.65]$} & {$[2.71]$} & {$[0.17]$} & {$[0.19]$} & {$[0.12]$} & {$[0.10]$} & {$[0.14]$} & {$[0.10]$} \\
\hline & $\{0.53\}$ & $\{0.77\}$ & $\{0.60\}$ & $\{0.60\}$ & $\{0.77\}$ & $\{0.89\}$ & & $\{0.77\}$ & $\{0.77\}$ & $\{0.91\}$ & $\{0.10\}$ & $\{0.77\}$ & \\
\hline No of observations & 3,542 & 3,041 & 3,026 & 3,034 & 3,033 & 3,011 & 2,963 & 4,401 & 4,418 & 4,408 & 4,415 & 4,407 & 4,393 \\
\hline No of individuals & 2,239 & 1,941 & 1,935 & 1,938 & 1,937 & 1,926 & 1,901 & 2,243 & 2,247 & 2,241 & 2,246 & 2,240 & 2,237 \\
\hline \multirow[t]{3}{*}{ Maternal transition out of } & 0.10 & 1.24 & 2.50 & 1.77 & 2.86 & 0.57 & 0.90 & 0.18 & 0.17 & 0.08 & 0.08 & -0.13 & 0.09 \\
\hline & {$[0.24]$} & {$[4.46]$} & {$[6.70]$} & [3.14] & {$[5.43]$} & [3.90] & [2.18] & {$[0.14]$} & {$[0.14]$} & {$[0.11]$} & {$[0.08]$} & {$[0.11]$} & {$[0.08]$} \\
\hline & $\{0.86\}$ & $\{0.86\}$ & $\{0.86\}$ & $\{0.86\}$ & $\{0.86\}$ & $\{0.88\}$ & & $\{0.86\}$ & $\{0.86\}$ & $\{0.86\}$ & $\{0.86\}$ & $\{0.86\}$ & \\
\hline No of observations & 3,648 & 3,133 & 3,117 & 3,125 & 3,124 & 3,106 & 3,053 & 4,464 & 4,481 & 4,470 & 4,480 & 4,467 & 4,454 \\
\hline No of individuals & 2,262 & 1,969 & 1,965 & 1,968 & 1,967 & 1,956 & 1,931 & 2,255 & 2,260 & 2,254 & 2,261 & 2,253 & 2,249 \\
\hline \multirow[t]{3}{*}{ Paternal transition in } & 0.25 & -4.27 & -7.90 & 1.67 & -2.27 & -2.28 & -1.22 & $-0.37 *$ & $-0.46^{* *}$ & $-0.30 *$ & -0.04 & -0.09 & $-0.25^{* *}$ \\
\hline & {$[0.30]$} & {$[4.60]$} & {$[5.26]$} & [3.39] & [5.54] & {$[4.28]$} & [2.31] & {$[0.19]$} & {$[0.20]$} & {$[0.16]$} & {$[0.09]$} & {$[0.14]$} & {$[0.10]$} \\
\hline & $\{0.68\}$ & $\{0.68\}$ & $\{0.37\}$ & $\{0.68\}$ & $\{0.68\}$ & $\{0.68\}$ & & $\{0.27\}$ & $\{0.26\}$ & $\{0.27\}$ & $\{0.68\}$ & $\{0.68\}$ & \\
\hline No of observations & 3,474 & 2,995 & 2,982 & 2,988 & 2,987 & 2,968 & 2,920 & 4,191 & 4,204 & 4,196 & 4,202 & 4,194 & 4,181 \\
\hline No of individuals & 2,142 & 1,873 & 1,869 & 1,872 & 1,871 & 1,858 & 1,834 & 2,163 & 2,167 & 2,163 & 2,167 & 2,162 & 2,158 \\
\hline \multirow[t]{3}{*}{ Paternal transition out of } & -0.10 & 2.75 & 2.49 & 6.50 & -3.52 & 4.78 & 2.55 & -0.10 & $-0.34 * *$ & -0.16 & -0.10 & -0.13 & $-0.16^{* *}$ \\
\hline & {$[0.37]$} & {$[5.43]$} & [9.59] & [4.99] & [7.92] & {$[6.26]$} & [3.16] & {$[0.15]$} & {$[0.14]$} & {$[0.11]$} & {$[0.07]$} & {$[0.11]$} & {$[0.08]$} \\
\hline & $\{0.80\}$ & $\{0.80\}$ & $\{0.80\}$ & $\{0.49\}$ & $\{0.80\}$ & $\{0.79\}$ & & $\{0.79\}$ & $\{0.19\}$ & $\{0.49\}$ & $\{0.49\}$ & $\{0.49\}$ & \\
\hline No of observations & 3,333 & 2,876 & 2,863 & 2,868 & 2,867 & 2,851 & 2,809 & 4,127 & 4,142 & 4,133 & 4,140 & 4,132 & 4,117 \\
\hline No of individuals & 2,137 & 1,870 & 1,864 & 1,867 & 1,866 & 1,856 & 1,834 & 2,167 & 2,171 & 2,166 & 2,171 & 2,166 & 2,162 \\
\hline
\end{tabular}

Notes: Results for each cell are estimated from a separate FE regression (2). Non-cognitive skills are reported by teachers. Other explanatory variables include the child's characteristics (age, school sectors, and number of siblings), both parents' characteristics (age and education), depression status of the other parent, local socio-economic background variables, state/territory dummies, year dummies, and survey quarters. NAPLAN test regressions also include test age and test years. Robust standard errors clustered at the individual level in square brackets. Adjusted $p$-values to account for multiple inference issue calculated using the Simes-Benjamini-Hochberg method are in curly brackets. The symbol *denotes unadjusted significance at the $10 \%$ level, $* *$ at the $5 \%$ level, and ***at the $1 \%$ level. 